\title{
Contribution a l'etude du fibrinogene, de la fibrinoformation, de la fibrinolyse par l'utilisation d'anticorps monoclonaux
}

Citation for published version (APA):

Mirshahi, M. (1984). Contribution a l'etude du fibrinogene, de la fibrinoformation, de la fibrinolyse par I'utilisation d'anticorps monoclonaux. [Doctoral Thesis, Maastricht University]. Rijksuniversiteit Limburg. https://doi.org/10.26481/dis.19841123mm

Document status and date:

Published: 01/01/1984

DOI:

10.26481/dis. $19841123 \mathrm{~mm}$

Document Version:

Publisher's PDF, also known as Version of record

Please check the document version of this publication:

- A submitted manuscript is the version of the article upon submission and before peer-review. There can be important differences between the submitted version and the official published version of record.

People interested in the research are advised to contact the author for the final version of the publication, or visit the DOI to the publisher's website.

- The final author version and the galley proof are versions of the publication after peer review.

- The final published version features the final layout of the paper including the volume, issue and page numbers.

Link to publication

\footnotetext{
General rights rights.

- You may freely distribute the URL identifying the publication in the public portal. please follow below link for the End User Agreement:

www.umlib.nl/taverne-license

Take down policy

If you believe that this document breaches copyright please contact us at:

repository@maastrichtuniversity.nl

providing details and we will investigate your claim.
}

Copyright and moral rights for the publications made accessible in the public portal are retained by the authors and/or other copyright owners and it is a condition of accessing publications that users recognise and abide by the legal requirements associated with these

- Users may download and print one copy of any publication from the public portal for the purpose of private study or research.

- You may not further distribute the material or use it for any profit-making activity or commercial gain

If the publication is distributed under the terms of Article $25 \mathrm{fa}$ of the Dutch Copyright Act, indicated by the "Taverne" license above, 
CONTRIBUTION A L'ETUDE

DU FIBRINOGENE, DE LA FIBRINOFORMATION,

DE LA FIBRINOLYSE PAR LUTILISATION

D'ANTICORPS MONOCLONAUX. 



\section{CONTRIBUTION A L'ETUDE \\ DU FIBRINOGENE, DE LA FIBRINOFORMATION, \\ DE LA FIBRINOLYSE. PAR L 'UTILISATION \\ D "ANTICORPS MONOCLONAUX.}

\section{Proefschrift}

ter verkrijging van de graad van Doctor in de Geneeskunde, aan de Rijksuniversiteit Limburg te Mastricht, op gezag van de Rector Magnificus, Prof.Dr. H.C. Hemker, volgens het besluit van het college van Dekanen, in het openbaar te verdedigen op vrijdag, 23 november 1984 om 16.00 uur

door

Massoud Mirshahi

geboren te Nishabour in Iran. 
Promotor: Prof.Dr. H.C. Hemker.

Referenten: Prof.Dr. C. Soria, Université de Rouen, Frankrijk. Prof.Dr. H.A.d. Lemmens.

Het drukken van dit proefschrift werd mogelijk gemaakt door substidies van:

De Stichting Wetenschappelijk onderwijs Limburg.

De stichting ter Bevordering van Wetenschappelijk anderwijs en onderzoek en Gezondheidszorgverlening te Maastricht. 
A tous les membres de ma famille

C'est grâce à eux que j"ai pu poursuivre mes êtudes en toute sêrénitê.

Qu'ils trouvent ici l'expression de ma grande affection et qu'ils me permettent de leur dédier à tous cette thèse. 

A Monsieur le Professeur H.C.HEMKER

Vous m"avez fait un grand honneur de me compter parmi vos élêves et d'avoir acceptê de juger ce trava11.Qu"il me soit permis de vous exprimer ma respectueuse admiration pour tous les travaux que wous rêalisez concernant la biochimie de 1 'Hemostase et ma profonde gratitude pour l'intérêt que vous avez bien voulu accorder a cette etude. 
A Mademoiselle le Docteur J. SORIA

A Mademoisel1e le Professeur C. Soria et

A Monsieur le Docteur C. BOUCHEIX

Qui ont inspiré le travail de cette thèse et qui on ont assuré la réalisation en me guidant sans relâche. Je leur dois tout ce travail et ma formation de chercheur.

Je les remercie de leur grande disponibilitë, de leur bienvefllance et de leur aide anicale de chaque instant. Les liens qui nous unissent ne sont pas seulement ceux d'un conseill ler à leur élève, mais aussi et surtout des liens d"amitié.

Je les remercie de leur gentillesse, de leur simplicité et de la grande qualité des consells qu'ils m'ont prodigués et c'est un honneur pour moi de les compter au nombre de mes amis. 

A Monsieur le Professeur A. BERNADOUJ

Que je remercie de m'avoir accuej 111 avec grande bienveillance dans son laboratoire où iil m'a permis de réaliser cette thèse.

Qu'il vetille trouver ici l'expression de ma respectueuse recomnaissance. 

A Monsieur le Docteur J.P. FALRE

Qui m'a accueilli dans le laboratoire

d'Ophtalmologie de 1'Hôtel-Dieu, qui m'a

consacrē gẻnëreusement son temps et $n^{\prime}$ a cessë

de me prodiguer de précieux consells et de

me faire profiter de son expérience dans le

domaine de 7 'irmunologie.

Je le prie de trouver ici le témoignage de

ma parfaite reconnaissance. 

A Monsieur le Docteur C. ROSENFELD et

A Messieurs 1es Professeur J.P. CAEN et M. SAMAMA

Je les remercie pour la qualitë de leur

enseignement, pour 7 "accueil chaleureux

qu'ils m"ont manifestế au sein de leur

service.

Je leur exprime toute ma reconnaissance et

mon profond respect. 

A Mons leur le Docteur J.Y. PERROT et

A Mademoiselle GIANONNI

Ils m'ont permis de réaliser cette thèse

dans une atmosphère confiante et amicale.

Je les remercie de leur amitiê. 

A Monsieur le Professeur Y. POLLIQUEN

Qui m'a fait 1'honneur de m'accepter dans son service dé I'Hôtel-Dieu.

Il a bien voulu me prodiguer ses conseils et ses encouragements.

Je l'en remercie et l'assure de ma reconnaissance et de mon respect. 

4 
A Madame Martine BEDU

Que je tiens tout particulièrement a remercier pour avoir participé avec beaucoup de compétence et grande gentillesse à l'édition de ce travail. 

- Chapitre I : Données actuelles sur 1'hybridation. Rappel sur la structure et la fonction du fibrinogène

Historique du développement de la technique d"hybridations cellulaires.

Rappel sur le fibrinogene 11

I- Structure du fibrinogène $\$ 1$

A : Structure tertiaire 11

B : Structures primaire et secondaire 13 Produits de degradation du fibrinogène par le bromure de cyanogène Chaines du fibrinogène Sites de fixation du calcium $\quad 18$

II- Biosynthèse du fibrinogène 19

II - Catabolisme du fibrinogene 22

IV La fibrinoformation 23

$\checkmark$ Rappel sur la dégradation du fibrinogène et de la fibrine par la plasmine

VI Etude immunochimique de la molécule de fibrinogène
A : Les différents épitopes localisés dans la molécule de fibrinogène
B : Modẻles proposés pour expliquer 1 'apparition de néo-antigènes
$c$ : Application de l'analyse immuno chimique du fibrinogène à l'étude de la structure tertiaire de la molécule

- Chapitre 1 I : Matériel et méthodes

A- Préparation des produits de dégradation de la fibrine

B- Immunisation des souris

C- Protocale de fusion 57

D- Préservation de clones $\quad 60$

E- Préparation des ascites 
II - Méthodes utilisées pour la sélection des lignées 62

A : Principe de la méthode immuno enzymologique 62

B : Materiel

Support solide

Antigènes utilises

64

Fibrinogène humain

Fragments de dégradation du fibrinogène

Produits de degradation de la fibrine

Chaines isolkes du fibrinogene

Monomères des $A$ et des $B$ de fibrine

IgG isolees à partir d'un anti serum

lgg marquees a la peroxydase

C: Protocole operatoire

1 - Imnobilisation de l'antigène sur la plaque de polystyrène

2 - Réaction antigène-anticorps

III - Methode immuno enzymologique utilisée pour etudier la réactivité de l'anticorps monoclonal

$v i s$ à $v i$ de l'antigène en solution

A: Principe de la réaction 74

B: Matériel 74

C: Protocole 74

1 - détermination de la dilution d'anticorps à utiliser

2 - Etape de compétition entre antigène soluble et antigène immobillisé pour se lier à l'anticorps

IV - Methode utilisée pour juger de la réactivité des anticorps vis a vis des autre proteines plasmatiques

$\checkmark$ Determination de la classe des IgG 79

- Chapitre III Résultats 80

I - Classification et 1 ère selection des hybrides 81

II Réactivité des anticarps selectionnes et clones vis à vis de l'antigène en solution 82

A : Détermination de la dilution du surnageant 82

$B$ Réactivite du fibrinogène, des complexes de dégradation de la fibrine et des produits de dégradation du fibrinogène vis à vis des anticorps monoclonaux 
Etude des anti D complets

Anticorps réagissant avec le

fibrinogène et le fragment $D$

Anticorps régissant avec le fibrinogëne inmobilisế mais non avec le fibrinogène en solution

Etude des anti $D$ néo

Etude comparée de la réactivité des anticorps vis aै vis des fragments D1 et D3

Etude des anti $E$

III - Reactivité des différents anticorps vis a vis des chaines dissociées du fibrinogène

IV Réactivité des anticorps vis à vis des autres protéines plasmatiques

$\checkmark$ Détermination de la classe des Ig 96

Chapitre IV Discussion des résultats

I Anticorps réagissant sur le fibrinogène et le fragment $D$ ou $E$

A - Anticorps réagissant avec le fibrinogène et le fragment D

B - Anticorps réagissant avec le fibrinogène et le fraginient $E$

II Anticorps ne régissant pas avec le fibminogène intact mais avec le fragment D

A Anti D néo anticorps

B Anticurps de conformation

III Comparaison avec les autres anticorps décrits dans la littérature

Chapitre $V$ Applications des anticorps monoclonaux selectionnés

Etude analytique de l'interaction entre les

differents monomeres par utilisation d'anti $D$ neo anticorps. Application a l'etude des troubles de l'agrégation des monomères. 
1 Mise au point d'une technique d'étude de 1 "interaction monomëres-fragnent 01

A - Principe de la technique 117

B - Matêriel et méthodes 117

C - Résultats 120

D - Discussion 122

II Application de la méthode 125

A - Etude phamacologique de certaines substances imhibant I agrégation des mononères. Dêtermination de leur réactiwi tê 125

B - Appitication particulière à l'étude d'un fibrinogène anomal homozygote, le fibrinogène Ales. Mise en ếvidence d'une anomallie du site de polymerilisation" "a" localitsêe sur la chaîne garma

1. Matêriel et méthode 126

2. Rësultats 130

3. Discussion 140

Dosage des produits de dégradation de la fibrine ou du fibrinogène directement dans le plasma

I Rappel des techniques utilisêes actuellement en biologie climique

A - Mé thódes basêes sur une reaction antigëne-anticorps.

$B$ - Le staphylo clumping test

II Techniques de dosage des produits de dêgradation de la fibrine par utilisation d'anticorps monoclonaux anti D-néo

A - Technique immuno-enzymolögique de Rylatt et al.

B - Technique personnelle au latex 147 1. Principe 147

2. Ma teriel et me thodes 147

3. Rếsultats 150

4. Discussion 150

- Concluston 156

- Bibliographie 
Quand il y a une brèche vascullaire, le fibrinogène, protécine soluble, est attaque par la thrombine generée, aboutissant a la formation de monomeres de fibrine qui spontanément s'agrégent pour donner naissance au caillot de fibrine destine a colmater cette brèche.

Les thromboses ou les coagulations intravasculaires sont des processus pathologiques résultant d'une activation de la coagulation. La fibrine ainsi formée n'est pas destinée à colmatem une brèche vasculaire, mais obstrue la micmocirculation. Un processus réactionnel de dégradation de ces caillots, ou fibrinolyse, est alors déclenché, visant à reperméabiliser les vaisseaux. La dégradation de ces caillotos est principalement assurée par la plasmine, qui résulte d'une activation locale, in situ, au niveau du caillot, du plasminogène. La fibrine est alors dégradée en produits de dégradation de la fibrine et la présence de ces dérivés dans le sang circulant témoigne donc de la présence d"un caillot de fibrine dans la circulation.

Le début de notre travail a etể de préparer des anticorps monoclonaux dirigés contre differents epitopes de la molecule de fibrinogene ou de ses derives. L'obtention d'anticorps monoclonaux diriges contre des néo-antigenes masqués dans la molécule du

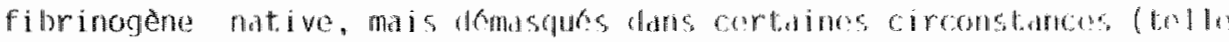
la degradation de la molécule de fibrinogene par la plasmine ou sa fixation sur un support solide) nous a permis:

1) d"apporter certaines informations concernant la structure tertiaire de la molécule de fibrinogène et de mettre en evidence certains changements conformationnels induits par la fixation du 
fibrinagene sur un support solide;

2) de réaliser le dosage des produits de dégradation de la fibrine en presence de fibrinogène, donc directement dans le plasma ;

3) d'évaluer avec précision et de façon analytique l'agrégation des monomères de fibrine, permettant ainsi de juger de l'efficacité de certaines drogues agissant à ce niveau.

En outre, l'utidisation de tels anticorps monoclonaux nous a permis de localiser dans un fibrinogêne anormal 1 'anomalie au niveau d'un site de polymerisation des monomères. L'étude d'un tel fibrinogène est donc très utile en vue de déceler la nature exacte de ce site de polymérisation, qui n'est pas encore déterminé. 
CHAPITRE I

DONNEES ACTUELLES SUR L'HYBRIDATION

RAPPELS SUR LA STRUCTURE ET LA FONCTION DU FIBRINOGENE 


\section{HISTORTQUE DU DEVELOPPEMENT DE LA TECHNIQUE}

D'HYBRIDATIOHS CELLULAIRE

En 1960, Georges BARSKI et ses collaborateurs (6) démontrèrent a Paris que le virus de Sendaf inactivé pouvait amener deux cellules de souris différentes a fusionner pour former une cellule hybride ayarit les proprietes des deux cellules parentales. Cette expérience fondamentale montrant que le virus de Sandaf pouvait engendrer des cellules a plusieurs noyaux, allait être à la base de la technique d'hybridation cellulaire. La formation de ces dernières a la suite d'une fusion entre cellules somatiques etait connue depuis deja plusieurs années. Elle remontait en fait à $1^{*}$ apparition du microscope optique, quand les biologistes avaient observé llapparition de cellules géantes a plusieurs noyaux dans les tissus épithếliaux infectes par les virus de la variole, de la varicelle, de l'herpes simple et d'autres encore. Mais en montrant qu'un virus pouvait etre réellement la cause d'une fusian cellulaire, l'expérience de Barsiki domnalt un moyen de contrôler la formation des hybrides. En cinq ans une technologie etait forgée pour induire la fusion de cellules animales et pour sélectionner les lignées engendrées par la division (clonale) indêfinie de certaines cellules hybrides.

Quelques années plus tard, l'intérêt de ces travaux etait confirmé, notamment par les possibilites qu'ils offraient de construire une carte chromosomique, en particulier humaine, et d'analyser certains aspects de régulations mis en oeurre dans les processus de differenciation cellulaire. 
Pour isoler les clanes hybrides nouvellement formés, on cultive habituellement le mélange de cellules dans un millieu spécial qui permet aux cellules hybrides de pousser, alors qu'il tue les cellules parentales non fusionnées, un tel milieu est appelé milieu sélectif.

Jahn Littlefield (117), en 1964, alors à la Harward Medical School, a mis au point un milieu sélectif pour selectionner une des cellules hybrides résultant de la fusion de cellules de souris (LMTK) dépourvues de thymidine kinase (TK) et de cellules de souris (A9) dépourvues d'hypoxanthine guanine phosphoribosyltransferase (HGPRT). Ce milieu sélectif contient, outre tous les composants nutritifs essentiels, de l'aminopterine. Cette drogue bloque la synthese de I'acide folique nécessaire à la production des précurseurs du DNA. Les cellules peuvent synthétiser ces précurseurs en présence d'aminopterine, si d'autres précurseurs du DNA sont présents, tels l'hypoxanthine et la thymidine. C'est pourquoi ce milieu spécial est appelé milieu HAT ( $H=$ Hypoxanthine, $A=$ Aminopterine et $T=$ Thymidine) (figure 1).

Dans le milieu HAT, les cellules parentales, qui n'ant pas fusionne et qui sont déficientes en enzymes HGPRT et TK, meurent car elles ne peuvent utiliser 1 "hypoxanthine et la thymidine pour la synthese du DNA.

En revanche, les cellules LMTK et A9 étant depourvues en enzymes différentes (TK pour LMTK et HGPRT pour A9), les cellules hybrides renferment les deux enzymes et peuvent donc utilliser les sources exogènes des précurseurs du DNA pour la synthèse de ce dernier. 


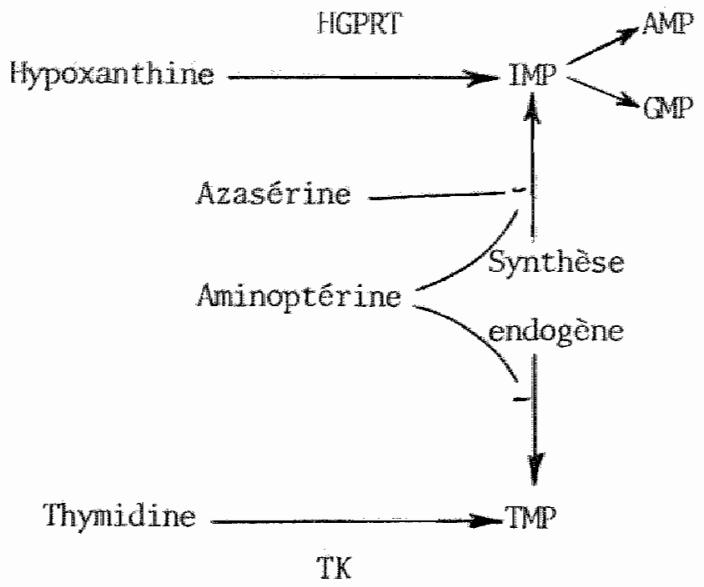

Figure 1: Synthèse des prêcurseurs de 1'ADN en prësence ou en l'absence d'aminoptérine. 
Ainsi un clone hybride peur prolliferer pour former une colonie visible de quelques milliers de cellules que l'on peut facilement isoler et mettre en culture, afin d'obtenir une population cellulaire importante pour les analyses biochimiques et chromosomiques. Aprês avoir fusionne des cellules de souris de differentes lignees, des experiences ideniques de fusion ont eté réalisées entre cellules humaines et cellules de souris LMTK ou A9. Pour ces expériences on utillise genéralement des lewcocytes ou des fibroblastes humains qui proviennent de prélèvement de la peau. Ces cellules possèdent normalement des enzymes HGPRT et TK, alors qu'il font défaut aux lignées A9 et LMTK respectivement. Les hybrides résultant de la fusion homme $x$ souris sont donc complëmentês en TK ou HGPRT, ainsi LMTK et A9 meurent, par contre, les hybrides homme $x$ souris proliferent dans ce milieu, car les enzymes deficientes de la souris LMTK ou A9 sont complémentées par les enzymes humains. Quant aux fibroblastes humains parentaux, ils poussent plus lentement que les hybrides et sont finalement eliminés. Les hybrides ainsi obtenus possèdent au depart un double stock chromosomique (celui die la cellule humaine et celui de la souris). Mais ils perdent par la suite certains de leurs chromosomes, ce qui permet d'attribuer aux chromosomes restant les fonctions qui persistent. Plus précisement, B.R. MIGEON (135) et C.S. MILLER de la John Hopkins Medical School, montrèrent que les hybrides issus de la fusion de cellules de souris et de cellules humaines avaient tendance à perdre les chromosomes humains et non ceux de souris. Certains de ces hybrides selectionnés et cultiwes dans le milieu HAT perdaient finalement tous les chromosomes humains d'exception du chromosone 17 ; leur survie montrait que ce chromosome 17 complementait la déficience en TK des cellules de souris LMTK : les hybrides qui 
perdaient par la suite le chromosome 17 devenaient sensibles à l'action lethale de l'aminopterine. Sur la base de ces observations. on a pu attribuer au chromosome 17 le gène humain codant pour TK et avec la même technique on a montré que le gène humäin codant pour I'HGPRT etait localise sur le chromosome $x$.

La decouverte de Kóhler et Milstein en $1975(107)$ sur le fait que I"hybridation cellulaire entre des lymphocytes de souris hyperimmunisee et des cellules myelomateuses de souris permettait de produire en quantite indefinie des anticorps monoclonaux de specificite très determinee, a attire l'attention d'une large communate scientifique. Cette technologie nouvelle est susceptible de résoudre un problëne crucial de l'immunologie: l'obtention d"anticorps monospécifiques strictement homogènes.

Hybridation et production d'anticorps monoclonaux

La synthèse des anticorps est assurée par une catégorie de globules blancs (lymphocytes B) qui aw terme de leur êvolution celluladre sont appeles plasmocytes. Ils excretent les anticorps dans le serum.

Glassiquement, pour obtenir un anticorps spécifique d'un antigène donne, on immunise un animal (lapin, chevre, mouton, souris) en lui injectantu pendant plusieurs semaines une préparation de l'antigêne plus ou molns purifie, la présence dans son organisme d'une substance etrangêre déclenche la réponse immunitaire.

Lorsqu'une molécule d'antigène portant plusieurs déterminants antigeniques penètre dans le corps d'un animal, cette intrusion entraine la proliferation de plusieurs lignëes de lymphocytes $B$ qui 
sécrètent chacun une molécule d'anticorps dirigée contre un déterminant antigénique (ou épitope). Un antisérum conventionnel contient un mélange de ces anticorps. On obtient des anticorps monoclonaux en faisant fusionner des lymphocytes de la rate avec des cellules de myelome. Les cellules hybrides sont ensuite clonées et chacun des clones sécrète une anticorps monoclonal adapté spécifiquement à un seul déterminant antigénique de la molécule d' antigène (Figure 2).

Les anticorps monoclonaux sont abtenus par la méthode habituelle (décrite dans le chapitre Materiel et Methodes) par fusion, à l'aide du polyếthylène-glycol, de cellules spléniques d'une souris (ou d'un rat) immunisée et de cellules d'un myelome de souris (NS1 ou SP2...) au d'un myélome de rat (FR...). Les hybrides sont sélectionnés sur milieu HAT. On mesure l'activité des anticorps sécrétés dans le milieu et on congèle par précaution un échantillon de chaque culture positive. Les hybrides sécrétant un anticorps sont clonés et l"activité de chaque clone est mesurée. Une partie de ceux qui donnent un résultat positif est congelêe, une autre est reclonêe. Le type d"immunoglobuline produit est caracterisé. Les clones retenus dëfinitivement peuvent être gardés congelés. Lorsqu'un clone est décongele on peut produire l'anticorps, soit en mettant les cellules en culture, soit en les injectant à des animaux pour induire des ascites (28). 


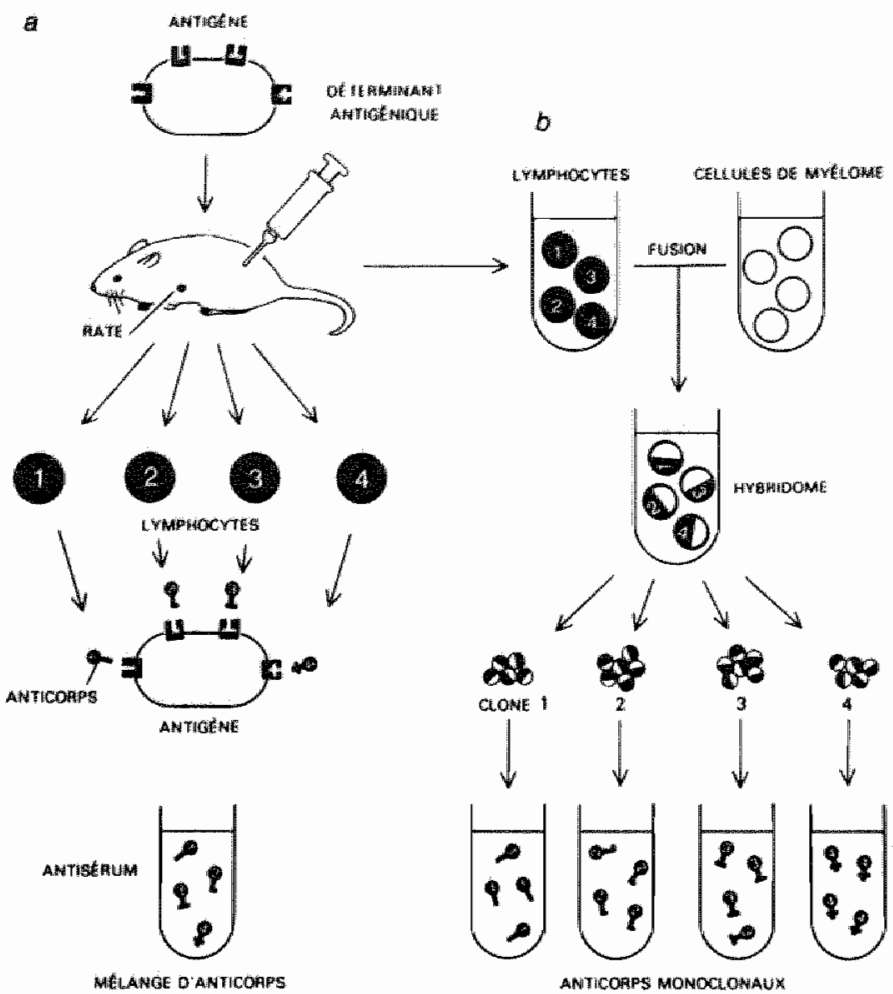

Fig. 2 : Schena d'hybridation cellulaire et d'obtention d"anticorps monoclonaux.

(d'apres Milstein. Pour la Science 1980) 
RAPPEL SUR LE FIBRINOGENE

\section{STRUCTURE DU FIBRINOGENE}

A. STRUCTURE TERTIAIRE

L'étude de la structure du fibrinogène a fait l'objet de nombreux travaux. Le fibrinogène est une protéine allongée, de poilds moléculaire 340.000 et composée de 3 nodules réunis par des filaments enroulés en hélices de $150 \mathrm{~A}$ de long et de $12 \mathrm{~A}$ de diamètre (Fig. 3). Le nodule central a un diamètre de $50 \mathrm{~A}$, tandis que les 2 nodules latéraux ont un diamètre de $60 \mathrm{~A}$. De chaque nodule latéral s'échappe un fragment de chaine protéique. En fait cette structure trinodulaire est très flexible et selon les conditions expérimentales la proténe peut être plus ou moins repliée $(81,55)$.

Doolittle (44) montre 4 régions principales dans le fibrinogène :

- le domaine central contenant l'extrémité $N$ terminal des 6 chaines polypeptidiques

- les structures hëlicoïdales

- les 2 domaines latéraux

- les fragments de chaines alpha formant des appendices sortant des deux domaines latéraux.

La dégradation enzymatique du fibrinogène par la plasmine se fait en des endroits précis de cette molécule qui sont compatibles avec le schéma trínodulaire de la protéine $(65,124)$. 


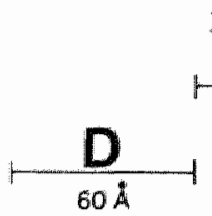

Zone helicoldale Lone hel icoidale $150 \mathrm{~A}$

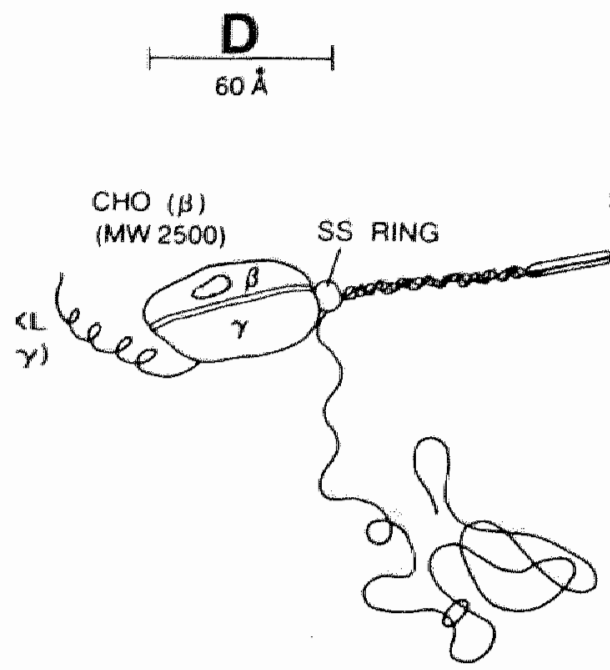

SS RING
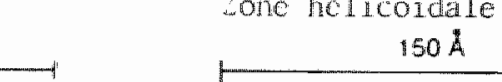
La première dégradation entraine l'elimination des appendices qui sortent de chaque nodule lateral et conduit a la formation du fragment $x$. Le fragment $x$ est alors degradé de façon asymetrique au niveau d'une des deux structures hélicoidales pour donner naissance au fragment $Y$ et à un fragment $D$. Le fragment $Y$ étant composé $d$ "un nodule latéral et du nodule central. Le fragment $y$ est alors à son tour dégradé au niveau de l'hélice réunissant les deux nodules, libérant un nouveau fragment $D$ et le fragment $\mathbb{E}$. Les différences de structure entre les deux domaines latéraux et le domaine central a été démontré par des études immunologiques montrant des déterminants antigeniques distincts pour les fragments $D$ (nodules latéraux) d'une part, et pour le fragment $E$ (nodule central) d'autre part.

\section{B. STRUCTLIRE PRIMAIRE ET SECONDAIRE DU FIBRINOGENE}

La molécule de fibrinogène est formée de 6 chaînes polypeptidiques $(13,87)$ symétriques deux à deux : Deux chaines $A$ alpha, deux chaines $B$ beta et deux chaines gamma dont la sequence en aminoacides est actuellement établie (93). Seules les chaines $B$ beta et A alpha renferment des carbohydrates formés d'acide sialique, de galactose, de $N$ acetyl glucosamine et de mannose. Les carbohydrates sont attachés aux chaines polypeptidiques au niveau de l'asparagine par une llaison $\mathrm{N}$ glycosidique. Leur structure est biantennaire et est représenté dans la figure 4 .

Les 6 chaînes sont réunies entre elles par 29 ponts disulfures (88). La malécule ne contient pas de résidu cystéine libre. 
De la séquence en acides aminés, il ressort que les résidus cystêine sont concentres dans 3 zones le long de chaque chaîne, l'une à l'extrémité $N$ terminal, la deuxiène dans une zone intermédiaire et la troisième l'extrémitế C terminal. L'emplacement des ponts S-S a été dêterminé sur le fibrinogène dégradé au niveau de la méthionine par le bromure de cyanogène $(12,93)$.

1) Produits de dégradation du fibrinogène par le bromure de cyanogène :

Cette dégradation conduit à l'apparition de 5 fragments de dégradation appelés de FCBM à FCB5 (FCB = Fibrinogène Cyan-Bromide) (Fig. 4). Le plus gros fragment est appelế FCBł (anciennement $N$-DSK ou $N$ terminal disulphide knot) (49). Il a structure dimerique (18) et renferme les extrémités $\mathbb{N}$ terminal des 6 chaînes. Il contient 11 ponts S-S et trois d'entre eux connectent les deux moitiés de la molécule de fibrinogène. Une liaison S-S est située entre les deux chaines alpha, deux liaisons $5-S$ entre les deux chaines ganma. Le FCBI a une structure voisine du fragment $E$ de dégradation du fibrinogène. Le deuxiême fragment ou FCB2 (72, 90) (encore appelé H01-DSK car hydrophobe) est un peu plus petit que le FCB1, il a une structure monomerique, ce qui explique qu'il y a deux fragments FCB2 par molécule de fibrinogène. Il contient des fractions intermediaires des trois chaînes d"une moitié de la molécule de fibrinogène. Il renferme 6 ponts $S-S$.

Les fragments FCB3 (ou Hi2 DSK), FCB4 (ou Ho2 DSK) et FCB5 ont des structures monomériques correspondant respectivement aux extrënités $C$ terminal des chaînes $A$ alpha, B beta et gamma. IIs renferment chacun un pont $S-S(72,91)$. La fïgure 5 représente la 


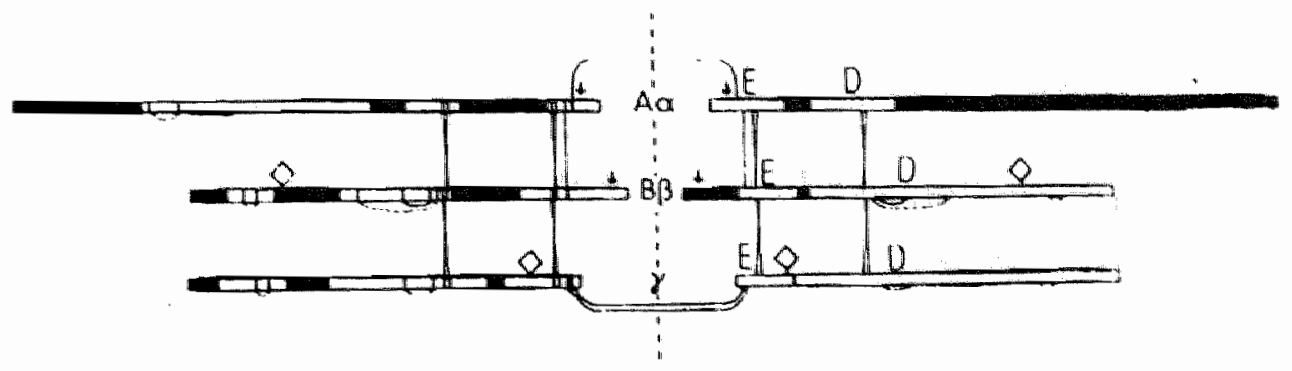

Fig. 5 : Structure primaire du fibrimogène

(les lignes de connection reprësentent les ponts disulfure)

Sur le côté gauche de la molécule, les parties blanches reprësentent les différents produits de dê̆gradation par le Bromure de cyanogène.

Sur le côté droit de la molécule, les parties blanches représentent les fragments de dëgradation par la plasmine.

(d'après Henschen et a7. Ann. N.Y. Acad. Sci. 1983, 4a9, 27).
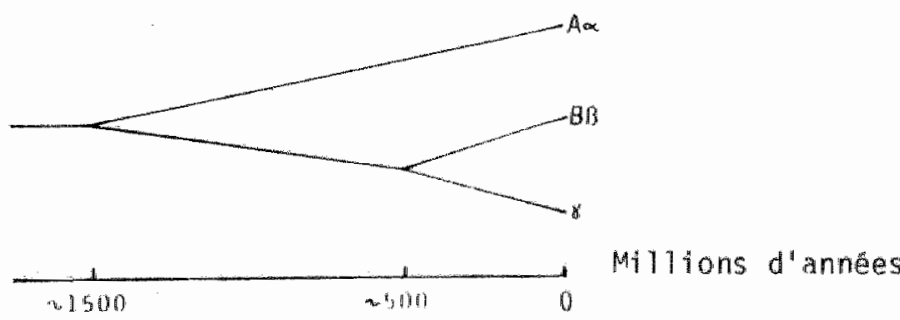

Fig. 6 : Evolution des 3 chaines du fibrinogène au cours du temps.

(d'après Henschen et al. Ann. M.Y. Acad. Sci. 1983, 4n8, 27). 
relation existant entre fragments de degradation par la plasmine et ceux induits par le bromure de cyanogène.

L'étude des sites de dégradation par la plasmine des chaines d'une part, et celle des sites intervenant dans les différentes étapes de la fibrinoformation sur chaque chaine d'autre part, sont êtudiés au niveau des paragraphes correspondants.

2) Chaines du fibrinogène

a) La chaine A alpha:

Elle a point molecculaire de 66.000 daltons et renferme 610 acides aminés. Les 16 premiers acides aminés de cette chaine constituent le fibrinopeptide A (FpA) quî est liberé après action de la thrombine sur le fibrinogène $(9,118)$. La microhétérogénéité du FpA a été dêcrite au paragraphe concernant la biosynthèse du fibrinogêne. De plus, alors que la séquence en acides amines de 1 à 7 est variable selon les espéces, la séquence de la position 8 à 16 est conserwé au cours de l'évolution des espèces (66) et une mutation dans cette derniere sêquence antraine un allongement important du temps de coagulation par la thrombine. Le role essentiel de cette fraction peptidique dans la liaison du fibrinogêne avec la thrombine a été êvoquée par Blomback qui a suggéré que la phénylananine en position 8 est spatialement proche de la liaison glycine-arginine rompue par la thrombine et en se liant a la thrombine participe de ce fiait à I'interaction de cette zone avec la thrombine $(16,17)$.

Lee tripeptide gly-pro-arg qui fait suite au FpA sur la chaine A alpha peut être libêrè apres action prolongée de la thrombine sur certains fragments, tel le FCB1 (21). Ce tripeptide qui est également 
tres conserve au cours de l'evolution joue un role dans la pollymerisation. En effet, Laudano et Doolittle (113, 114) ont montrê que ce tripeptide avait la propriété de se combiner au fibrinogene et au fragment D. De plus, lorsqu'il se combine au fibrinogène il inhibe la coagulation de ce dernier par la thrombine. Ce tripeptide constitue le site de polymerisation " $A$ ". Le fait que ce peptide se lie au fragment 01 et non au fragment 03 (dont la chaine gamma est plus dégradée que celle du fragment 01 , au niveau de I'extrémité c terminal comme il sera vu au chapitre concernant la dégradation du fibrinogène) permet de conclure que le site complémentaire "a" qui se lie au gly-pro-arg est situé à l'extrểité $c$ terminal de la chaine gamma (46).

b) La chaîne $\mathrm{B}$ beta

Elle a un poids moléculaire de 52.000 daltons et est constituée de 461 acides aminés. Elle renferme une chaîne biantennalre d"hydrates de carbone fixées sur l'asparagine en position 364 (92, 183). Les 14 premiers acides aminés de la chaine constituent le fibrinopeptide $B$ ( $F p B$ qui est detache par action de la thrombine (15). Comme pour la chaine A alpha, le tripeptide gly-his-arg qui fait suite au $\mathrm{FpB}$ joue un rôle dans la polymérisation de la fibrine. Ce tripeptide constitue le site "B" de polymérisation qui se lie à un site complémentaire "b" situé dans le domaine D de la molecule (46).

c) La chaîne gamma

Elle a un poids moléculaire de 48.000 daltons et est constitué de 411 acides amines. Comme la chaîne beta, el le renferme une chaîne bicatenaire d'hydrates de carbone fixes sur l'asparagine en position $52(106)$. 
De nombreuses homolagies existent entre les trois chaines, ce quí a fait suggêrer a Henschen l'existence d'un ancêtre commun à ces trais chaines (96) (Fig. 6). Ces chaines sont associées entre elles par des forces attractives et egalement par des 1 iaisons S-S.

\section{3) Sites de fixation du calcium sur la molecule de fibrinagène}

11 existe trois sites de fixation du calcium sur le flbrinogene. Deux sont présents sur le damaine D de la molécule, au niveau de l'extremité c terminal de la chaine gamma (138), tandis que le troisieme site de fixation est situé sur le fragment E (139). La sequence en acides amines correspondant aux sites de fixation du calcium au niveau des chânes gamma et des chaines beta a été proposee par Henschen du fait de l'homologie de la sequence en amino acides de ces zones, avec celles fixant le calcium au niveau de la calmoduline $(197)$.

\section{BIOSYNTHESE DU FIBRINOGENE}

Le fibrinogêne est une protéine synthêtisée principalement par Le fole (175). mais aussi par les mega-caryocytes (8). Sa production thepatique est assez importante, puis 1,5 a $5 \mathrm{~g}$ de fibrinogène sont synthetisés par jour.

La demi vie du fibrinogene est de 3 a 5 jours.

Chaque chaine apparaît être le produit de gènes distincts et les chaines formes s'assemblent au niveau du réticulum 
endoplasmique. La synthèse du fibrinogène peut augmenter sous I"influence de différents stimuli et constitue une protéine importante de l"inflammation.

Des expériences effectuées après incorporation de sëlểno-méthionine, il ressort que contrairenent à ce qui est observê pour de nombreuses proteines, des variations importantes de la concentration plasmatique en fibrinogène ne jouent aucun róle dans la régulation de la synthèse de cette protéfine (3). En revanche le fragment $D$ injecté à l'animal induit une synthèse accrue de fibrinogène par l'hépatocyte (105). Ill reste toutefois à établir si le

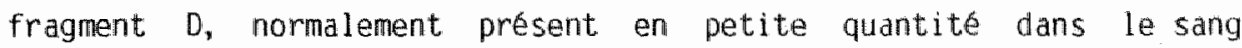
circulant, joue un rôle physiologique important dans la biosynthêse du fibrinogène. De plus, il se pourrait que le fragment $D$ ne constitue qu'un intermédiaire dans cette stimulation.

Le fibrinogène ainsi synthêtisé présente une microhétérogénéitế.

L"hétérogéneité au niveau de la chaine A alpha a une double origine.

- La première est liée à la composition du fibrinopeptide (FpA) situe a l"extremite $N$ terminal de la chaine $A$ alpha $(15,104)$. L'acide amine $\mathbb{N}$ terminal du FpA peut manquer (FpAy) ou le résidu serine en position 2 peut être phosphorylế (FPAP).

- La deuxième est liée au fait que la chaine A alpha est trés susceptible à une dégradation protéolytique, le fragment de chaine A alpha quì sort du domaine D étant très vulnerable.

Toutefois l'attaque protéolytique de la chaine $A$ alpha qui a lieu in vivo n'est pas très bien etablie. En effet, une dégradation du fibrinogêne par la plasmine ne semble pas pouvoir s'effectuer car 
la generation de plasmine a partir du plasminogene, ne se produit qu'en présence d'un calllot de fibrine (101). De plus, la plasmine susceptible d'etre generée est neutralisêe par les antiplasmines circulantes $(33,37)$. II semblerait plutôt que la degradation du fibrinogêne se fasse par l'intermediaire d"autres enzymes proteolytiques; tels certains enzymes leucocytaires (156).

Lhétérogenéité de la chasne $B$ beta semble etre uniquement liee a une teneur en acide sialique variable. Cette microhétêrogénéité peut être mise en êvidence par chromatographie échange d'ions ou par isofocalisation. La chaine $B$ beta $L$ contiendrait deux molecules d'acide sialique, tandis que la chaine $B$ beta $R n^{\prime} e n$ contiendrait qu'une $(73)$.

L"hêtérogénéité de la chaîne gama a également une double origine.

Comme pour la chaîne B beta, la chainne gamma peut posséder un ou deux résidus d'acide silique (176).

Outre cette glycosylation differente, il existe aussi deux types de chaines gamma, l'heterogeneite rểidant au niveau de la partie $c$ terminal de cette chaine. Cette hêtérogenéité a êté dénontrê par chromatographile du fibrinogène sur DEAE cellulose avec ellution en gradient. En effet, deux pics majeurs de fibrinogêne pouvaient être idertifies (53). Le premier pic constitue 85 go da totalite du fibrinogene et est caractérisé par la structure (A alpha, B beta, gamma)2. Le deuxieme plc ne renferme que $15 \%$ du fibrinogene dont la moltie des chalnes gama est identique a celle du premier pic, tandis que l'autre moitié des chaines gamna est constitue par des chaines 
gamma" dont le poids moléculaire est superieur de 2.000 daltons par rapport à celui des chaînes gamma $(61,133)$. La sequence supplémentaire de la chaine gama' est de 20 acides amines commençant à 4 residus de l'extrêmité $c$ terminal de la chaîne gamma (192). Cette sequence peptidique supplémentaire est particulièrement riche en acide glutamique et en acide aspartique, expliquant la charge négative élevée de la chaine gamma' et l'élution retardée de ce deuxième pic par rapport au premier.

11 a êté montré que les hepatocytes peuvent synthetiser du fibrinogène contenant les deux types de chaines et que dans ce deuxième pic la structure du fibrinogène est représentée par la formule (A alpha)2, (B beta)2, (Gamma, Gamma') (135). Un troi sième pic de fibrinogène prësent à l'état de traces est constitué uniquement de la forme (A alpha, B beta, gamma') 2.

L'analyse d'un fibrinagène anormal hétérozygate (fibrinogène Paris I) a permis de montrer que ces chaines gamma et gamma' dérivaient vraisemblablement d'un seul gène. En effet, dans le variant gamna Paris I, il est retrouve des chaines gama Paris I et des chaînes gamma' Paris 1 (191). Si les chaines gamma et gama' étaient codees par deux gênes différents la mutation de paris 1 ne se produirait que pour un seul gène et seule la chaine gamma Paris I serait anormale et non les deux chaines gamma et gamma'. IL semblerait donc que les deux chaînes gamma et gamma' solent codbes par un même gène mais qu'il y aurait deux épissages diffêrents sur le mRNA conduisant a la synthèse de chaines gamma et gamma" (192). 
megacaryocytes, les études sont contradictoires. Toutefois, Belloc et al. (8) ont montré une biosynthese du fibrinogene par les megacaryocytes. Concemant l"etude genetique, le fibrinogène intraplaquettaire dans les dysfibrinogenenemies congếnltales a étế trouve anomal dans certains cas, nomal dans d'autres. Mais un trouble de stockage de la forme anormale n"est pas exclu. De même, il a été trouvé que le fibrinogène plaquettaire ne renfermait pas de chaîne gama' (60), mais 1 a encore il se pourrait que du fait de la presence de nombreux résidus acides presents dans cette chaine gama', seul le fibrinogene (A alpha)2, (B beta)2 et (gama) 2 pouvait etre stocke, tandis la fome (A alphaj), (B beta)2, (gamma, gamma') moins hydrophobe que la forme precédente ne puisse pas être internalisée dans les gramules alpha.

\section{CATABOLISME DU FIBRINOGENE}

Le catabolisme du fibrinogène est inconnu. En effet, comme il a deja ête soullgne la degradation du fibrinogene par la plasmine n'est. pas physiologique. La mise en évidence de chalnes A alpha degradées pourrait etre liee à ure degradation lors de la purification du fibrinogene.

La présence de fpA dans le sang cimculant têmolgne d"un processus de coagulation in vivo, mais les calculs tenant compte de la quantite de fpA d'une part, et de la demi-vie du fpA dans la circulation d'autre part, semblent demontrer que seulement 2 a $3 \%$ du fibrinogene serait ainsi catabolise. 


\section{LA FIBRINOFORMATION}

La transformation du fibrinogene en fibrine s'efrectue schématiquement en 3 étapes principales:

- action protéolytique de la thrombine sur le fibrinogène aboutissant après élimination des fibrinopeptides $A$ puis $B$ ău monomêre de fibrine.

- agrégation des monomères de fibrine par des forces attractives.

- stabilisation de la fibrine par action du facteur XIIla. En réalité les différents stades sont étroitement intriqués.

L'initiation de la fibrinoformation réside dans le clivage protélytique par la thrombine de la chaîne A alpha du fibrinogène au niveau de la liaison gly-arg située en position $46-17$ conduisant à la libération de deux fibrinopeptides $A$ à partir des deux chaînes $A$ alpha et à la formation du monomère (des A) de fibrine (59). Cette elimination du fibrinopeptide A va permettre l'agrégation des monomères de fibrine par des forces attractives $(52,131)$. En effet, l'élimination des fibrinopeptides $A$ va entraîner le démasquage de sites de polymerisation permettant ainsi $1^{\prime}$ agregation des monomères.

Le schéma de l'agrégation des monomères est partiellement établi : après élimination des fibrinopeptides $A$, deux monomères vont s'unir, le domaine $E$ d'un monomère, s'unissant au domaine D d'un autre monomére créant ainsl un dimère dont les deux sous unités se chauvauchent. 
Puis par un mecanisme identique d'union du domaine D d"un monomère avec le domaine $E$ d'un autre monomere, des monomeres vont s'accrocher a chaque extrêmite de ce dimère formant ainsi des protofibrilles à deux brins où les molécules de monomeres se chevauchent, comme le montre la Figure 7 .

Secondairement a cette polymérisation longitudinale, les protofibrilles vont s'associer lateralement pour donner naissance à des fibres plus epaisses. Cette polymerisation latérale est secondaire * la protéolyse de la chaine $B$ beta par la thrombine au niweau d'une liason gly-arg située en position 14-15, l'ellimination du fibrinopeptide $B$ a partir de la chaine $B$ beta favomisant la polymerisation latérale des protofibrilles.

Le mécanisme biochimique de cette polymerisation est actuellement partiellement connu. La polymerisation résulte de deux types $d^{\prime i n t e r a c t i o n s ~(27): ~}$

- I"interaction du site "A" avec un site complémentaire "a" situé dans le domaine $D$ et présent au niveau de l extrémité $C$ terminal de la chaine gamma. Le site " $A$ " situe a l'extrémite $N$ terminal de la chaine alpha est non disponible dans le fibrinogène, mais exposé apres limination du fpA.

- l'interaction du site "B" avec un site complémentaire "b", situé dans le domaine $\mathrm{D}$ et présent au niveau de l'extrémité C terminal de la châne beta. Le site " $B$ " situé a l'extremite $N$ terminal de la chaine beta est non disponible dans le fibrinogène mais exposé après elimination du fpB. 


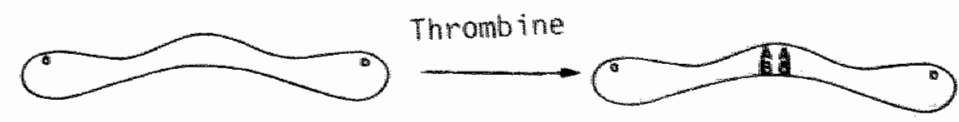

Fibrinogenne Monomère de fibrine

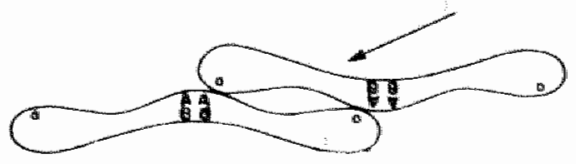

Dimère de Fibrine

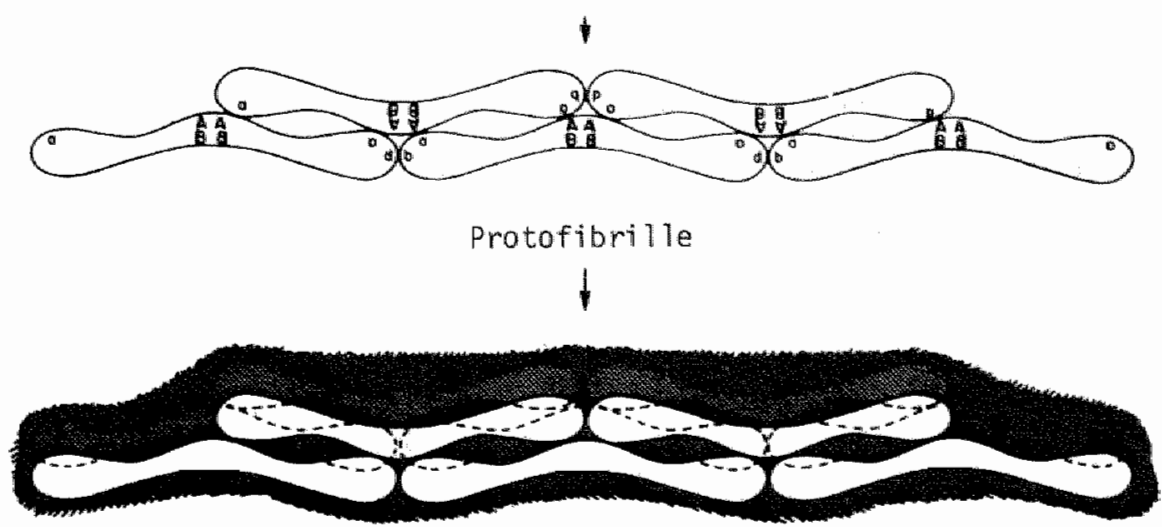

Polymère de fibrine

Fig. 7 : Schëma de la polymérisation des monamêres de fibrine.

(d'après Budzynski et a1. Ann. N.Y. Acad. Sci. 1983, 408, 299). 
de fibrine wa etre stabilisé par le facteur xilla en présence de calcium. L'activation du facteur XIII en facteur XIIla nécessite l'action de la thrombine: La stabilisation est due â la formation de Llaisons de transamidation entre la glutamine, qui joue le role d'accepteur, et la lysine, qui joue le rôle de donneur (119). Cette stabilisation de la fibrine se fait elle mene en deux etapes. La première, tres rapide qui nécessite peu de facteur XIII, entraine la formation de liaisons entre deux chaînes gamma de deux monomères differents de fibrine, créant la formation de liaisons très stables entre deux domaines $D$ de deux molécules adjacentes de monomères. Les chaines gama de deux monomères de fibrine etant orientëes de façon antiparallele, il y a création entre les deux chaines gamma, de deux lialsons (glutamyl)-lysine entre les sites donneurs (lys 405 ) et accepteur (Gln 307) comme le montre la figure 8 (32, 165).

La deuxiême etape, plus lente et nécessitant plus de facteur XIIIa que pour l'étape précédente, consiste en la formation de liaisons de covalence entre plusieurs chaines alpha de differents monomeres de fibrine. Chaque chaine alpha possède deux sites glutamyl accepteurs (position 328 et 366 ) et cinq sites lysine donneurs potentiels (entre alpha 518 et alpha 584) entrainant ainsi la formation dun réseau hautement intriquế en lía son de covalence (40). Cette formation de liaisons de covalence entre les chaines alpha de fibrine stabilise le caillot et peut être aussi favorise l'association latérale des protofibrilles qui forment alars des fibres epaisses et opaques. Le caillot ainsi stabilise est moins facilement dégradé par la plasmine qu'un caillot non stabilisé, car les zones helicoidales qui constituent des zones strategiques dans l'attaque protéolytique sont alors protégées $(67,98)$. 


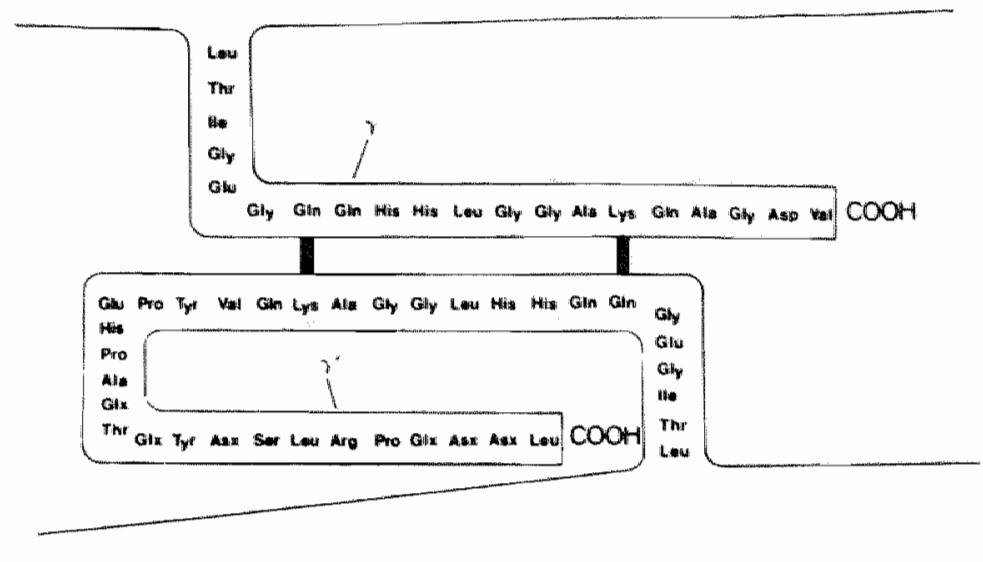

Fig. 8 : Schéma de la dimérisation des chaînes gamma induite par le facteur XIIIa.

(d'après Mo

Ann. N.Y. Acad. Sci. 1983, 408, 97). 
Tableau 1. Schena de la fibrinoformation selon Hantgan et al. $(82)$.

1) fibrinogêne $\frac{\text { actiwation }}{\text { thrombine }}$ liberation du $f \mathrm{pA} \rightarrow$ monomère (des A)de fibrine

$$
\text { polymêrisation }
$$

2) monomères des $A$ de fibrine

2a)

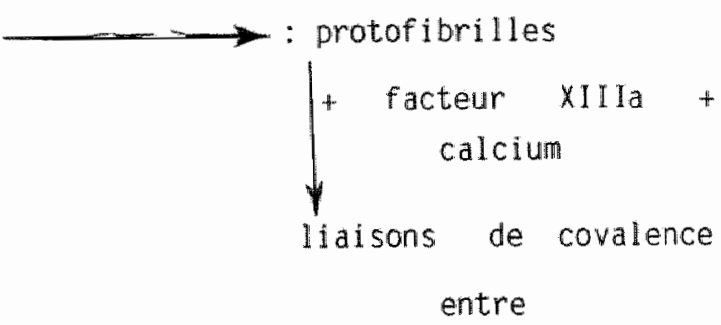

2b)

deux chaines gamma

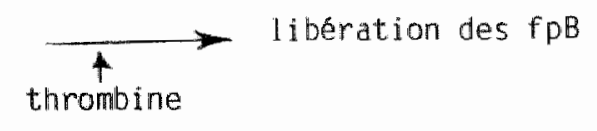

association laterale

3) protofibrilles $\longrightarrow$ réseau de fibrine

$$
\downarrow \begin{gathered}
\text { facteur XIIa } \\
\text { calcium } \\
\text { Iifaisons de covalence } \\
\text { entre }
\end{gathered}
$$$$
\text { plusieurs chaines alpha }
$$

In vivo la formation de fibrine s'effectuerait en deux étapes (19). La fibrine I est la fibrine formee initialement lars de la liberation du seul fibrinopeptide A. La fibrine Il a une structure plus compacte et est formée après le depart du fibrimopeptide $B$. 
produisait qu'après la polymerisation liee au départ du fibrinopeptide A, la polymérisation rendant plus accessible la liaison gly-arg rompue par la thrombine sur la chaine $B$ beta. Cependant, recemment, par I'analyse de la fibrinoformation, dans le cas d'un fibrinogène anormal (fibrinogène Metz) i $\downarrow$ a pu être montré que la coagulation pouvait être liêe uniquement à une polymérisation secondaire au départ des fibrinopeptides B, les fibrinopeptides A n'etant pas détachés de la chaîne A alpha de ce fibrinogène. En effet, dans ce fibrinogène l'arginine en position 16 de la chaine A alpha, est mutee par de la cysténe et la liaison cys-gly n'est pas attaquée par la thrombine (95).

Dans les coagulations intra-vasculaires (CIVD) outre les dépôts de fibrine, les monomères de fibrine s'associent aussi avec du fibrinogène ou avec des produits de dégradation issus de la fibrine (ou du fibrinogène) formant des complexes solubles (103, 162, 164). La recherche de ces complexes solubles de haut poids moléculaire dans le sang constitue un critère important de diagnostic des CIVD.

D'autres enzymes que la thrombine peuvent entrainer la coagulation du fibrinogène, c'est par exemple le cas de la reptilase qui ne détache que le fpA et non le fpB. 


\section{RAPPEL SUR LA DEGRADATION DU FIBRINOGENE ET OE LA FIBRINE PAR LA PLASMINE}

La plasmine est une enzyme protéolytique qui clive les liaisons lysine-arginine du fibrinogene et de la fibrine. Elle resulte de la transformation du plasminogène inactif en plasmine, enzyme active. Cette activation a lieu sous 1 'influence de differents activateurs:

- l'activateur tissulaire du plasminogène (tpA) sécrété par la cellule endotheliale (74). Toutefois l'activation du plasminogène par le tpA n'a lieu qu'en présence de fibrine. Hoylaerts (100) a suggêrế 1.'existence d'un complexe ternaire fibrine tpA-plasminogène.

- l'urokinase (186) (UK) qui existerait dans le plasma sous forme de pré-urokimase inactive. Cette pré-UK serait transformée en UK active sous l'influence de traces de plasmine.

- Le facteur XI activé de la coagulation combiné a un co-facteur encore inconnu $(79,136)$.

Du fait de la présence de grande quantités d'antiplasmines circulantes qui neutralise la plasmine circulante et du fait de la potentialisation induite par la fibrine lars de l'activation du plasminogène en plasmine, la dégradation du fibrinogene circulant ne semble pas avoir lieu in vivo. En revanche, la fibrine qui ne renferme que peu d'antiplasmines peut être aisement dégradée par la plasmine.

Nous etudierons séparément le schema de degradation du fibrinogene et de la fibrine par la plasmine. 


\section{A. DEGRADATION DU FIBRINOGENE}

La dégradation du fibrinogêne par la plasmine est représentée dans la figure $9(179)$.

- Le premier stade de la dégradation aboutissant aux fragments x. Le stade le plus précoce de la dégradation du fibrinogêne est la rupture de la chaine $A$ alpha au voisinage de l'extrémité $C$ terminal (134). Un peptide de 27 acides aminés est tout d'abord 11 bếé à partir de l'extrémite $C$ terminal de la chaîne $A$ alpha (39) et cette forme un peu dégradée du fibrinogène serait pour" certains auteurs présente en quantité non négligeable dans le sang circulant (94). Puis, cette chaîne $A$ alpha est de nouveau dégradée en diffërents endroits localisés entre de deuxième tiers de la chaine (au niveau de I"extrémité $\mathrm{C}$ terminal) et le premier tiers au niveau de l'extrémité $\mathbb{N}$ terminal). Cette degradation entraine une augmentation de la solubilite et une diminution de la coagulabilite de la protéine (97).

Parallêlement la chaîne $B$ beta est également attaquée par la plasmine au voisinage de 1 'extrëmite N terminal liberant une série de peptides parmi lesquels le $B$ beta $1-42$, le $\mathrm{B}$ beta $1-21$ et le $B$ beta 13-53. Certains d'entre eux, tel que le $B$ beta $\|_{m} 42$ canstituent des marqueurs de 1'attaque proteolytique du fibrinogene (160).

L'ensemble de ces degradations condult a la production de la famille de fragments $\times$ (precoces ou tardifs) selon limportance de la degridation.

- Le deuxième stade de la dégradation (120, 122) est constitué par clivage assymétrique du fragnent $x$ dans une zone localisée au 

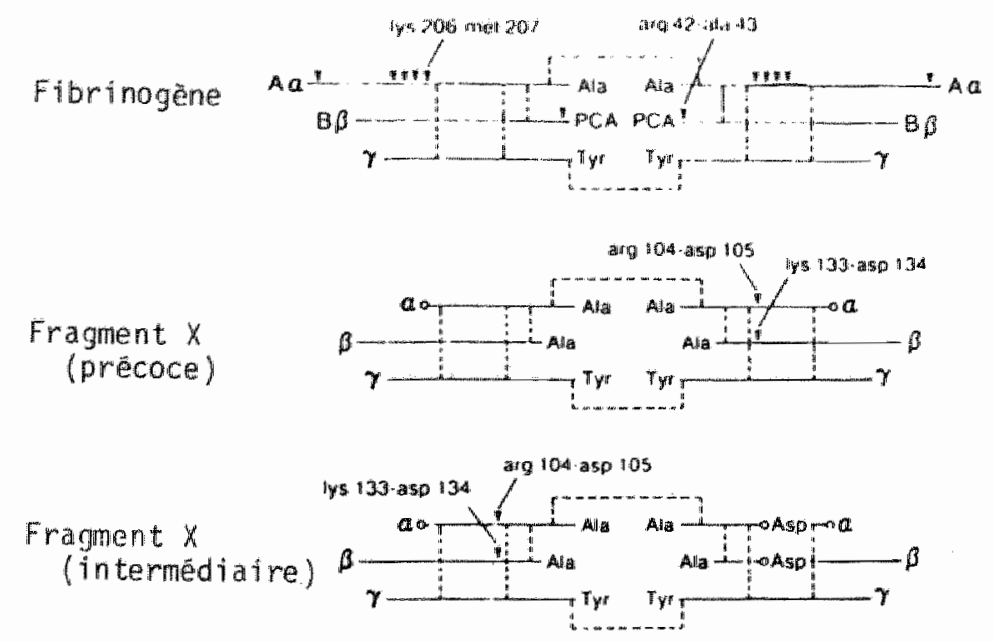

frragment $x$ (tardif)

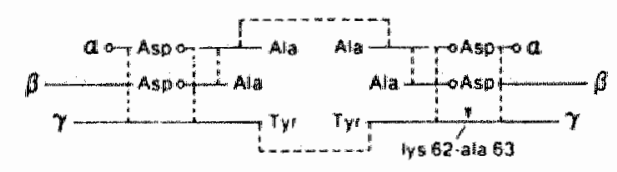

Fragment $Y \quad$ The

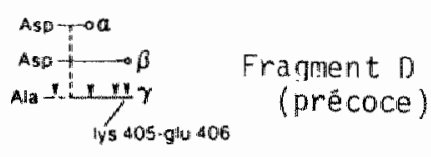

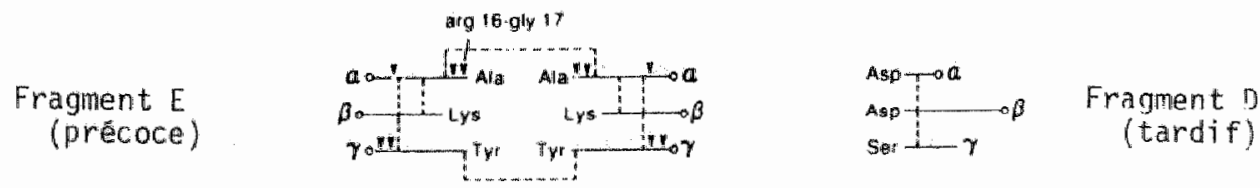

Fragment $\mathbb{E}$

(tardifi)

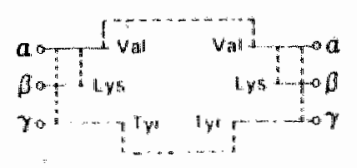

Fig. 9 : Dégradation du fibrinogène par la plasmine.

Emplacement des différents sites de dégradation enzymatique (d"après Takagi et Doolittle, Biochemistry, 1970, 14, 940) 
milieu de la structure helicoidale, interessant les trois types de chaînes d'un seul coté de la molécule et libérant une molécule de fragment 0 a partir dun des domaines c teminaux, tandis que le fragment résiduel, assez important, constitue le fragment $\gamma$. Le fragment $D$ est danc constitué du domaine Det d'une partie de la structure hélicoídale. Le fragment yétant constitué de la deuxième partie de la structure hélicoldale, coupée par la plasmine, et des domaines $D$ et $E$ réunis par la deuxième structure hélicoldale non attaquée $(120,122,123)$. Ce schéma est représenté dans la figure 10.

- Le troisième stade de la dégradation consiste en la dégradation du fragment $Y$ conduisant à la formation d'un autre fragment $D$ et du fragment $E$, de poids moleculaire respectifs de 100.000 et de 50.000. Ce clivage a lieu au niveau de la deuxieme structure hélicoidale qui n'avait pas encore été scindée lors du clivage assymétrique du fragment $X(62,63,124)$. Une serie de clivages au niveau de la chaine gamma donne naissance à des fragments D plus dégradés : le premier de ces clivages a lieu au voisinage de l'extrémité $\mathbb{N}$ terminal, mais secondairement la chaine gamma résiduelle est également dégradêe ä partir de l'extremité c terminal $(97)$.

Il est à noter que le calcium influence aussi la structure du fragment D de degradation ( 84 ), Le calcium protegeant la chaine gamma d'une dégradation plasminique plus poussée. En présence de calcium la chaine gamma du fragment 0 possède un poids moleculaire de 38.000 at le résidu c terminal est l'acide aminé en position gamna 411 du fibrinogène. En revanche, en présence d'EGTA la chaine ganma du fragment $D$ a un poids moléculaire de 25.000 et le rësidu $c$ terminal 

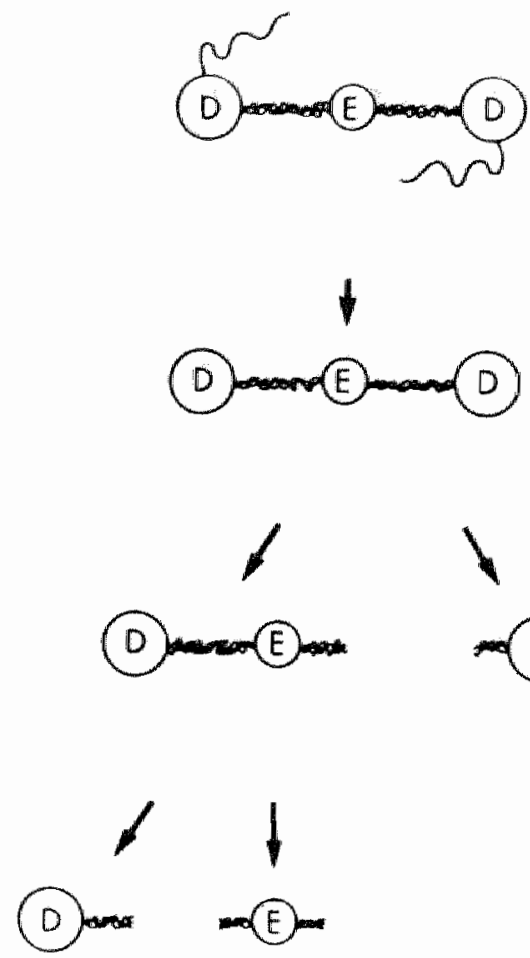

Fig. 10: Degradation asymétrique de la molécule de fibrinogéne.

(d'après Marder et al.

J. Biol, Chem. 1969, 244, 2111). 
est $1^{\prime \prime a c i d e ~ a m i n e ́ ~ e n ~ p o s i t i o n ~ g a m m a ~} 303$. La transition entre le fragment D\|l (obtenu lors de la dégradation du fibrinogène en présence du calcium) et le fragment 03 (abtenu après clivage du fibrinogène en présence d'EGTA) résulte donc d'un clivage de la chấne gamma au niveau du résidu ganma 303 .

Ces dégradations plus ou moins poussées sur la chaine gamma sont très importantes à considérer car la chaîne gamma du fragment D1 ou D cate possède un site de polymerisation, tandis que celle du fragment D3 ou DEGTA en est dépourvue. Ainsi l "étude d'un tel fragment gamma 303-gammia 411 peut apporter des éléments concernant la nature de ce site de polymerisation.

De même Marguerie et PLow d"urie part (125) et Niewi arowski et al. d"autre part (137) ont montré que le fragment 01 contrairement au fragment $D 3$ possédait un site permettant au fibrinogène de se lier aux plaquettes stimulées par I"ADP. Hawiger (86) isolant différents peptides de la chaine gamma, a pu montrer que le peptide intervenant dans la fixation du fibrinogène sur les plaquettes stimulées étalt le penta decapeptide gamma 397-gamma 411.

De même que pour le fragment $D$, le fragment $E$ peut subir aussi diffêtents clivages par la plasmine, conduisant à un produit final, le fragment $E$ tardif, de poids moléculaire 35.000. Ces cliwages tardifs du fragment $E$ ayant lieu au miveau de l'extrémité $\mathbb{N}$ terminal de la chaîne A alpha entrainent une disparition du site de polymèrisation "A" complementaire du site "a" présent au niveau du fragment D (150). 
B. DEGRADATION DE LA FIBRINE STABILISEE

La dégradation de la fibrine stabilisée conduit a la formation de différents produits de dégradation dont l'architecture est dérivee de celle de la fibrine, tenant compte des liaisons reunissant les monomêres de fibrine en protofibrilles à deux brins (57). De plus les sites de degradation du fibrinogène par la plasmine sont également accessibles sur la fibrine stabilisee (65, 124).

On appelle fragment, des dérivés réunis entre eux par des liaisons de covalence, donc non dissociables par les detergents, il s'agit par exemple du fragment DD réunis par les liaisons de covalence au niveau des chaines gamma tandis que les complexes consistent en I"association de un ou plusieurs fragments réunis entre eux par des farces attractives et donc dissociables par les détergents (57).

La première sous-unité décrite a été le complexe D-D-E résultant de l'association par des forces attractives d'un fragment $D-D$ issu de deux monomères adjacents, avec un fragment $E$ provenant d'un troisième monomère present sur l'autre brin de la protofibrille (64, 101), comme J'fllustre la figure 11.

Plus tard, d'autres complexes de plus haut poids moléculaire ont eté mis en évidence (1). Leur structure a pu être êtablie par differents auteurs en confrontant les résultats fournis par electrophorèse en gel de polyacrylamide en milieu non dissociant de ces complexes, d'une part, et ceux fournis en milieu dissociant d'autre part $(56,59,70,80)$. C'est ainsi que Francis et Marder ont classé les dérivés de dégradation plasminique de la fibrine stabilisée 


\section{(D) 3000}

y

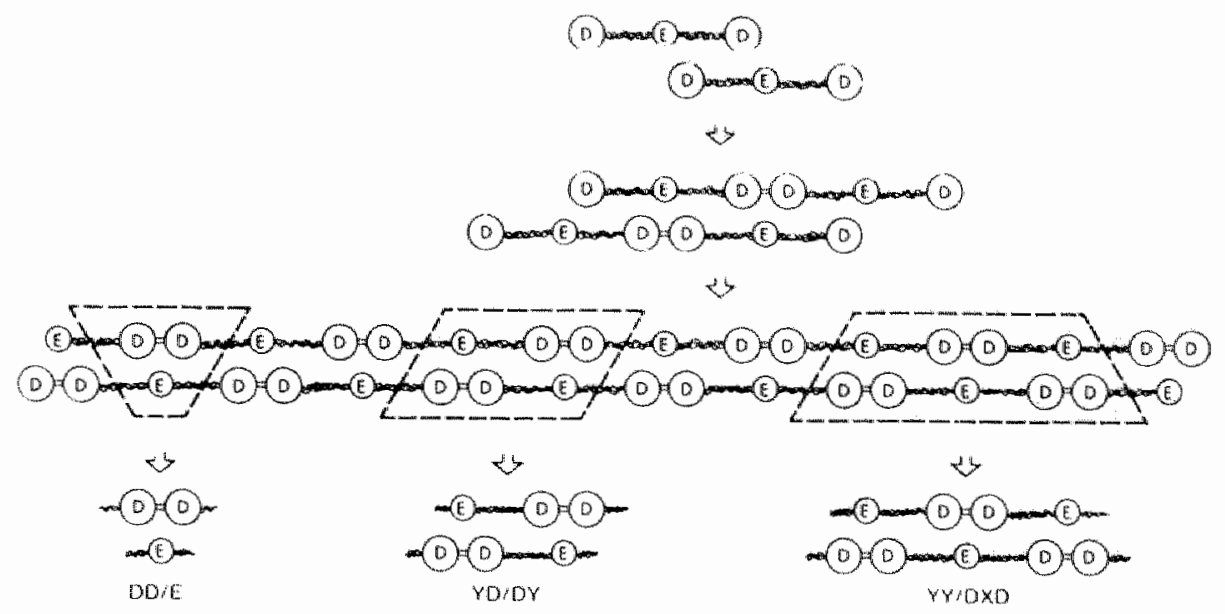

:ig. 11 : Schëma de la dëgradation de la fibrine stabilisêe. Formation de divers complexes.

(d'après Marder et al. Haemost. and Thromb. 198?, p 145, Lipincott Company).

\begin{tabular}{|c|c|c|c|c|c|}
\hline Complexes & PM & Structure & Fragments & PM & Structure \\
\hline \multirow{3}{*}{$\overline{D D} / \mathrm{B}$} & & & $\mathrm{E}^{*}$ & $44-55,000$ & \\
\hline & $228 \mathrm{om}$ & & $D^{*}$ & 100,000 & \\
\hline & & & $Y^{*}$ & 150,000 & \\
\hline \multirow[t]{2}{*}{$\mathrm{DY} / \mathrm{YD}$} & 465,000 & & DD & 195,000 & \\
\hline & & & $x^{*}$ & 247,000 & \\
\hline \multirow[t]{2}{*}{$\mathbf{Y} / \mathbf{D X D}$} & 703,000 & & DY & 247,000 & \\
\hline & & & $\mathbf{Y Y}$ & 285,000 & \\
\hline \multirow[t]{4}{*}{$\mathbf{Y X D} / \mathrm{DXY}$} & 850,000 & & $\mathbf{X D}$ & $\begin{array}{l}334,000 \text { or } \\
365,000\end{array}$ & \\
\hline & & & $\mathbf{X Y}$ & $\begin{array}{l}365,000 \text { or } \\
391,000\end{array}$ & \\
\hline & & & DXD & 461,000 & \\
\hline & & & YXD & 500,000 & \\
\hline
\end{tabular}

唒. 12 : Principaux complexes de dégradation de la fibrine stabilisée.

(d'après Marder et Francis, Ann. N.Y. Acad. Sci., 1783, 408, 395).

PM : Poids Molêculaire. 
en différents complexes issus de l'association de différents fragments (58). Ceci est objectivé dans les figures 12 et 13.

Lors d'une très longue exposition des complexes D-D-E à la plasmine, 11 peut $y$ avoir dissociation du complexe en fragments $D-D$ et en fragment $E$ (148), car le fragment $E$ est degradé en fragment $E$ tardif perdant alors le site de polymerisation "A". Toutefois, ce phênomène n'est jamais observe in wivo, mais seulement in vitro.

La dégradation de la fibrine stabilisée par la plasmine se fait en différentes phases $(58,57,125)$, la dégradation commençant par la périphếrie du caillat (Figure 14).

- lère Phase : il y a une protéolyse très limitee du caillot à sa surface, les produits de dégradation restant fixés à la surface du caillot car les domaines $D$ et E restent fixés de façon covalente à la matrice de la fibrine.

- 2ème Phase : les produits de dégradation de la fibrine restent fixés à la matrice du caillot par les forces attractives et de ce fait peuvent être détachés du caillot par des détergents, tel le SDS.

- 3ême Phase : les complexes solubles de dégradation sont li bếrés spontanément du caillot.

- 4ème Phase : les complexes de degradation libérés sont alors dégradés en complexes de plus petite taille et dont le plus petit est le complexe $D-D-E$.

En fait, si les complexes D-D-E sont bien formés in vitro, in vivo les complexes de haut poids moléculaire sont protégés d"une dégradation plasminique par les antiplamines circulantes. Ce qui 


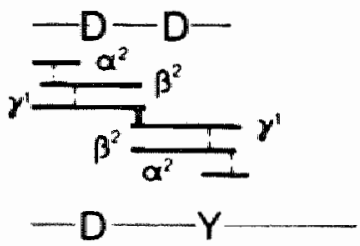

\section{MW \\ $184600 \quad y^{\prime}-y^{\prime}$}

$\gamma^{\frac{I}{ \pm}} \beta^{2} \frac{\alpha}{\alpha^{\prime} \longrightarrow}+\gamma_{E}^{E}$

$226400 \gamma-\gamma^{\prime}$

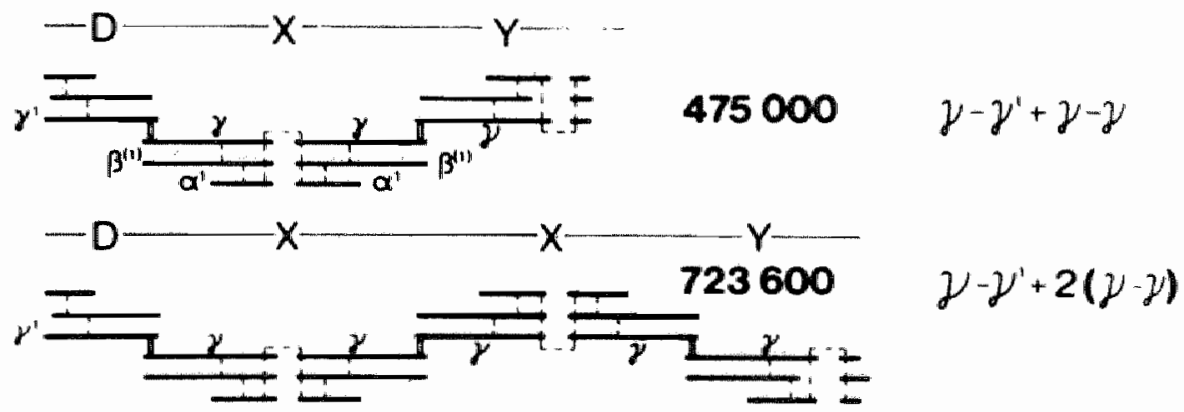

Fig. 13 : Structure des complexes de dégradation de la fibrine stabilisée. 
fibrine stabilisĕe
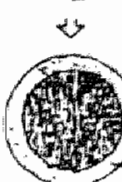

fibrine stabilisee

phase 1

phase? (PDFb détaché du caillot par le SDS

๘

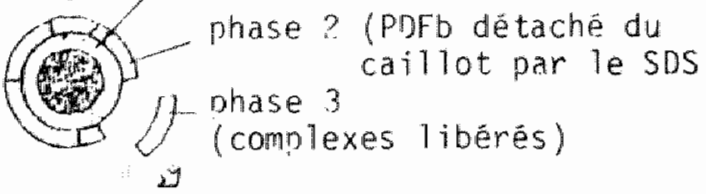

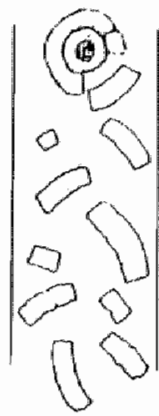

iN Wivo

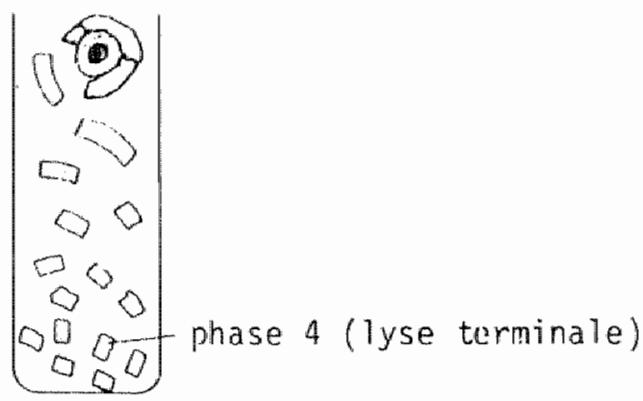

IN WIIRO

Fig. 14 : Diffêrentes étapes de la dégradation de la fibrine.

(d'après Francis, Marder, Barlow

d. Clin. Invest. $1980,56,1033)$. 
explique que les complexes D-D-E sont en quantite peu importante et que l'om trouve principalement des complexes de haut poids moleculaire.

\section{ETUDE IMMUNOCHIMIQUE DE LA MOLECULE DE FIBRINOGENE}

L'analyse immunochimique du fibrinogène a beaucoup progressé ces dernières années. En effet, de nombreux anticorps capables de reconnaitre differents épitopes de la molecule ont ete produits. Ces études permettent de tirer des conclusions sur la configuration de la molécule de fibrinogêne. En outre, la production de tels anticorps peut permettre d'établir des donnếes sum les relations entre structure et fonction de la molécule. Enfin, dans certains cas, l'utilisation de tels anticorps permettra de reconnaitre si la molecule de fibrinogëne a êté dégradée ou modifiee. Cette dernière application d'anticorps spécifiques peut avoir des champs d'application très vastes dans 1 "investigation biologique ou l'analyse de certains biomateriaux comme nous l'avons montré. La plupart des anticorps produits et decrits dans la litterature, carrespondent des anticorps obtenus par immunisation de l'animal avec des fragments de la molécule de fibrinogene. A 1 'heure actuelle des anticorps monaclonaux specifiques pour certains épitopes sont également produits. Nous allons analyser successivement:

1) Les différents épitopes détectables sur la molécule de fi ibri nogène

2) Les modeles proposés pour expliquer l'apparition de néo-antigènes qui sont masqués dans la molécule de fibrinogène intacte 
et $n^{\prime}$ apparaissent qu'après clivage.

3) L'application de cette andlyse immunochimique du fibrinogène à l'étude de la structure tertiaire de la molécule de fibrinogène et à l'analyse des modifications de cette structure lors de la degradation du fibrinogêne ou lors de la fibrinoformation.

A. LES DIfFERENTS EPITOPES LOCALISES DANS LA MOLECULE DE FIBRINOGENE

1) Epitopes au niveau de la chaîne A alpha du fibrinogène

La chaîne A alpha peut être divisée en trois parties :

- celle qui est présente dans le domaine $E(5,71,121)$,

- celle qui est présente dans le domaine 0 , ce fragment est três court dans la chaine A alpha $(35,43,113,114)$

- et les $2 / 3$ de la chaine $A$ alpha environ (48.000 daltons) situés a l'extérieur des 2 domaines du fait de leur structure hydrophile (83, 99, 180).

a) Epttopes au niveau du fpA:

A L'extremité $\mathrm{N}$ terminal de la chaine $\mathrm{A}$ alpha est localisé le fibrinopeptide $A(f p A)$, qui est libéré du fibrinogène lorsque celui-ci est en contact avec la thrombine ou avec la reptillase. Il est constitué de 16 amino acides (Ala, Asp, Ser, Gly, Glu, Gly, Arg, Phe, Leu, Ala, Glu, Gly, Gly, Gly, Val, Arg).

Deux groupes d'anticorps anti-fpA permettent de différencier deux épitopes pour le fpA.

Le premier groupe d'anticorps réagit avec un épitope qui est faiblement exprimé quand le fpA est intégré dans la molécule de 
fibrinogene et qui devient accessible lorsque le fpA est détache de la molecule de fibrinogene (143). Pour avoir une fixation equivalente d'anticorps, il faut que le fibrinogene soit en concentration molaire 1500 fois plus ellevee que celle du fpA libre. Lorsque le fibrinogène est purifié la réactivité pour cet anticorps anti-fpA augmente. Il faut 6 fois moins de fibrinogène isole que de fibrinogene plasmatique, pour avair la même fixation d'anticorps sur le fibrinogène. Cette observation indique que lors de son isolement, le fibrinogêne a subi une modification structurale permettant une meilleure accessibilite du $f p A$ pour $I^{\prime} a n t i-f p A$. Cet anticorps anti-fpA reconnait un epitope qui est centre sur les residu A alpha Phe 8 et Asp 7. Toutefois $1^{\prime a r g}$ en position 16 est également nécessaire à la réactivité de cet épitope (187). Canfield et al. (30) ont suggéré que la conformation du fpA était influencee par son attachement a l"aide d'une liaion covalente au résidu gly-localisé en position 17 dans la chaine A alpha du fibrinogène. Différents travaux semblent prouver que le défaut de reactivite du fpA dans la molecule de fibrinogène vis-à-vis de ces anticorps n'est, pas lié à un encombrement stérique par le reste de la molécule de fibrinogène, mais plutôt à changenent de conformation tertiaire entrainant une modification de l"affinité de l'epitope pour ce type d"anticorps (144).

Le deuxieme groupe d'anticorps anti-fpA reconnait un epitope revele aussi bien sur le flbrinogène non dégrade que sur le fpA libre. Cet epitope est localisé au niveau de la séquence A alpha1-7 et les résidus glu 5 et gly 6 sont nếcessaires $(143,187)$. 
b) Epitopes localises au niveau de la fraction $C$ terminal de la chaîne A alpha

Cette partie de la molécule peut être isolée du fibrinogène par clivage à l'aide du bromure de cyanogène et correspond à la chaine alpha du fragment Hi2-DSK ou FCB3. Le poids moléculaire de ce fragment de chaine alpha est de $28.000(76)$. Ce fragment fait partie d'un fragment plus gros (poids moléculaire 48.000 daltons) de la chaîne alpha détaché de la molécule de fibrinogène par la plasmine. Trois epitopes ont pu être localisés et exprimés aussi bien dans le fragment de poids moléculaire 48.000 que dans le fragment de poids moléculaire 28.000. Un de ces épitopes est localisé dans le fragment alpha 253-268, un autre dans le peptide alpha 540-554 (187). Enfin le troisième épitope est immunochimiquement homologue, ou réagit de la même façon avec l'anticorps qu'un épitope localisé au niveau de la chaine gamma. Cet épitope a été décrit sous le nom de DEDS alpha (34).

2) Epitopes au niveau de la chaîne $B$ beta

Différents peptides peuvent être détachés de la chaine $B$ beta dans des circonstances bien définies. Le fibrinopeptide $B$ (fpB) ( 181 , 188) est liberé du fibrinogène lorsque celui-ci est soumis a l'action de la thrombine. Il est formé de 14 amino-acides et selon la nomenclature officielle, le $f p B$ est connu sous le nom de fragment $B$ beta $1-14$.

La plasmine attaque également la fraction $\mathrm{N}$ terminal de la chaine $B$ beta, mais les fragments liberés sont plus gros que le $f p B$, comme il est exposé au chapitre concernant la dégradation du 
fibrinogène par la plasmine. Diffêrents epitopes ont pu être individualisés au niveau de l'extrémite $\mathrm{N}$ terminal de la chaîne beta.

Epitapes au niveau du $f p B$

- Le fpB renferme deux epitopes $(181,188)$.

Le premier est dépendant de I'Asp 5 et de 1'Asn en 6, ma is est également influence de façon variable par I"Arg 14 en position $C$ terminal du $f p B$.

Le deuxième épitope dépend de la séquence Glu 7 - Glu 8. La structure terminée par 1'Arg 14 entre également en jeu.

Ces faits sont importants à considerer du point de vue pratique, car in vivo le $f p B$ perd très rapidement $1^{\prime}$ Arg 44 du fait de la présence de carboxy-peptidase ce qui est très bien objectivé par HPLC (111). Les épitopes permettant de reconnaitre le fpB étant plus ou moins dépendants de $1^{\prime \prime} \mathrm{Arg} 14$, le dosage du fpB ne peut pas servir de marqueur à une activation de la coagulation. Pour que le dosage du fpB puisse être utilisé comme marqueur de l'activation de la coagulation, il faudrait préparer un anticorps dirigé contre le fpB 1-13 (danc dépourvue en arginine) (47).

- Le fragment $B$ beta $1-42$ represente un marqueur de 1 'attaque du fibrinogène par la plasmine.

on peut considerer que, à des stades precoces de la dégradation par la plasmine du fibrinogene ou de la fibrine 1 , le fragment $B$ beta $1-42$ est liberé $(25,123,153,180)$. Cependant dès que la fibrine I se transforme en fibrine II, apres libération du fpB, la liaison $B$ beta 42-43 devient moins accessible au clivage par la plasmine (151). Cependant, la dégradation plasminique conduit alors au fragment beta 
15-42 et peut etre beta $21-42$. Le fragment beta $1-42$ renferme au moins 4 epitopes (145), au niveau des fragments $B$ beta $1-14$, $B$ beta 1-21, $B$ beta $15-42$ et également $B$ beta $21-42$.

Pour differencier le $\mathrm{fpB}(\mathrm{B}$ beta $1-14)$ et le fragment $B$ beta 1-42, Nossel a proposé de doser l'immunoréactivitế avant et après addition de thrombine (145). L'augmentation de réactivité du fpB après action de la thrombine permet d'valuer le fragment $B$ beta $1-42$. Ce procéde est basé sur le fait que I'immunoréactivité du fragment $B$ beta 1-14 est nettement diminuée quant le fpB fait partie d'une longue sequence comme le fragment $B$ beta $1-42$. Cette différence de réactivité peut être expliquée, soit par un masquage d'epitope du fpB par la sequence $B$ beta 15-42, soit par un changement de conformation. La réactivité du fragment $B$ beta $1-42$ vis-à-vis de l'anticorps anti fpB est donc três sêrieusement augmentêe quand le fragment $B$ beta $1-42$ est soumis à l'action protélytique de la thrombine.

\section{3) Epitopes and neau de la chaine gamma}

Quand des anticorps anti-fibrinogène sont préparés, les anticorps reagissant avec la chaine gama representent seulement moins de $10 \%$ des anticorps obtenus. En outre, les anticorps préparês en immunisant les animaux avec la chaîne gamma isolee, reagissent fablement avec le fibrinogene intact $(75,157)$. En effet, sur les 11 a 13 épiltopes présents sur lä chaine gamma, seul 2 ou 3 sont exprimés dans le fragment natif.

Les différents êitopes peuvent être classês en différents groupes, comne le montre la figure 15. 


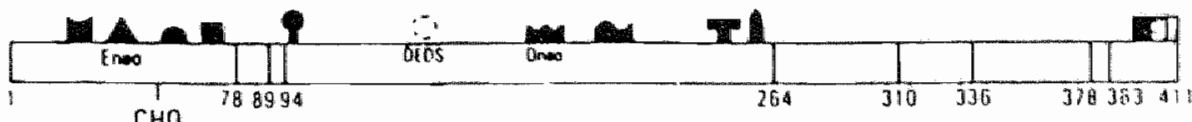

Fig. 15: Distribution des différents épitopes connus sur la chaîne gamma du fibrinogène (d'après Plow et Edgington, Seminars in Thromb. and Haemost. 1982, 8, 36). 
a) Epitopes prêsents dans la région $N$ terminall de la chaine gama au niveau du domane E de la molecule de fibrinogene et dans la zone proximale des zones hélicoidales. Des anticorps ont été produits contre ces fragments et ont permis la caracterisation diepitopes à ce niveau (35). Ces épitopes sont bien accessibles sur la chaine gamma mals IIs n'apparaissent pas sur la molécule de fibrinogène intacte. En effet, dans la molecule de fibrinogère, les epitopes sont masqués dans les zones helicoidales ou dans le fragment $E$ au niveau des boucles formées par des ponts disulfures inter-chañes. Parmi ces 4 epitopes, la structure de l'un d'entre eux ayant les caractéristiques d'un néo-antigène $E$, a pu être précisêe et est constituée du peptide gamma 36-54 (48, 158). Ces Epitopes dewlennent accessibles après l'elimination du fragment $B$ beta 1-42 par la plasmine.

b) Epitopes présents dans la région centralle de la chaîne gamma (gamma 95-264) correspondant à un fragnent de chaîne gamma obtenu par dégradation par le bromure de cyanogène. Au moins 5 épitopes présents dans des fragments tryptiques du gamma 95-264 ont pu etre identifies par Fair (50) localises respectivement en gamma 95-108, 109-194, $198-247,248-256$ et $257-264$.

Tous ces épitopes, bien que présents dans la molécule de fibrinogene, sont peu accessibles à $1^{1}$ anticorps dans le fibrinogene intact. La réactivité n"apparaît qu'après degradation plasminique et elle augmente encore apres séparation des charnes. 
Parallèlement Plow et al. ont decrit un D néo antigène (154, 155) dont l'épitope est localisé dans le fragment gamma 160-197. Cependant, il est difficile de savoir si ce D nëoantigene correspond a un des antigènes décritus par fair.

Enfin, Cierniewsky et al. (34) ont décrit le DEDS-Gamma, il s'agit d'un epitope localise au niveau de la chaine gamina, et. 1 'expression de cet epitope est dépendant de I'interaction entre le fragment $D$ et $E$. En effet, il est présent sur le complexe entre le fragment $D$ et le fragment $E$, par contre il est totalement absent dans le fragment $D$ et le fragmet $E$ pris jsolement.

L'expression de cet épitope est dépendant d'interactions qui peuvent se consituer entre les deux domaines.

c) Epitopes localisés à l'extrémité C terminal de la chaine gamma partie de la molécule renfermant les sites de covalence induits par le facteur XIIIa entre différentes molécules de fibrine

Lahiri et al. (112) d'une part, et Budzynski et al. (26) d'autre part, ont obtenus des anticorps en immunisant des lapins avec la fraction C terminal de la chaine gamma dimérisée. Les anticorps obtenus réagissent preferentiellement avec les dimères de chaine gamma, mais ne réagissent que três falblement avec la fraction $c$ terminal de la chaîne gamma à l'état de monomère. Ces anticorps reconnajssent un antigène qui est plus exprimé sur la molécule de fibrine stabilisée que sur la fibrine non stabilisée, cet epitope etant localisé au niveau de l'extrémité c terminal des chaines gamma. 


\section{MOOELES PROPOSES POUR EXPLIQUER L"APPARITION DE NEO-ANTIGENES}

11 apparait ainsi que certains épitopes ne sant pas exprimés à l'exterieur de la molécule de fibrinogène, mais peuvent apparaitre, soit apress degradation. soit après modification allostérique, soit aprês agrégation de fragments par des liaisons de covalence. Trois mécanismes differents ont pu être proposés pour expliquer 1"apparition de ces né-antigenes, qui apparaissent apres clivage.

1) Nêantigènes apparaissant aux sites de clivage par l'enzyme (115)

2) Néoantigènes pouvant être liés à un changement de conformation de la molecule : une nouvelle conformation pouvant à elle seule induire la formation d'un nouvel epitope (190).

3) Démasquage d'épitopes qui étaient masqués du fait de I'encombrement stêrique (48, 158, 159)..

Les néoantigènes décrits dans la littêrature ont été localisês au niveau du fragment $D$ et au niveau du fragment $E(155)$.

- Les D nếoantigenes sont localises au niveau de la châne gamma dans la fraction centrale gamma 95-264. Un D néoantigène decouvert par Edgington a eté identifié dans la séquence 160-197.

- Le E neoantigene a ete egalement localise dans la chaîne gamma et correspond au fragment ganma $36-53$.

- Enfin, des marqueurs de la dimerisation du fragment 0 ont pu être mis en evidence. 
La réaction de transamidation se fait entre une lysine et une glutamine de deux chaînes gamma de deux fragments differents (31, 178). La dimérisation des chaines gamma induit un alignement des deux chaines gamma, alignement anti-parallele. La nouvelle structure créce par cet alignement contient un néoantigène absent dans la chaîne gamma dissociée.

C. APPLICATION DE L'ANALYSE IMMUNOCHIMIQUE DU FIBRINOGENE A L'ETUdE DE LA STRUCTURE TERTIAIRE DE LA MOLECULE. MODIFICATIONS DE STRUCTURE INDUITE PAR LA DEGRADATION DU FIBRINOGENE OU LORS DE LA FIBRINOFORMATION

La préparation d'un groupe d'anticarps reconnaissant des épitopes bien définis à l'intérieur de la molécule, permet d'apporter des précisions sur la configuration tertiaire de la molécule. Comme il a été établi par Plaw et Edgington (160), les différents épitopes reconnus ont été placés dans le modèle trinodulaire du fibrinogène et à chaque fois il est noté si l'épitope est reconnu par les anticorps au niveau du fibrinogene hatif ou si au contraire, l'épitope est masque dans le fibrinogene natif. De plus, la recomaissance des Epitopes permet de preciser la fonction de ces structures dans la molécule de fibrinogène. Enfin, la reconnaissance d'épitopes pernet de mettre en évidence des modifications de la molécule au cours de la fibrinoformation par exemple. 
Différentes conclusions concernant la structure du fibrinogène ont pu être tirếs de cette étude. La structure trinodula ire de la molecule de fibrinogène $(43,45)$ est actuellement admise par tous. Grace aux etudes immunochimiques, il a pu être montré que le fibrimogene etait en fait une molecule très flexible, puisque, bien que separes par les structures hellicolidales, les domaines $D$ et E du fibrinogene sont intriques. Cette association des fragments $D$ et $E$ dans la molécule de fibrinogène a été rêuelée par la mise en evidence d'un épitope present dans la chẩne gamma, facilement mis em evidence dans le complexe $D-E$, mals absent du fragment $D$ et du fragment $E$ isole (DEDS-gamma) (77).

Durant la fibrinoformation, les monomeres de fibrine sont beaucoup plus rigides et ne se présentent que sous la forme allongée, permettant alor's l'interaction des monomeres entre eux pour former les fibres de fibrine (127), comme le montre la figure 16.

De plus, lors de la dégradation du fibrinogène, on assiste à une detorsion de la structure hélicoidale. En effet, dans la molecule de fibrinogène, aucun épitope n'est exprimé, ni dans le fragment beta 75-115, ni dans le fragment gamma 19-78, car les charnes sont fortement entrelacées (160). Lors de la dégradation du fibrinogène, certains épitopes localisés au niveau de ce fragment de chaine gamna peuvent être dêmasqués. Ce démasquage d'épitopes a permis de suggerer que pendant la dégradation une détorsion des segments hélicofdaux se falsait. En outre, un changement de conformation des differents domaines est observe pendant la degradation, comme il a eté prouve par l'apparition de réoantigènes présents aussi bien sur lé fragment a que sur le fragment $E$. Le néantigene gamma $36-53$ apparait sur la molécule de fibrinogene des que le fragment $B$ beta $1-42$ est liberé de 


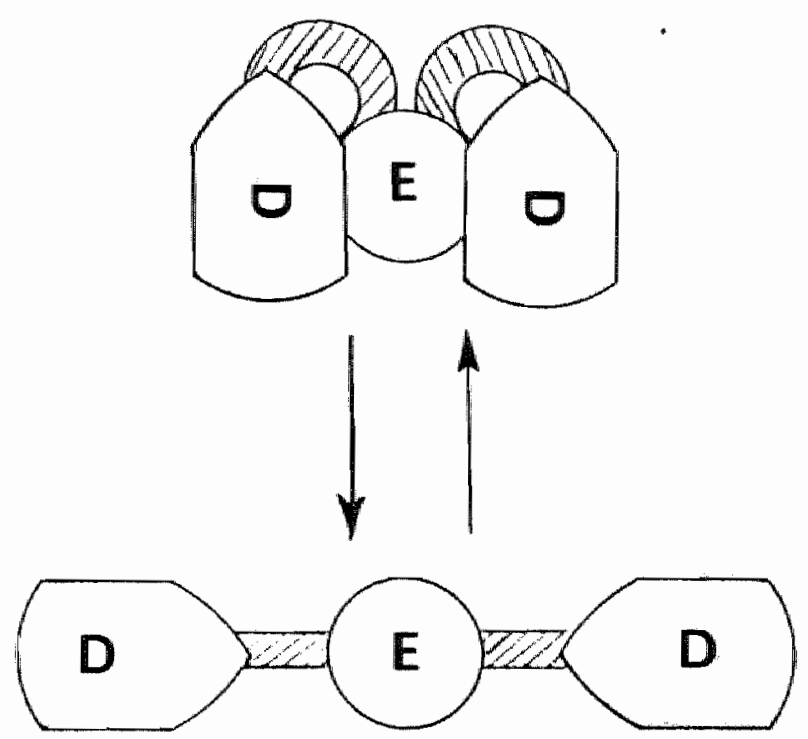

Fig. 16: Flexibilité de la molecule de fibrinogène au cours de sa transformation en monomere de fibrine. 
la molecule. Ce qui montre bien que cette liberation conduit à une transition allostérique de la nolécule avec apparition de nouvelles interactions a l'intêrieur de la molecule.

Enfin, l'exploitation d'une telle étude immunachimique permet egalement d'apporter des modifications sur la conception classique de la fibrinoformation. En effet, 11 etait admis que la fibrinoformation se faisait progressivenent, puisque la liberation du fpA devait aboutir a la formation de (des A) monomeres de fibrine et il était suggere que le depart de fpA de la molecule de fibrinogène était nécessaire pour le fpB soit libéré a son tour sous I'action de la thrombine (36). Cette hypothese a eté infirmé puisqu'il a été montré que la líaison b beta 14-15 êtait facillement accessible dans la molécule de fibrinogene (160). Les resultats de cette étude immunochimique sont d'alleurs en bon accord avec ceux de soria et al. qui ont montré par l'etude du fibrinogène metz que le détachement du fpB pouvalt se faire en l'absence de libération de fpA.

- Enfin, si de nombreux anticorps permettent de différencier le fibrinogene de ses produits de dégradation, peu d'anticorps ont ete decrits permettant de différencier le fibrinogène de la fibrine. Des efforts ont ete falts dans des directions differentes telle que la recherche d'anticorps reagissant avec des epitopes localises au voisinage de la zone de clivage de la thrombine sur la chaine A alpha et $B$ beta.

Kwan et al (140) ont obtenu des anticorps en immunisant un animal dirige contre le fragment de la châne beta qui fait suite au fpB. L'epitope reconnu par cet anticorps est masque dans le flbrimagene et est très bien reconnu dans la fibrine. Cet anticorps ne 
reconnaît pas non plus les produits de dégradation de la fibrine, car le fragment beta $15-42$ est eliminé lors de l'attaque de la fibrine par la plasmine.

Des anticorps peuvent reconnaitre des épitopes localises au niveau de régions plus éloignées du site de clivage de la thrombine et qui seraient plus exposés dans la molécule de fibrine du fait des changements topographiques qui se produisent durant la fibrinoformation.

Enfin, les liaisans de covalence entre deux chaines gamma conduisant aux dimères gamma, peuvent également faire apparaitre des épitopes conformationnels, permettant de différencier la fibrine stabi lisée du fibrinogène. 
CHAPITRE II

MATERIEL ET METHODES 


\section{PREPARATION D' UN ANTICORPS MONOCLONAL}

\section{A. PREPARATION DES PRODUITS DE DEGRADATION DE LA FIBRINE}

Voir le paragraphe concernant les antigènes utilisés pour tester les surnageants.

\section{B. IMMUNISATION DES SOURIS}

Deux souris Balb/c âgées de six semaines ont été injectées au jour 1 (J1) avec $100 \mu g$ de produits de dégradation de la fibrine en solution dans $0.3 \mathrm{ml}$ de $\mathrm{NaCl} 0.15 \mathrm{M}$ additionné d'une quantité égale d"adjuvant de Freund complet. Un tiers a été injecté intrapéritonéalement et les deux tiers restant en sous-cutané. Au jour 21 une deuxieme injection de $100 \mu 9$ de produits de dégradation de la fibrine a été faite, puis 4 jours plus tard la rate a êté prélevee stérilement et les cellules mises en suspension, afin d'être fusionnées avec la lignée de myélome.

\section{PROTOCOLE DE FUSION}

Nous avons fusionné deux fois $3 \times 10^{7}$ cellules de rate avec $5 \times 10^{7}$ cellules de myêlame NSI en utilisant pour cela la méthode decrite par Kohler et Milstein en 1975 et madifiée par Fazekas de St Groth. Le 
protocole etait donc le suivant $(51,106,107)$.

Le jour précedant la fusion:

1) On prépare des milieux stériles suivants: $30 \mathrm{ml}$ de sucrose (0.34 M), 100 ml de milieu standard composé de RPMI 1640 contenant 10 \% de sérum de veau foetal, $200 \mathrm{ml}$ de milieu HAT (milieu standerd + hypoxanthine $10^{-4} \mathrm{M}+$ aminopterrine $4 \times 10^{-7} \mathrm{M}$ et thymidine $1,6 \times 10^{-3} \mathrm{M}, 2$ $\%$ de glutamine $200 \mathrm{mM}, 1 \%$ de pyruvate de $\mathrm{Na} 100 \mathrm{mM}$ et 100 unites de Pénicilline $+50 \mu g$ de streptomycine par $\mathrm{ml}, 2 \mathrm{ml}$ de solution de fusion à $2 \mathrm{~g}$ de PEG 4000 pour $2 \mathrm{ml}$ d'eau distillee, solution stéril lisée à l'autoclave.

2) On prépare les macrophages à partir de 5 souris Balb/c en rinçant leur cavité péritonéale avec $5 \mathrm{ml}$ de la solution de sucrose. Les macrophages sont réunis et comptés, puis centrifugés pendant $10 \mathrm{mn}$ à 200 G avant d'être remis en suspension dans du millieu HAT à la concentration de 6\%10 macrophages par $\mathrm{ml}$. $100 \mathrm{microlitres}$ de cette suspension sont distribués daris les trous de microplaques de culture et placés dans un incubateur à $\mathrm{CO} 2$ sous une humidité de $85 \%$ et une pression partielle de CO2 de $7 \%$.

Le jour de la fusion:

1) Les cellules myélomateuses en culture sont récupérées par centrifugation des suspensions cellulaires dans des tubes de $50 \mathrm{ml}$. Les culots sont réunis dans un tube qui est rempli avec $50 \mathrm{ml}$ de milieu standard, les cellules sont comptées, recentrifugées pendant 10 mn $\$ 200$ G et mises en suspension dans volume de milieu RPMI tel que les cellules soit à 10 cellules par ml.

2) Les cellules de la rate prélevées stêrilement sont également 
lavées une fois dans $50 \mathrm{ml}$ de cl Na $0.15 \mathrm{M}$ et centrifugées pendant 10 $m$ aे $200 \mathrm{G}$. Les cellules sont remises en suspension en ClNa $0,15 \mathrm{M}$ de manière à avoir 10 cellules par ml.

Ces deux étapes sont réalisêes parallèlement, à la temperature du laboratoire, dans une hotte à flux laminaire.

3) La fusion est réalisée en mélangeant $5 \mathrm{ml}$ de suspension de cellules de myêlome avec $3 \mathrm{ml}$ de la suspension de cellules spleniques dans un tube de $50 \mathrm{ml}$ rempli avec du RPMI ou du milieu standard. La suspension ainsi obtenue est centrifugée à $200 \mathrm{G}$ pendant $10 \mathrm{mn}$. Après avoir enleve le surnageant et remis le culot en suspension, on ajoute $1 \mathrm{ml}$ de la solution de fusion, goutte à goutte en $1 \mathrm{mn}$, en agitant le tube de façon constante et en le plongeant ensuite pendant 90 secondes dans un bain-marie a $37 \mathrm{C}$. On arrête la fusion en ajoutant lentement 20 ml de milieu standard ou RPMI dans des conditions bien déterminées : $1 \mathrm{ml}$ les premières 30 secondes, $3 \mathrm{ml}$ pendant les 30 secondes suivantes et le reste pendant la deuxième minute. Le tube est ensuite rempli avec le milieu standard et laissé au repos pendant $5 \mathrm{mn}$, puis centrifugé pendant $10 \mathrm{mn}$ à $200 \mathrm{G}$. Le culot cellulaire est alors lave par $50 \mathrm{ml}$ de milleu standard. Après une nouvelle centrifugation, les cellules sont remises en suspension dans $50 \mathrm{ml}$ de milleu HAT par un pipettage doux en êvitant de détruire les agrégats. La suspension cellulaire est alors distribuée dans les microplaques raison de 100 microlitres par puits et les microplaques sont replacés dians l'incubateur ä $\mathrm{CO} 2$.

Les jours suivants la fusion:

Les hybridomes sont surveillés régulièrement. Au jour 6 après 1 a fusion, $50 \%$ du surnageant de chaque puits est remplacé par du milieu 
HAT, au jour 10, les collonies sont visibles a l'oeil nu. Les surnageants peuvent être testês entre le loe et le 14e jour.

D. PRESERVATION OES CLONES, CONGELATION

Les cellules des puits contenant une sécrétion intéressante sont transférés imëediatement dans les puits de macroplaques de cultures à 24 puits et donc chacun a été rempli par $2 \mathrm{ml}$ de milieu HAT. Dès que les cellules ont atteint 50 \% de la confluence dans ces macroplaques, elles sont clonées et reclonées afin d'être sur de preserver la sécrétion. Les clonages sont effectues à la dilution limite. Les lignées cellulaires parentales, c'est à dire avant. clonage, sont congelees apres les avoir fait proliferer en flacon dans un volume de milieu standard de $10 \mathrm{ml}$, afin de congeler une quantité suffisante de cellules. La congêlation est effectuée de la manière suivante : les cellules sont centrifugées puis remises en suspension dans $1 \mathrm{ml}$ de sérum de veau foetal contenant $5 \%$ de DMSo. Les cellules sont alors distribuêes dans trois ampoules de $2 \mathrm{ml}$ en polystyrene et placees pendant une nuit dans un congelateur a $-80^{\circ} \mathrm{C}$, avant d'être transférées dans un conteneur d'azote liquide.

E. PREPARATION DES ASCITES RICHES EN ANTICORPS

Elle est realisée par injection des cellules d'hybridome produisant un anticorps préalablement sélectionné. Une semaine avant L"injection des cellules, $0,5 \mathrm{ml}$ de pristane est administré a une 


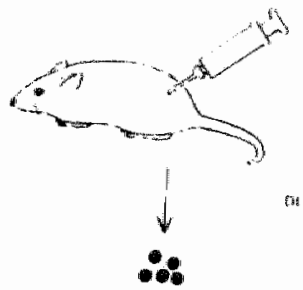

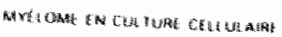

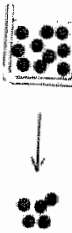

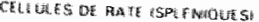

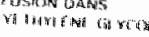
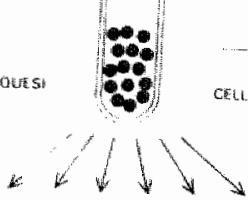

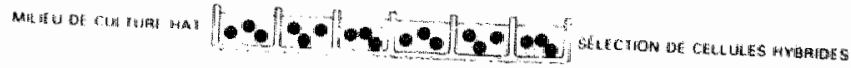

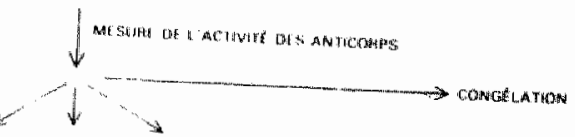

Gonage
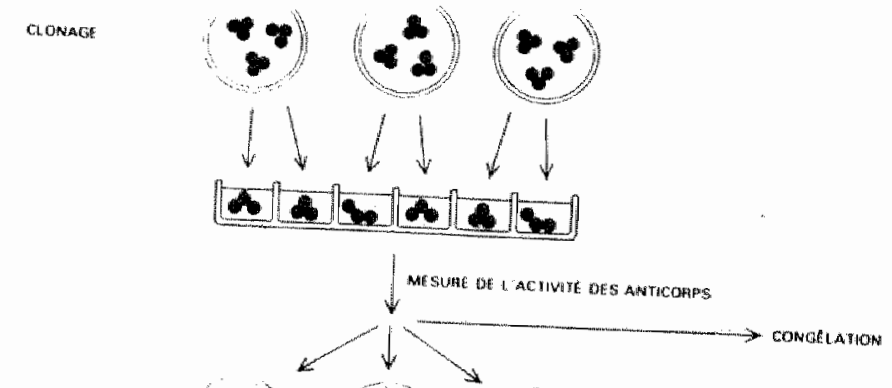

POE WEAG CLONNARE
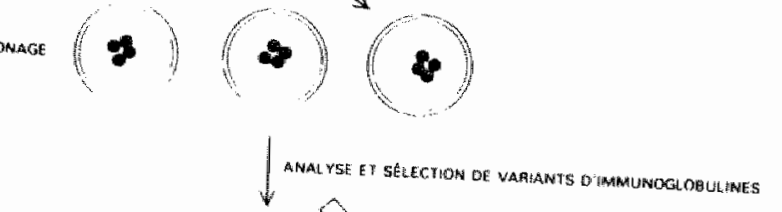

Cunits SLECHronves

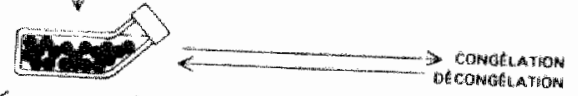

CAOSSANCE

In cur rumit
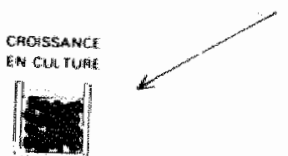

.

$\because \because$

An Thoor:s

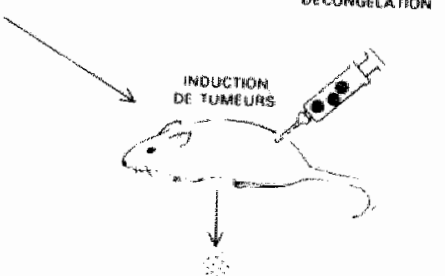

A.A Trophip

Fig. 17 : Schêma des différentes êtapes de l'abtention d'anticorps nonoclondux.

(d'après Milstein pour la science, 1980). 
souris Balb/c en injection intraperitonéale dans le but de créer une irritation locale. Hut jours plus tard, 10 millions de cellules d'hybridomes somt mises en suspension dans $1 \mathrm{ml}$ de sérum physiologique et la suspension cellulaire injectée intraperitonéalement à la souris, prealablement traitee par le pristane. L'ascite apparait 10 jours apres linjection de cellules et les prëlevements d'ascite sont effectués regulierement.

Le schema de l'abtention des hybridomes producteurs d"anticorps monoclonaux est representé dans la figure 17.

\section{METHODES UTILISEES POUR LA SELECTION DES LIGNEES}

Pour dêterminer la spécificité des anticorps sécrétés et evaluer leur titre, nous avons choisi l'immuno-enzymologie.

\section{A. PRINCIPE DE LA METHODE IMMUNO-ENZYMOLOGIQUE}

Dans un premier temps les surrageants a tester sont incubes en prêsence de tween avec differents antigenes fixés sur un support sollde. Dans ces conditions experimentales, seuls les anticorps vont se fixer d'antigene immobilise et il $n^{1} y$ a pas de fixation non specifique d'autres proteines, du fait de la presence de tween.

Dans un deuxième temps, l'anticorps (Ig de souris) susceptible d"être fixê à l'antigène immobilise est rếvele par une Ig de chềre anti Ig de souris marqué à la peroxydase. L'activité de la péroxydase fixee sur le support est alors mesuree en utilisant un substrat 
63

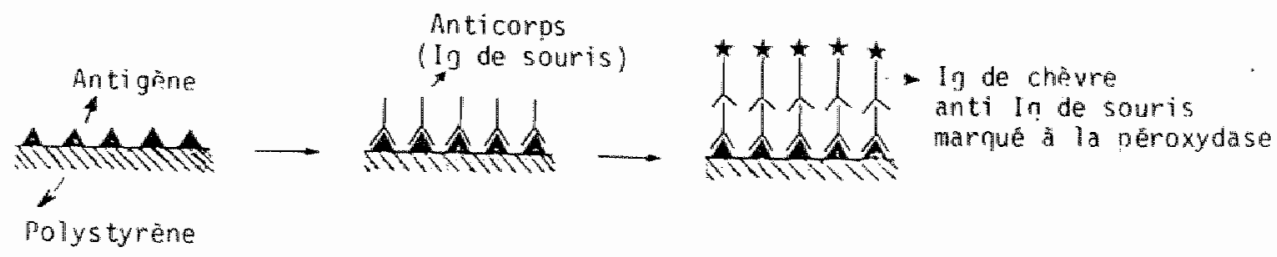

Fig. 18 : Schéma de la réaction Immuno-enzymologique utilisé pour tester les surnageants de culture 
chromogene en présence d'eau oxygénee. La réaction est schematisée dans la figure 18.

\section{B. MATERIEL}

1) Le support solide choisi pour fixer l'antigene a été les plaques de polystyrène Dynatech M 29 B à 96 puits pour microELISA, car la fixation de l'ntigene sur ces plaques est très reproductible. De plus, ce support est traité par irradiation aux rayonnements gamma, ce qui permet une meilleure capacité d'absorption qua celle se produisant sur les mermes supports non traites.

\section{2) Antigenes utilisés pour tester les surnageants}

a) Fibrinogène huma in (Labaratoire Kabi, Stockholm).

b) Fragment de dégradation du fjbrinogène.

Les fragments $D$ et $E$ ont eté isolés selon lla technique de Nilhen (140). La dêgradation du fibrinogène a été rélisée en incubant $10 \mathrm{ml}$ d'une solution de fibrinogene a $10 \mathrm{mg} / \mathrm{ml}$ dans du chlorure de sodium $0,15 \mathrm{M}$, phosphate $0,05 \mathrm{M}, \mathrm{pH} 7,35$, avec deux unités de plasmine (laboratoire Novo) a $37 \mathrm{C}$ pendant 8 heures.

A la fin de cette période d'incubation, la solution dégradée de fibmogene est dialysee $\$ 4^{\circ} \mathrm{C}$ contre du tampon phosphate $0,01 \mathrm{M}, \mathrm{pH}$ 8,2. La séparation des fragnents $D$ et $E$ est alors effectuée par chromatographie echange d'ions. A cet effet, l'échantillon est appliquë sur une colonne de DEAE cellulose de $20 \times 2,5 \mathrm{~cm}$ puis élué en gradient de force ionique, le tampon initial etant du tampon phosphate 
$0,01 \mathrm{M}, \mathrm{pH} 8,6$ et le tampon final du tampon phosphate $0,3 \mathrm{M}$, pH 8,6 . Dans de telles conditions, le fragment $D$ est élué au debut du gradient, tandis que le fragment $E$ est elue avec le tampon final.

Pour obtenir les fragments 01, la dégradation du fibrinogène par la plasmine est réalisée en milieu $\mathrm{Cl} 2 \mathrm{Ca}:$ à $2 \mathrm{ml}$ de solution de fibrinagène à $6,5 \mathrm{mg} / \mathrm{ml}$ dans du $\mathrm{NaCl} 0,15 \mathrm{M}$, sont ajoutés $0,25 \mathrm{ml} \mathrm{Cl} 2$ Ca $M / 4$ et $0,5 \mathrm{ml}$ de plasmine à $2 \mathrm{u} / \mathrm{ml}$.

Après 2 heures d'incubation à $37^{\circ} \mathrm{C}, 0,4 \mathrm{ml}$ de plasmine à $2 u / m 1$ sont de nouweau ajoutés à la solution. Après 2 nouvelles heures dincubation à $37^{\circ} \mathrm{C}$, la plasmine est éliminée par chromatographie sur sépharase lysine (laboratoires Pharmacia) en tampon tris $0,05 \mathrm{M}$ pH 7.4.

La solution renfermant les fragnents $D$ et E est alors soumise à une dialyse contre du tampon tris $0,01 \mathrm{M}$ pH 8,6 et la separation des fragments $D$ et $E$ est réalisée selon Nilhen par chromatographie sur DEAE cellulose: l'échantillon est appliqué sur une colonne de DEAE cellulose de $10 \times 1 \mathrm{~cm}$, puis l'élution est réalisée à l'aide d'un gradient de tampon tris, le tampon initial étant du tampon tris $0.01 \mathrm{M}$ $\mathrm{pH} 8,6$, et le tampon final du tampon tris $0,5 \mathrm{M} \mathrm{pH} 8,6$.

Le fragment Di est élué dans le premier pic. Le fragment É est elue dans le deuxiène pic. Les deux pics correspondants aux fragments o1 et E sont soumis a une dialyse contre du chlorure de sodium $0,15 \mathrm{M}$.

Pour obtenir le fragment 03, la degradation du fibrinogène est réalisée en milieu EOTA (10 mM) puis la séparation est effectuee comme prếcédemment. 
Le contrôle de pureté de ces différents fragments est effectué :

- Par electrophorese en gel de polyacrylamide à $5 \%$ en présence de SOS selon la technique de Weber et Osborn (185),

- Par dosage immuno-enzymologique par méthode ELISA, selon Engwall et Carlsson (49).

Le protocole utilisé sera exposé dans le paragraphe sur les conditions experimentales concernant le controle de la fixation d'un antigène sur une plaque de polystyrene. Dans ces conditions operatoires et compte tenu de la trêss grande sensibilitế de dosage, il peut être affirmé que les fragments 0,01 et 03 isolés ne sont pas contaminés par du fragment $E$, les fractions isolées de fragments 0 ne réagissant pas avec les Ig anti fragment E immobilisếs. Cette technique ELISA nous a permis en outre de déterminer la teneur en fragment D1 et D3 dans les fractions obtenues.

c) Produits de dégradation de la fibrine 11 sont obtenus selon le protacole de Gaffney et al. $(68,69)$ après digestion partielle $(50 \%)$ d'un caillot de fibrine stabilisé. Cette obtention se fait en diffêrentes etapes:

1) Préparation d'un caillot de fibrine stabilisé

A une solution de fibrinogène humain Kabi à $3 \mathrm{mg} / \mathrm{ml}$ en solution dans du chlorure de calcium $40 \mathrm{mM}$, sont ajoutes du facteur XIII (fibrogamine, Laboratoire Behring) de manière d avoir une concentration finale en facteur XIII dans la solution identique $a$ celle presente dans le plasma normal, puis de la thrombine (Behring) a la dose de $5 \mathrm{u} / \mathrm{ml}$. Aprés une incubation de 2 heures à $37^{\circ} \mathrm{C}$, le caillot est lavé, essoré. 
2) Lyse du caillot

Les caillots ainsi laves sont incubes dans une solution de plasmine (Laboratoire Kabi) à 2 u/mi lou dans une solution de plasminogène, puis dans une solution de streptokinase). Lorsque le caillat est lysé de $50 \%$ environ, la sollution surnageante renfermant les produits de dégradation de la fibrine est récupếrée, puis débarassée de plasmine par filtration sur une colonne de sépharose lysine (Pharmacia)

3) Separation des complexes de dégradation de la fibrine

Elle est réalisee par chromatographie sur colonne de sépharose 4B (Pharmacia), l'élution etant réalisée à l'aide d'un tampon tris HCl 0.1 M, pH 8,5. Au Vo de la colonne sont elués les complexes de haut poids molếculaire, tandis que les complexes DDE sont elués plus tardivement. La teneur en produits de dêgradation de la fibrine dans chaque pic est évaluée d"après la densitể optique à $282 \mathrm{~nm}$ d'une part et par agglutination de particules de latex sensibilisées avec de L'antifibrinogène (laboratoire Stago, Anières, France).

Les produits de degradation de la fibrine ainsi isoles ont ete analysés par electrophorèse en gel de polyacrylamide à 4 on millieu non dissaciant selon la technique de Davis (42). Ils sont constitues essentiellement de complexes de degradation de la fibrine. Toutefois une petite quantite de fragment D et de fragnent E libres est presente dans les echantillons, phénomène egalement retrouvé par Gaffney (69). Cependant cette quantité de fragments D et E libres dans les Echantillons ne dépasse jamais $15 \%$.

d) Chaînes isolées du fibrinogène :

Leur obtention a été réalisée par technique echange d'ions sur cM cellulose selon la technique de Henschen et Edman (89) après 
dissociation des chaines par le mercaptoethanol et I'urée suivie d'une carboxymethylation de ces chaines.

e) Monomères (des $A$ - des B) de fibrine:

Leur préparation est effectuée par dissolution dans I"urée AM d"un caillot abtenu par coagulation par 2 ude thrombine de $1 \mathrm{ml}$ dune solution de fibrinogene a $10 \mathrm{mg} / \mathrm{ml}$ dans une solution d'EOTA $1 \mathrm{mM}$. La teneur en monomères dans la solution est évaluée d'après la densité optique à $282 \mathrm{rm}$.

3) IgG isolees à partir d'un anti sêrum comercial préparé chez le Iapin : leur isolement a eté effectué par chromatographie sur DEAE selon la technique de corthier et al. (38).

Les antiserums anti fibrinogène, anti $D$ et anti E proviennent du laboratoire Stago.

4) IgG marquées à la péroxydase

Le marquage des Ig a été réalisé par la technique en deux temps d'Aurameas (4).

5) Autres réactifs ou matériel utilise

- Ig de chevre anti Ig de souris marque a la peroxydase (Laboratoire EY)

- Tween 20, albumine bowine (fraction V), orthophenyllène diamine (Sigma)

- Dynawasher automatique : appareil automatique de lavage de plaques

- Spectrophotamètre adapté à la lecture automatique directe de la 
densite optique au niveau de chaque cupule de la plaque : autoreader Dynatech MR 580, cet appareil présente l'avantage d"être un lecteur à double longueurs d'onde, ce qui permet d'bliminer tout bruit de fond cause par les imperfections au niveau des supports plastiques.

- Replicateur : portoir de 96 tulipes de $50 \mu l$ permettant de recueillir simultanement les liquides sumageants au niveau des 96 puits de la plaque de polystyrène (Dynatech).

6) Tampons utillisés par la réaction immuno-enzymologique

- Le tampon servant à dissoudre les proteines destinées à être fixees sur la plaque de polystyrene (ou tampon de "coating") consiste en du tampon phosphate $0,1 \mathrm{M}, \mathrm{pH} 7,4$.

- Le tampon PBS-Tween utilisé dans la réaction antigène-anticorps consiste en du chlorure de sodium 0,135 M-phosphate 0,0175 M, pH 7,4 contenant $1 / 1000$ d'albumine bovine et $0,5 / 1000$ de tween 20 .

- Le même tampon contenant $1 / 1000$ de tween 20 est également utilisé pour les dilutions au $1 / 2$ de manière à ce que 1 a concentration finale en tween 20 solt toujours de $0,5 / 1000$. Le tween 20 est ajoute au tampon pour eviter les adsorptions non specifiques sur la plaque de polystyrène, tandis qu'a cette concentration le tween $20 n^{\prime}$ inmibe pas la réaction antigène-anticorps.

- La solution de lavage des plaques de polystymene consiste en du CINa $0,15 \mathrm{M}$ renfermant $0,5 / 1000$ de tween 20 .

- Le tampon pH 5 de dissolution de l'orthophénylene diamine (OPD) est constitué d'acide citrique $0,05 \mathrm{M}$ - phosphate disodique $0,1 \mathrm{M}$.

- Le réactif destiné a révéler la peroxydase est constitué par une solution d'OPD a $40 \mathrm{mg} / 100 \mathrm{ml}$ de tampon phosphate citrate $\mathrm{pH} 5$. renfermant $40 \mu l$ de perhydrol à $30 \%$ (193). 


\section{PROTOCOLE OPERATOIRE}

1) Imnobilisation de l'antigene sur la plaque de polystyrène

a) Cas où l"aritigène est soluble

L"antigene est imnobilisé sur la plaque de polystyrène par addition dans chaque puits de $200 \mu$ de solution protéique à $1 \mu \mathrm{g} / \mathrm{ml}$ dans le tampon phosphate $0,1 \mathrm{M}$ pH 7,4. Après une incubation de 18 heures a $37^{\circ} \mathrm{C}$, la solution surnageante est éliminée puis la plaque est soumise à 4 lavages successifs avec $300 \mu 1$ par puits de la solution de lavage. Différentes plaques sont réalisêes, plaques contenant du fibrinogène immobilisé, ou du fragment $D$, ou du fragment $E$ ou des produits de dégradation de la fibrine (PDFb).

Au cours d'expériences préliminaires, après incubation de 18 heures à $37^{\circ} \mathrm{C}$ des différentes solutions protéiques avec la plaque de polystyrène, les solutions ont été récupérées afin de déterminer la quantité résiduelle de proténe susceptible de se trouver dans ces solutions. A cet effet une réaction ELISA a êté rếalisee selon la technique d'Engwall et Carlsson (49). Dans les conditions expérimentales que nous avons déterminées [dans un premier temps fixation d'ig purifies provenant $d^{*} u n$ anti-sêrum antifibrinogène, ou anti-fragment $D$, ou anti-fragment $E$, sur la plaque de polystyrène realisêe par incubation 18 heures a $37^{\circ} \mathrm{C}$ d'une solution a $10 \mu \mathrm{g} / \mathrm{ml}$ $d^{*}$ Ig purifite dans du tampon carbonate-bicarbonate, $\mathrm{pH} 9,6$ suivie de 4 lavages de la plaque, dans un deuxième temps incubation des Ig immobilisés ávec la solution susceptible de renfermer le fibrinogène, le fragment $D$ et le fragment $E$ renfermant du tween et dans un 
troiseme temps révelation du fibrinogène, du fragment 0 ou du fragment $E$ par des Ig marquées à la péroxydase ut llisees a la dilution optimale ( $1 / 50$ dans nos conditions) $]$.

Il a pu être démontré ainsi que toute la quantité de protéine incubee avec le polystyrène est fixée dans les conditions choisies. car après incubation, les solutions surnageantes renferment des quantitées d'antigène résiduel inférieures à $50 \mathrm{ng} / \mathrm{ml}$.

b) Cas où l'antigêne est insoluble dans le tampon phosphate, ma is saluble en urée $4 M$.

Le protocole utilisé est celui decrit par Stanilawski et al. $(174)$

- Une activation préalable des plaques de polystyrenene est nécessaire. Elle est réalisée par une incubation de 2 heures a $50^{\circ} \mathrm{C}$ des plaques, avec une solution de glutaraldehyde a $0,025 \%$ dans du C03Na2 pH 9, $0, \hat{\imath} \mathrm{M}(100 \mathrm{ul} / \mathrm{puits})$ suivi de 3 lavages àl'eau distillee.

- L'immobilisation de la protéine a lieu en incubant 18 heures à $37^{\circ} \mathrm{C}$ $100 \mathrm{Hl}$ de la solution protéique en solution dans I urée 4M. La solution d'uree 4 M est obtenue par dissolution d'urée dans l'eau distillée, puis le pH est amené $\mathrm{pH} 7,5$. Les antigenes insolubles utilisês ont été respectivenent : les chaines $A$ alpha, $B$ beta et gamma utilisées ä une concentration de $10 \mu \mathrm{g} / \mathrm{ml}$ dans l'urée $4 \mathrm{M}$ et les monomères utilises aux concentrations de $10 \mu \mathrm{g} / \mathrm{ml}$ et de $5 \mu \mathrm{gg} / \mathrm{ml}$ dans 1 urée $4 M$.

Comme pour le cas de l'antigène soluble, après ce temps d'incubation, la solution protéique est éliminée, puis la plaque est soumise a 4 lavages successifs dans la solution de lavage. 


\section{2) Peaction antigene-anticorps}

a) Prêlevenent des surnageants:

Pour automatiser le prélèvement nous avons mis au point une technique rapide utilisant le réplicateur, permettant ainsi de tester simultanément les 95 puits de la plaque de culture d'hybridomes. Cette technique consiste à prélever en même temps $50 \mu l$ de chaque surnageant d'une plaque de culture à l'aide de réplicateur à 96 tulipes qui est adapté à cette plaque et préalablement stérilisé à la flamine puis refroidi. Les surnageants sont alors transferés dans une plaque वै 96 puits renfermant $50 \mu l$ de tampon PBS-tween 1/1000 par simple apposition du réplicateur au niveau de la plaque. Cette plaque est appelée plaque de transfert. Chaque puits de cette plaque de transfert contient donc $50 \mu l$ de surnageant de culture dilué au $1 / 2$ et l'emplacement de chaque surnageant correspond à l'emplacement des surnageants de la plaque où a été réalisé l'hybridation.

Dans chaque puits de la plaque de transfert sont ajoutés $200 \mu \mathrm{l}$ de támpon PBS tween $-0,5 / 1000$ réalisant une dilution finale du surnageant au $1 / 10$.

b) Reaction antigene-anticorps

$50 \mu 1$ de chaque dilution au $1 / 10$ de ces surnageants présents dans les 96 puits de la plaque de transfert sont préleves de nouveau à I"aide du rêplicateur et disposés dans les puits correspondants d'une plaque où l'antigène a été immobilisé et dans lesquels auront été disposés au préalable $50 \mu$ de tampon PBS tween. Par cette technique les anticorps sont testés en même temps vis-à-vis des differents antigènes répartis dans différentes plaques.

Dans notre protocole les différents surnageants de culture sont 
Dans notre protocole les différents surnageants de culture sont testés simultanément sur du fibrinogène immobilisế (lere plaque), du fragment $D$ (Zeme plaque), du fragment $E$ (3eme plaque), des complexes de dégradation de la fibrine stabilisée (Aene plaque).

Après une incubation de 2 heures à $37{ }^{\circ} \mathrm{C}$ des differents surnageants avec les antigènes immobilisés, les surnageants sont éliminés et les plaques lavées 4 fois avec la solution de lavage.

c) Détection des anticorps liés à l'antigène immobilisé.

A chaque puits sont ajoutés $200 \mu l$ d'une dilution au $1 / 1000$ idlans le tampon PBS tween $0,5 / 1000{ }^{\prime}{ }^{*}$ Ig de chèvre anti Ig de souris marqués à la peroxydase.

Après 2 heures d'incubation $₫ 37^{\circ} \mathrm{C}$ les plaques sont llavees 4 fois, puis l'anticorps marqué à la péroxydase fixế sur la plaque est évalué par dosage de la péroxydase réalisé en ajoutant $200 \mu 1$ de la solution d'OPD. Après exactement 3 minutes d'incubation, lá réaction est bloquée par addition dans chaque puits de $50 \mu l$ d'acide sulfurique 2,5 N. La coloration développée au niveau de chaque puits est évaluée par mesure de la D.0. à $492 \mathrm{~nm}$ en utilisant l'autoreader.

d) Certains surnageants sélectionnês ont été testés sur les chaine A alpha, B beta et gamma immobilisées, ainsi que sur les monomères immobi lisés. 


\section{METHODE IMMUNO-ENZYMOLOGIQUE UTILISEE POUR ETUDIER LA REACTIVITE DE L'ANTICORPS MONOCLONAL VIS-A-VIS DE \\ L'ANTIGENE EN SOLUTION}

Une etude immuno-enzymologique par competition en deux temps ast réalisee selon le protocole décrit par Soria et al. pour le dosage du fibrinopeptide $A(112)$.

A. PRINCIPE DE LA REACTION.

11 est representé dans la figure 19. La fixation de 1 "anticorps a l'antigène immobilise est inhibée de façon compétitive par 1 'antigène en solution. Il existe une relation inverse entre la quantite d'antigene solubilisé incubé avec anticorps, et la quantité $d^{\prime}$ anticorps qui se fixera secondairement sur l'antigène immobilisé.

B. MATERIEL

Les reactifs utilises sont identiques a ceux de la technique precédente.

C. PROTOCOLE

La technique se fait en differentes etapes: 


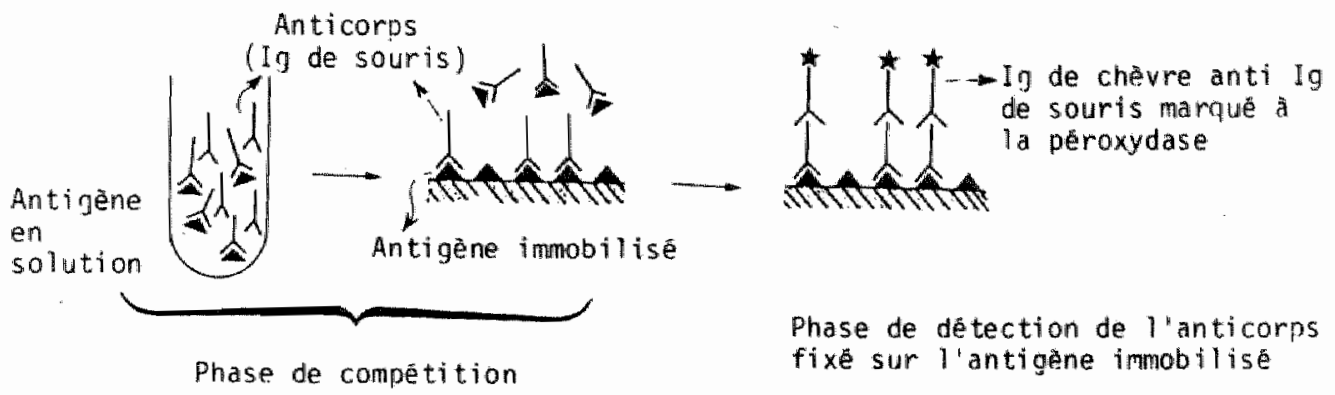

Fig. 19: Réaction de compẹtition antigène-anticorọs entre antigenne en solution et antigène immobilisê. 
1) Determination de la dilution d'anticorps a utiliser

Sur les plaques de polystyrène où l'antigène a étế immobil isế, sont distribues dans chaque puits $200 \mu 1$ de dilutions progressives d'anticorps dans 10 tampon PBS tween $0,5 / 1000$. Les dilutions utilisees sont de $1 / 10$ d 1/5120 pour les surinageants de culture et de $1 / 500$ a $1 / 128000$ pour les ascites.

- Apress 2 heures dincubation les plaques sont lavées 4 foils comme prêcédement et la quantité d'anticorps fixé à la plaque est ếvaluée selon le protocole decrit préalabement pour la sélection des lignếs en ajoutant $200 \mu \mathrm{l}$ d'Ig de chère anti Ig de souris marquêes à la péroxydase, puis en déteminant l'activité de la péroxydase liée à la plaque.

La dilution d'anticorps à utiliser dans l'épreuve de competition est celle qui correspond à $80 \%$ de la fixation maximale dans les conditions opératoires. D'après la courbe d'etalonnage de l'anticorps etablie en portant en abscisses (en échelle logarithmique) l'inverse de la dilution d'anticorps, et en ordonnées len échelle arithmetique) la 0.0 . correspondant à l'activité de la péroxydase reflet de la flxation d'Ig anti Ig de souris marquees à la perroxydase.

2) Etape de competition entre antigene soluble et antigene Immobilise pour se lier à 1 "anticorps.

a) Reaction de competition

La réaction de competition est effectuée en deux temps. Les experiences sont rêdisees dans des tubes a hếmolyse en verre, à usage unique.

- Dans un premier temps $450 \mu \mathrm{l}$ de dilutions progressives en tampon PBS 
tween d'antigènes (concentrations en antigènes allant de $100 \mathrm{\mu g} / \mathrm{ml}$ à $375 \mathrm{ng} / \mathrm{ml}$ ) sont préincubés 18 heures à $4^{\circ} \mathrm{C}$ avec $50 \mu \mathrm{l}$ de surnageant de culture (ou d'ascite) utilisé à une dilution finale dans la mixture d'incubation correspondant à celle préalablement déterminée, la dilution de l"anticorps étant également réalisée en tamponPBS tween). Différents antigènes sont testés parallèlement :

- le fibrinogène

- le fragment $D$ ou le fragment $E$ (selon que l'épitope révélé par cet anticorps soit situé dans le domaine $D$ ou dans le domaine E de la molécule)

- les produits de dégradation de la fibrine stabilisée.

Après le temps d'incubation, les tubes sont centrifugés.

- Dans un deuxième temps $200 \mu l$ de chaque échantillon ainsi incube avec l'antigène en solution sont déposés dans les différents puits de la plaque de polystyrène où est immobil isé l'antigène. Après 2 heures d'incubation à $37^{\circ} \mathrm{C}$, les surnageants sont éliminés et les plaques lavées 4 fois dans les conditions déjà décrites.

b) Evaluation de la quantité d'anticorps fixế sur l'antigène immobil i sé.

La quantité d'anticorps fixée au niveau de chaque puits est Évaluée par la même technique que celle utilisée pour tester les anticorps. La droite détalonnage est tracée sur du papier semi logarithmique, en portant en abscisses la quantité d'antigène en sollution incubé avec l'anticorps (en échelle logarithmique) et en ordonnées la 0.0. traduisant l'activité de la përoxydase et représentant donc la quantité d'anticorps fixé à la plaque (échelle ar ithmétique). 
IV. METHODE UTILISEE POUR JUGER DE LA REACIIVITE DES ANTICORPS VIS-A-VIS DES AUTRES PROTEINES PLASMATIQUES

En effet, un anticorps monoclonal réagissant avec un seul épitape de la molécule, 11 se pourrait que cet épitope puisse se retrouver dans d'autres protéines, autres que le fibrinogène et ses dérivés. Pour apprécier la réactivité des anticorps que nous avons selectionne vis-a-vis des autres protéines plasmatiques, nous avons déterminé si l'incubation du surnageant de culture utilisé à la dilution optimale pendant $18 \mathrm{~h}$ a $4^{\circ} \mathrm{C}$ avec le plasma d'un malade atteint d"afibrinogénémie congenitale (concentration plasmatique en fibrinogène $20 \mathrm{ng} / \mathrm{ml})$ probablement dilué au 1/2 dans du PBS tween 1/1000 etait capable d'inhiber la fixation des anticorps sur le fibrinogène (ou un de ses fragments de dégradation) immabilisé, selon de protocole operatoire de compétition exposé précédement.

Le dosage du fibrinagène dans le plasma et les plaquettes de ce malade a été réalisé par la technique ELISA de Engwall et Carlsson (49), le fibrinogène à doser étant pris en sandwich entre les Ig antifibrinogène fixées sur un support solide et les Ig antifibrinogène marquêes à la péroxydase.

Dans les conditions opératoires dejà exposées dans le paragraphe concernant le controble de l'immobilisation de l'antigène sur la plaque de polystyrène, la réaction est linéaire pour des concentrations allant de $10 \mathrm{ng} / \mathrm{ml}$ à $600 \mathrm{ng} / \mathrm{ml}$ de flbrinogène, ce qui permet de réaliser un dosage précis, sensible et reproductible du fibrinogêne quand celui-ci est en faible concentration. 


\section{DETERMINATION DE LA CLASSE DES Ig OBTENUS PAR LES HYBRIDOMES}

La classe d'immunaglobul ines sécretées par les hybridomes a ete déterminée en incubant dans un premier temps les surnageants en culture dilués dans le tampons PBS tween avec du fragment D immobilise pour les anti $D$, ou du fragment $E$ immobilise pour les anti $E$, selon la technique utilisée pour la sélection des lignées sécrétant des anticorps. Toutefois, 5 incubations identiques sont réalisées pour chaque anticorps.

Dans un deuxième temps les immunoglobulines fixées sur l'antigène immobilisé sont révélées par incubation avec 5 antisérums anti Ig de souris différents: anti $\operatorname{Ig} G$, anti IgG $2 \mathrm{a}$, anti $\operatorname{Ig} \mathrm{g}$, anti IgN et anti 75 (Laboratoire Nordic, anticorps obtenu chez la chèvre). Les antisérums sont utilisês dilués au 1/500 dans le tampon PBS tween.

Dans un troisième temps, I'Ig de chèrre susceptible d'etre fixêe à l'lg de souris est révélée par une nouvelle incubation des plaques avec des Ig anti Ig de chèvre marquées à la péroxydase (reactif Nordic utilsé a une dilution au 1/500 dans le PBS tween), suivie d'une révélation de la péroxydase par la technique précédemment décrite. 
CHAP ITRE III

RESULTATS

OBTENTION D'HYBRIDOMES PRODUISANT DES ANTICORPS DIRIGES CONTRE

DES DERIVES DE LA FIBRINE

SELECTION DE CERTAINES LIGNEES 
Quatre hybridationsont été reali sees.

- Pour la première hybridation, 10 boites de culture cellulaire a 96 puits ont éte ensemencées avec les hybrides lymphocyte/plasmocyte.

- Pour les trois suivantes, 5 bortes de culture à 96 puits ont été utilisees par hybridation.

\section{CLASSIFICATION ET PREMIERE SELECTION DES HYBRIDES OBTENUS}

Pour ces hybridation correspondant a 2400 surnageants testes nous avons trouvé 324 surnageants possédant une réactivitế vis-â-wis du fibrinogène ou des produits de dégradation de la fibrine ayant servi à l'immunisation des souris.

En effet, par le test immuno-enzymologique précédemment décrit, les Ig présentes au niveau de ces surnageants se fixaient au fibrinogène ou au produits de dếgradation de la fibrine (pdFb) fixês sur le puits, fixation révelee secondairement par des ig de chèvre anti Ig de souris marquées à la pêroxydase.

Parmi ces 324 hybridomes, 4 d'entre eux ont eté selectionnes immédiatement, car les Ig sécrétés par ces cellules avaient la proprieté de réagir avec le fragment $D$ et avec les PDFb, mais ne réagissaient, ni avec le fragment $\mathbb{E}$, ni avec le fibrinogène non dégradé fixé sur le polystyrène. La réactivité de ces anticorps vis-â-vis du domaine $D$ de la molecule de fibrinogene et leur absence de réactivitê vis-a-vis de la molecule entière de fibrinogêne, nous"a conduit a les dénommer anticorps-"anti D néo", selon la dénomiritulon de Edgington et Plow. Ces anticorps anti-D néo ne se fixent pas sur 
les monomères de fibrine immobilisées sur la plaque de polytyrène.

Parmi les 319 hybridones restant, nous en avons sélectionné 62 , car le surnageant de leur culture avalt une réactivité importante vis-ä-vis du fibrinogène et des pdfb $(0,0$. correspondant à l'activité de la péroxydase, supérieure à 1,5 en $2 \mathrm{mn}$ ). Parmi ces 62 hybrides, 15 sécrétalent des anticorps réagissant avec le domaine $E$ de la molécue de fibrinogène, mais non avec le domaine $D$ (anti E) et les 47 autres sécrétaient des anticorps ayant une réactivité vis-à-vis du domaine $D$ et non vis-à-vis du domaine E (anti D complet).

Parmi ces anticorps, les 4 anti $D$ néo, 5 anti $E$ et 9 anti $D$ complets ont été clonés, puis une foís les clones sélectionnés par la même technique que celle qui a servi a analyser les premiers surnageants. Le surnageant des clones ainsi sélectionnés a été soumis à une étude plus approfondie.

II. REACTIVITE DES ANTICORPS SELECTIONNES PUIS CLONES VIS-A-VIS

DE L'ANTIGENE EN SOLUTION. EPFEUVE DE DEPLACEMENT

A. DETERMINATION DE LA DILUTION DU SURNAGEANT D'HYBRIDOME A REALISER POUR PRATIQUER UNE EPREUVE DE DEPLACEMENT

Cette détermination est effectuée sur le fibrinogène ou le fragment D immobilisé dans le cas des anti D et sur le fibrinogène ou le fragment $E$ immobilisé dans le cas des anti $E$.

- Aux fortes concentrations en anticorps (dilutions peu 
importantes) il y a une fixation maximale d"anticorps sur la plaque où l'antigène a été fixé, quelle que soit la dilution d'anticorps. Puís, à partir d'une certaine dilution il y a une diminution progressive de la fixation d'Ig. Il existe une relation semi logarithmique entre l'inverse de la dilution effectuée (échelle logarithmique) et la D.0. à $492 \mathrm{~nm}$ (échelle arithmétique) représentant l'activité de l'immuno-péroxydase fixée à la plaque. Les pentes des droites ainsi etablies en mettant en abscisses l'inverse de la dilution d'anticorps (échelle logarithmique) et en ordonnées la quantite d'anticorps fixés à l'antigène immobilisé, varient d'un anticorps à l'autre (Fig. 20).

Dans la réaction d'inhibition de la fixation de l'anticorps sur l'antigène immobilisé, la dilution d'anticorps à utiliser est celle pour laquelle la fixation d'immunoglobuline sur l"antigène immobilisé est comprise entre 60 et $80 \%$ de la fixation maximale. En effet, pour que la réaction d'inhibition soit sensible, il ne faut pas se trouver en excès d'anticorps.

B. REACTIVITE DU FIBRINOGENE, DES COMPLEXES DE DEGRADATION DE LA FIBRINE ET DES PRODUITS DE DEGRADATION DU F匹BRINOGENE EN SOLUTION, VIS-A-VIS DES ANTICORPS MONOCLONALX

La réaction de compétition entre antigène en solution et antigène immobilisé pour se combiner à l"anticorps est pratiquée.

En portant en abscisses la quantité d'antigène en solution (échelle logarithmique) incubé avec l'anticorps et en ordonnées la D.0. (échelle arithmétique) correspondant à la quantité d'anticorps fixê sur l'antigène immobilisé, il peut être déterminé : 
Fig. 20: Courbe d'étallonnage de différents anticorps sur du fúbrinogêne immobillìsé.

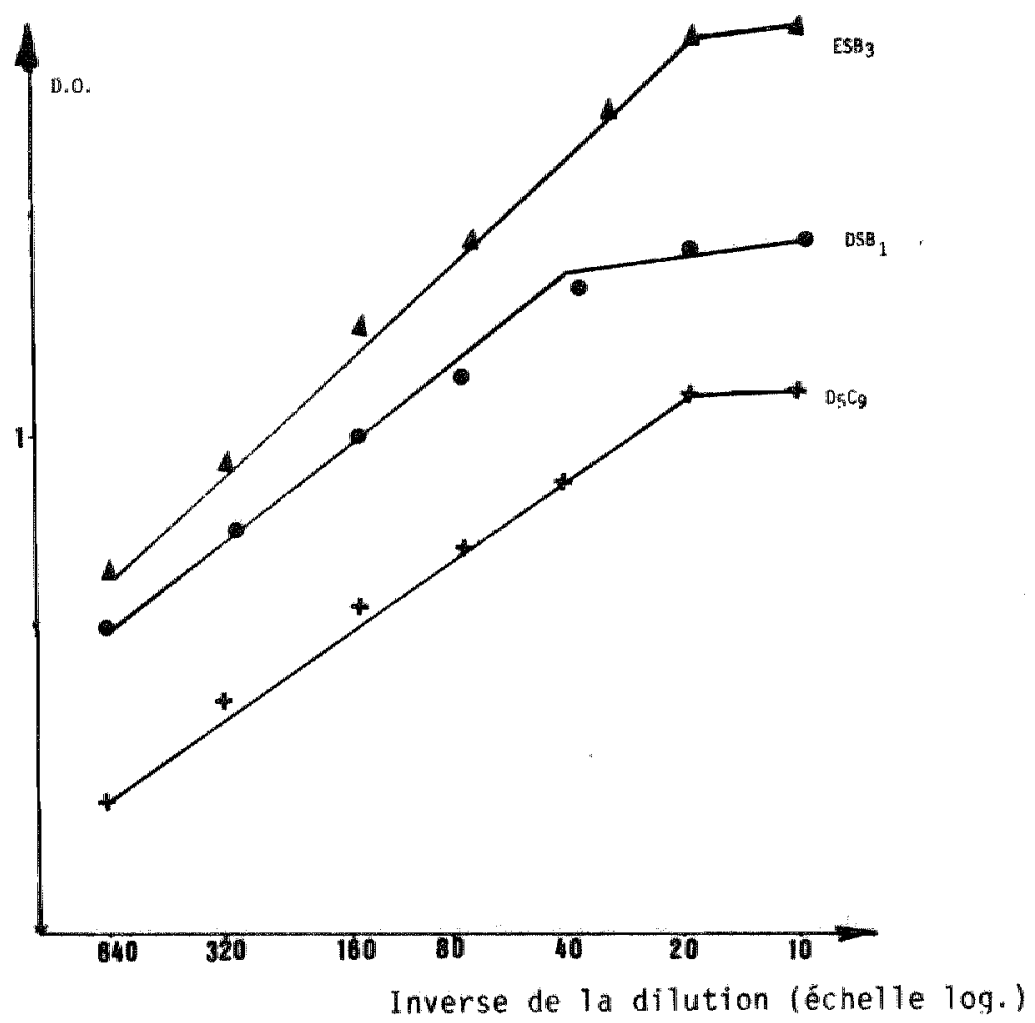


1) La dose minimale d'antigène en solution qui entraine l'inhibition totale de la fixation de l"anticorps à l"antigène immobil isê.

2) Les doses d'antigène pour lesquelles il y a une relation lineaire inverse entre la quantite d'antigène en solution incube avec l'anticorps et la quantité d'anticorps qui se fixe sur l'antigène immobi li sé sur la plaque de polystyrène.

La pente de cette droite est variable selon les anticorps. On evalue ainsi la quantité d'antigène qui induit 50 \% d'inhibition de la fixation de l'anticorps sur l'antigène immobilisé sur la plaque de polystyrène.

3) La réactivité de l'anticorps vis-à-vis du fibrinogene en solution en comparaison avec celle observée vis-à-vis des pdFb en solution et du fragment $D$ dans le cas des anti D ou du fragment $E$ dans le cas des anti $E$.

\section{1) Etude des anti-D}

a) Etude des anticorps réagissant avec le fibrinogène et avec le fragment $\mathrm{D}=$ ant $1-\mathrm{D}$ complets .

Neuf surnageants de culture ayant la speccificité d'un ariti-D complet ont ete analyses.

- Anticorps rëagissant aussi bien avec le fibrinogêne immobilisé qu'avec le fibrinogene en solution.

Sept surnageants de culture utilisés aux dilutions préalablement déterminées, lorsqu'ils sont incubés en phase liquide avec des concentrations progressivement décroissantes d'antigène, se fixent d'autant moins sur l'antigène immobilisé, qu'il y a plus d'antigère en solution. 
Fig. 21: Inhibition de la fixation du DSB sur du fibrinogẻne immobilísé induite par incubation prếalable du 05B par du fibrinogène (- - du fragment $\mathrm{D}(\mathrm{O}-\mathrm{O})$ et des $\mathrm{PDFb}(+-+)$ en solution.

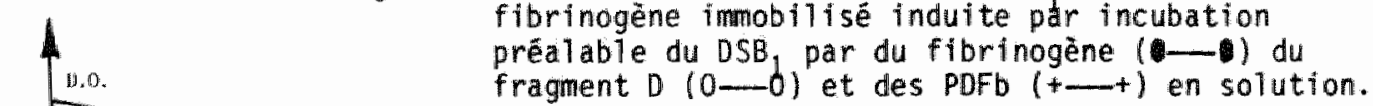

Q.15 0.3 Q.6 2.5 10 2 存 50

Quantitë d'antigène en solution $(\mu \mathrm{g} / \mathrm{m} 1)$ Echelle logari thmique. 
Les résultats abjectives dans la figure 2 imontrent le type de courbe d'inhibition obtenue selon les antigènes solubles utilisés (fibrinogène, fragment $D, P Q F b$ ).

Des différences peuvent être objectivées dans la capacité du fibrinogène, du fragment $D$ ou des PDFb pour inhiber la fixation d'un même anticorps monoclonal sur du fibrinogène immobilisé, comme le montre le tableau II.

Ce tableau résume les propriétés des différents anticorps vis-â-vis des differents antigènes en solution.

- Anticorps réagissant différemment avec le fibrinogene en solution et le fibrinogène fixé sur le polystyrène.

Deux surnageants de culture de cellules se comportent tout à fait diffêremment des surnageants du groupe précédent. En effet, lorsqu"ils sont incubés à la dilution préalablement déterminée avec du fragment $D$ ou des PDFb en solution, comme pour les anticorps précédents, il est abservé une diminution de la quantité d'anticorps fixẻ sur ل"antigene immobilisê (fibrinogène ou fragment 0) d"autant plus importante que la concentration en fragment D ou en PDFb en solution est plus importante.

En revanche lorsque ces deux anticorps utilises toujours à la même dilution sont incubés avec une solution de fibrinogène (quellle qu'en soit la dose) il. n'a pas été abservé d'inhibition de fixation d'anticorps, que ce soit sur le fragment o ou sur le fibrinogene immobilise (fig. 22). Le tableau III résume les caracteristiques de ces deux anti-D reconnaissant le fibrinogene immobilise et non le fibrinagène en solution. 
Fig. 22: Inhibition de la fixation du DSB, sur du fibrinogëne immobilisé induite par incubation préalable du $D B_{3}$ par du fibrinogène (-0),
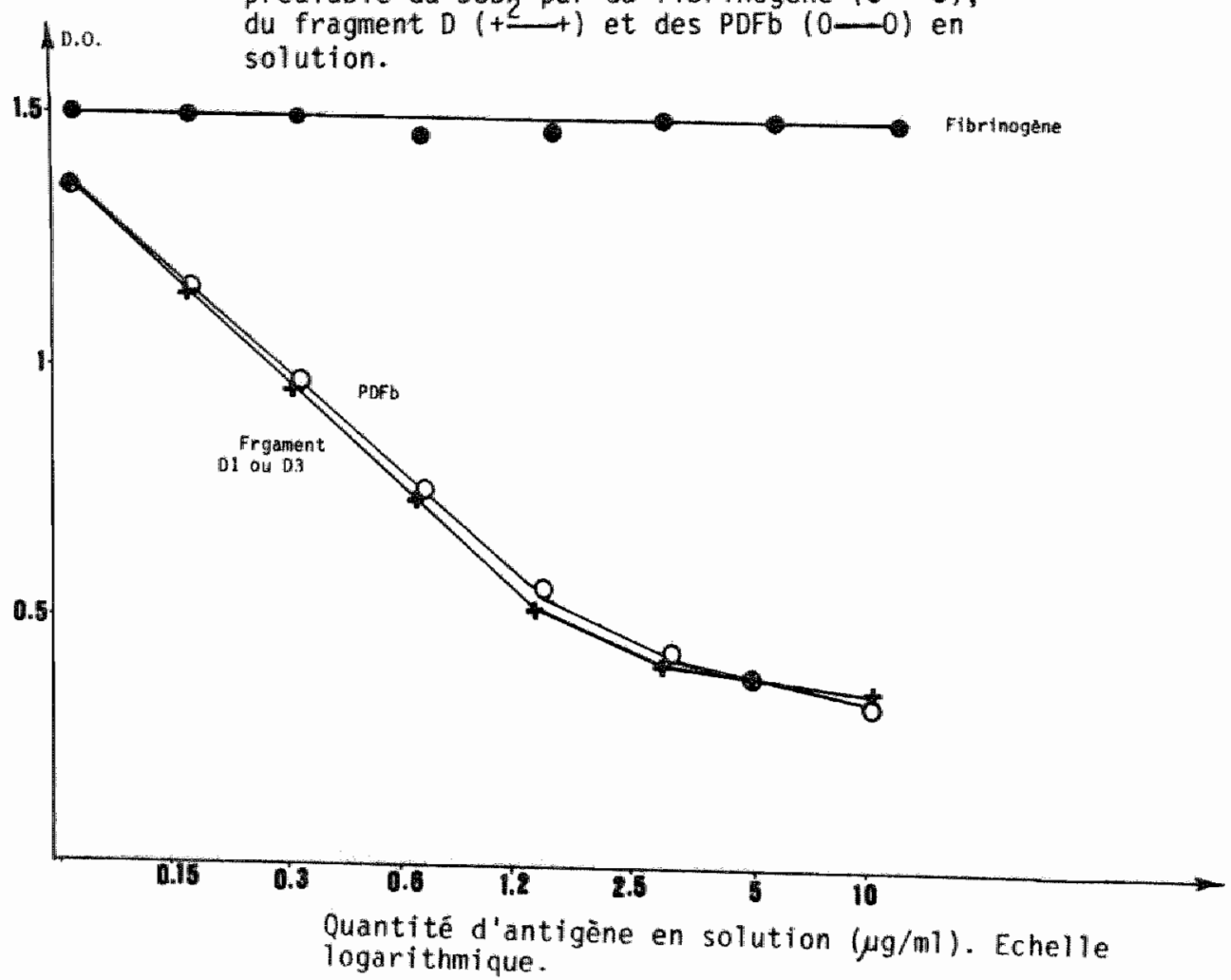


\begin{tabular}{|c|c|c|c|c|c|c|c|c|c|}
\hline \multicolumn{10}{|c|}{$\begin{array}{l}\text { Quantité d'antigène en solution nécessaire }(\mu \mathrm{g} / \mathrm{m} \mathrm{l}) \text { pour } \\
\text { induire une inhibition de la fixation de l'anticorps } \\
\text { monoclonal sur du } \mathrm{Fg} \text { immobilisé. }\end{array}$} \\
\hline & \multicolumn{3}{|c|}{ Fübrinogène } & \multicolumn{3}{|c|}{ Fragment $D$} & \multicolumn{3}{|c|}{ PDFb } \\
\hline & $\begin{array}{l}100 \\
d^{\prime}\end{array}$ & d'inhibition & $0 \%$ & \multicolumn{3}{|c|}{ d'inhibition } & $\begin{array}{r}100 \% \\
0 "\end{array}$ & $\begin{array}{c}50 \\
\text { nhibi }\end{array}$ & $\begin{array}{l}0 \% \\
\text { on }\end{array}$ \\
\hline DSB 1 & 100 & 4 & 0,3 & 6 & 0,45 & 0,10 & 3 & 0,8 & 0,1 \\
\hline DSB3 & 5 & 1,2 & 0,1 & 6 & 1,4 & 0,45 & 6 & 1,7 & 0,4 \\
\hline DSB4 & $>100$ & - & - & $>50$ & - & - & $>50$ & - & - \\
\hline D5C9 & 25 & 1,5 & 0,18 & 25 & 2,0 & 0,36 & 6 & 1,0 & 0,36 \\
\hline D4A 10 & 10 & 1,0 & 0,1 & 12 & 1,2 & 0,18 & 12 & 1,2 & 0,36 \\
\hline$B 4$ & 12 & 1,5 & 0,36 & 25 & 6,0 & 0,36 & 25 & 6,0 & 0,36 \\
\hline D5C9 & 6 & 1,0 & 0,36 & 6 & 1,0 & 0,36 & 1,5 & 0,4 & 0,36 \\
\hline
\end{tabular}

Tableau II. Caractéristiques des principaux anti-D complets sélectionnés. 
Tableau III : Caractêristiques des deux anti-D reconnaissant le flbrinogène imnobil isê et non le fibrinogène en solution.

\begin{tabular}{|c|c|c|c|c|c|c|c|}
\hline \multicolumn{8}{|c|}{$\begin{array}{l}\text { Quantité d'antigène en solution nécessaire ( } \mu \mathrm{g} / \mathrm{ml} \text { ) pour } \\
\text { induire une inhibition de la fixation d'anticorps } \\
\text { monoclonal sur du fibrinogène immobilisé. }\end{array}$} \\
\hline & Fibrinogene & \multicolumn{3}{|c|}{ Fragment 01} & \multicolumn{3}{|c|}{ PDFb } \\
\hline & $\begin{array}{l}100 \% 50 \% \quad 0 \% \\
\text { d'inhibition }\end{array}$ & $100 \%$ & $\begin{array}{l}50 \% \\
\text { hibitio }\end{array}$ & $0 \%$ & $\begin{array}{r}100 \% \\
d^{\prime \prime}\end{array}$ & $\begin{array}{r}50 \% \\
\text { nhibit }\end{array}$ & $0 \%$ \\
\hline DSB2 & $-\quad>50$ & 2,5 & 0,300 & 0,038 & 2,5 & 0,300 & 0,04 \\
\hline $\mathrm{D} 5 \mathrm{H} 4$ & $-\quad->100$ & 25 & 10 & 1,5 & 25 & 3 & 0,4 \\
\hline
\end{tabular}

Ces anticorps ont donc la particularité de reconnatre le fibrinogène quand il est fixé sur un support solide et de ne pas réagir avec le fibrininogène en solution.

b) Etude des anticorps anti-D néo

Quatre surnageants de culture dont la particularitê lors de la sélection des lignées était de se fixer sur les PDFb stabilisés ou le fragment $D$ immobilisé, mais non sur le fibrinogène, ont été également analysés. Lorsque ces 4 surnageants dilués à la dilution préalablement déterminée, sont incubés avec des concentrations progressivement décroissantes d'antigène (fibrinogène, fragment $D$ ou PDFb) il est observé que :

- la diminution de la fixation d'anticorps sur le fragment D 
immobilise est d"autant plus importante que l'anticorps est incube avec des quantités plus grandes de fragment $D$ ou de PDFb en phase Ilquide.

- aucune diminution de fixation d'anticorps sur le fragment D immobilise n'apparait en revanche lorsque l'anticorps est incube avec des doses même importantes de fibrinogène en solution. Le tableau IV résume les propriétés de ces anti-D néo anticorps.

Tableau IV : Caractéristiques de ces anti-D néo anticorps

Quantité $d^{*}$ antigène en solution nécessaire ( $\left.\mu \mathrm{g} / \mathrm{ml}\right)$ pour induire une inhibition de la fixation d'anticorps monoclonal sur du fragment D immobilise.

\begin{tabular}{|c|c|c|c|c|c|c|}
\hline & \multicolumn{3}{|c|}{ Fragment D } & \multicolumn{3}{|c|}{ PDFb } \\
\hline & $100 \%$ & $\begin{array}{l}50 \% \\
\text { hibiti }\end{array}$ & $0 \%$ & $100 \%$ & $\begin{array}{r}50 \% \\
\text { mhibiti }\end{array}$ & $0 \%$ \\
\hline DSB 14 & 50 & 6 & 0,19 & 6 & 0,70 & 0,090 \\
\hline DSB 11 & 10 & 10 & 0,018 & 10 & 10 & 0,019 \\
\hline DSB 13 & 1,2 & 0,10 & 0,018 & 1,2 & 0,300 & 0,018 \\
\hline
\end{tabular}

L'anticorps DSB14 est particulièrement intéressant, car comme il apparait dans ce tableau IV et dans la figure 23. Cet anticorps est beaucoup plus déplacé par les PDFb que par le fragment $D$ isole.

c) Etude comparée de la réactivitê des anti-D vis-à-vis du fragment D1 et du fragment 03 . 
F19. 23: Inhibition de la fixation du DSB 14 sur du fragment D immobilisé induite par incubatión probable du

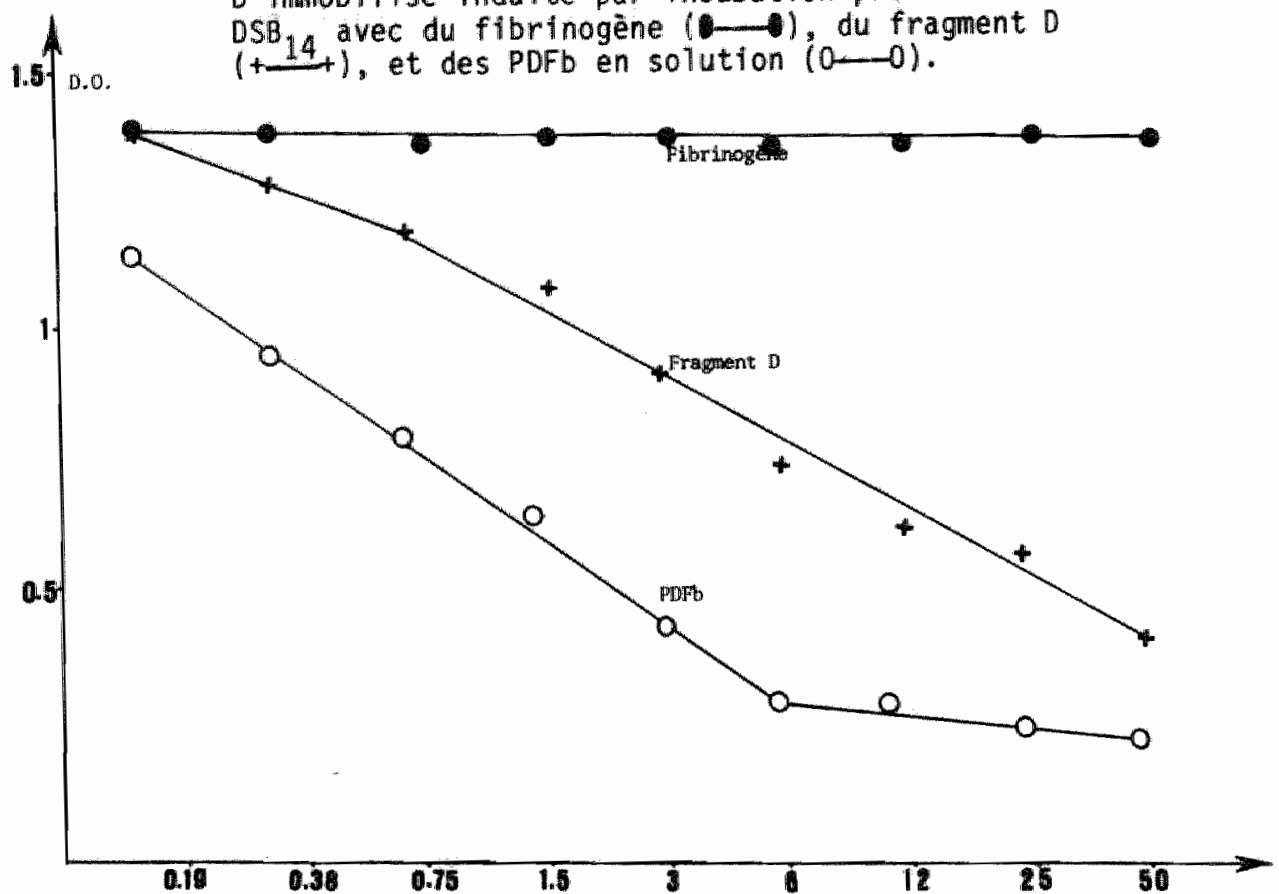

Quantitë d"antigène en solution $(\mu g / m))$. Echelle logarithmique. 
Parmi les anticorps anti-D complets, 2 se sont rêvêlés particulièrement intéressants, car il a pu être montré par des épreuves de compétition que ces deux anticorps réagissaient avec le fragment D1 immobilisế ou en solution, mais pas avec le fragment D3. II $5^{\prime a g i t}$ de $l^{\prime a n t i c o r p s}$ B.4 et D4A10 qui réagissent bien avec le fragment D1 en solution, puisque le fragment D1 incube avec l'anticorps est capable d'inhiber la fixation de cet anticorps sur du fibrinogène immobilisé (Tableau II). En revanche le fragment 03 , à la: concentration de 100 gamma/ml n'est pas capable d'inhiber la fixation de ces anticorps sur le fibrinogène fixé sur le polystyrène.

\section{2) Etude des anti-E}

Parmi les 15 sumageants de culture ayant la specificite anti-E qui ont été sélectionnés et clonés, 5 d'entre eux ont êté analysés en detail.

Les anticorps monoclonaux anti-E obtenus, ont ete dénommes anti-E complets, car ils réagissent avec le fibrinogène et le fragment E. Les resultats sont objectivés dans la figure 24 et dans le tableau V. Ils montrent les relations existant entre le degré d'inhibition de la fixation de l"anticorps monoclonal sur ou fragment E immobilise et la quantité de fibrinagène, fragmert $E$ ou PDFb en phase liquide incubes avec l'anticorps. 
Tableau $V$ : Caractéristique des principaux anti-E obtenus.

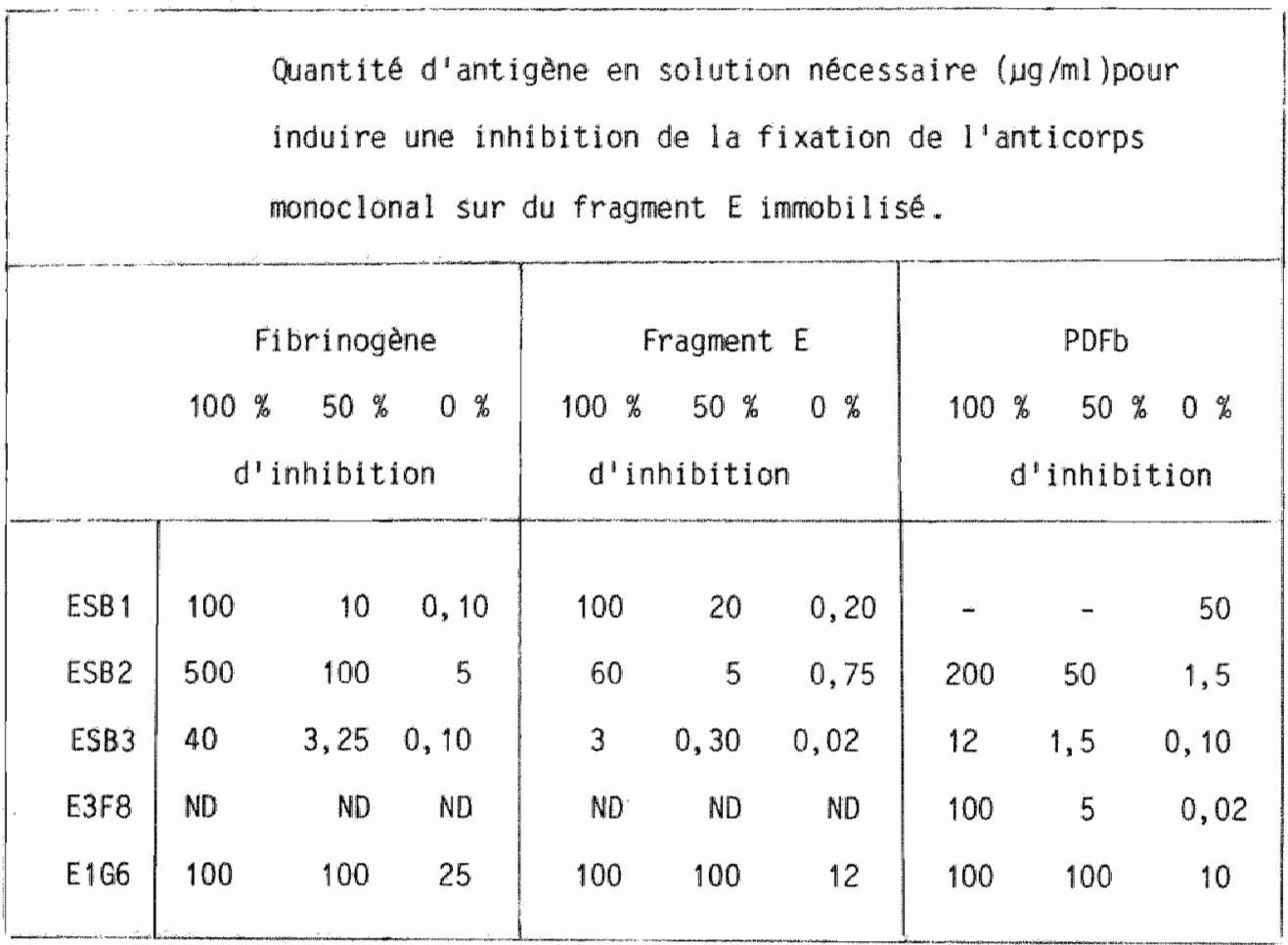

L'anticorps ESBI a la particularité de ne pas réagir avec le PDFb, alors qüil réagit avec le fibrinogène et le fragment $E$.

\section{REACTIVITE DES DIFFERENTS ANTICORPS VIS-A-VIS DES CHAINES DISSOCIEES DU FIBRINOGENE}

La réactivite de certains anticorps sélectionnes a été etudiee vis-ä-vis de la chaine A alpha, de la chaine $B$ beta et de la chaine gamma préalablement fixées sur le polystyrêne. Pour la majorité des anticorps, aucune réactivité vis-a-vis des chalnes dissociées n'a été mise en evidence puisque ces anticorps étaient incapables de se fixer 
Fig. 24: Inhibition de la fixation du ESB3 sur du fragment $\mathbb{E}$ immobilisé induite par incubation prëalable de ESB3 avec du fibrinogène (C- $)$, du fragment $E(+-+)$

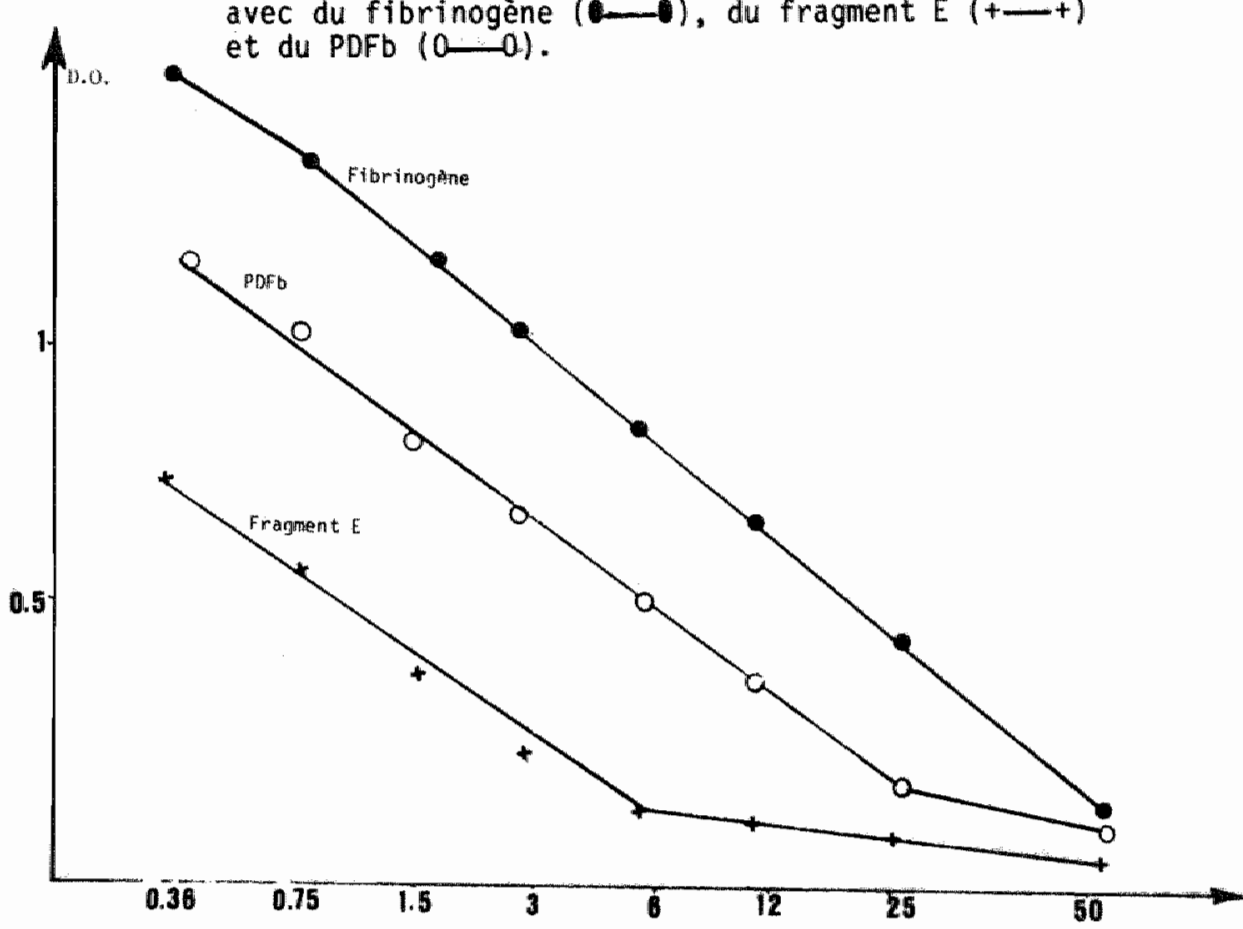

Quantitể d'antigène en solution $(\mu \mathrm{g} / \mathrm{m} 1)$. Echelle logari thmi que. 
sur les chaines immobilisees sur le support solide. Toutefois, il a été trouvế que l'anticorps DSB 1 (anti-D complet) réagissait avec la chaine garma isolêe et que l'anticorps DSB 12 (anti-D néo anticorps) reagissait avec la chaine $B$ beta.

\section{REACTIVITE DES DIFFERENTS ANTICORPS VIS-A-VIS DES AUTRES PROTEINES PLASMATIQUES}

$L^{\prime}$ incubation 18 heures à $4^{\circ} \mathrm{C}$ des anticorps sélectionnés avec un volume égal de plasma de malade atteint d"afibrinogénémie (1a dilution finale d'anticorps étant celle choisie pour les épreuves de déplacement), n'entraine pas d'inhibition de la fixation des anticorps sur le fragment $D$ ou le fragment $E$ immobilise. Cette constation nous permet d'affirmer que ces anticorps ne réagissent pas avec des protéines plasmatiques, autres que le fibrinagène.

\section{DETERMINATION DE LA CLASSE D'Ig DES ANTICORPS SELECTIONNES}

Curleusement, tous les anticorps sélectionnes appartiennent a la classe $d^{\prime} I g G 1$, puisque ces anticorps fixés à l'antigène immobilisé sont uniquement capables de fixer l'anti-IgGl de souris preparé chez la chèvre, rêvélé ultêrieurement par Ig des anti-Ig de chèvre marquées à la peroxydase. En revanche, dans les mêmes conditians, ces anticorps ne fixent ni les anti-IgG2a, ni les anti-lgGab, ni les anti-IgM. Par contre, il peuvent se combiner l'anti-Ig 75 de souris. 
CHAPITRE IV

DISCUSSION DES RESULTATS OBTENUS SUR LES

ANTICORPS MONOCLONAUX SELEGTIONNES 
Les hybridations que nous avons effectuées ont conduit à l'obtention de différents anticorps monoclonaux dirigés contre differents épltopes de dérivés de la fibrine. Les hybrides sêllectionnés puis clonés que nous avons retenus semblent avoir des propriétés différentes quant à leur réactivité vis-à-vis des differentes proteines susceptibles de réagir avec eux, comme le montre le tableau récapitulatíf et compte tenu de lleur affinité vis-à-vis des differents antigènes (Tableau VI).

En particulier, des anticorps dirigés contre des épitopes accessibles dans la molécule dégradée mais masqués dans la molécule intacte de fibrinogène ont été sélectionnés. Il s'agit des D néo anticorps et des $E$ néo anticorps. Le fait que nos anticorps ne réagissent pas avec d'autres protéines plasmatiques (comme il a été montré par l'absence de consormation des différents anticorps lors de leur incubation avec le plasma d'afibrinogénémie) nous autorise à utiliser ces différents anticarps pour doser les antigènes dêrivés du fibrinogène ou de la fibrine dans des plasmas.

\section{ANTICORPS REAGISSANT SUR LE FIBRINOGENE ET LE FRAGMENT D OU LE FRAGMENT E}

Lorsque I"anticorps réagit sur un épitope à la fois accessible sur le fibrinogène et sur un de ses produits de dégradlation (anti-D ou anti-E) la réactivité de l'anticorps vis-ă-vis du fibrinogène peut être différente de celle observée vis-ă-vis du fragment de degradation. 


\section{HYBRIDONES}

1 ere inwestigation

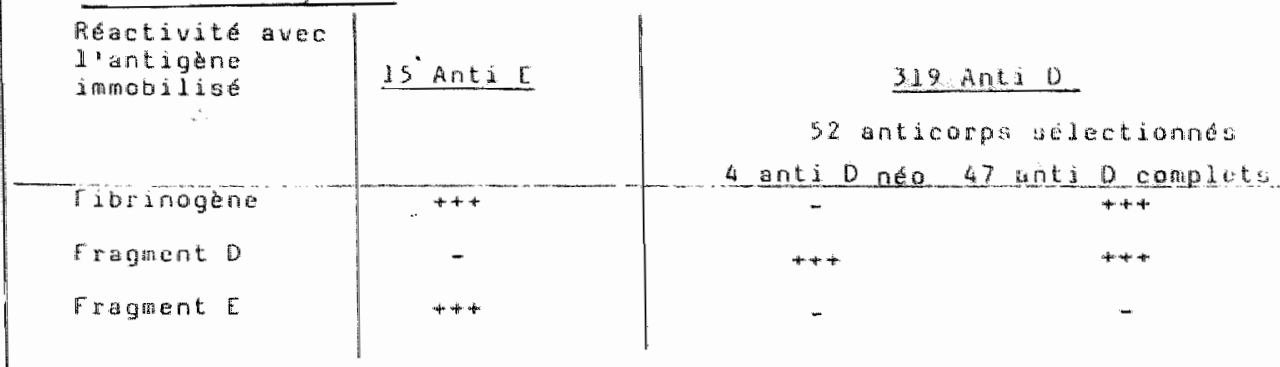

2 êtue investigation

5 clonages

4 clonages

9 chonges

Inhibition de $1 \mathrm{a}$

fixation de 1 *

anticomps sur 1 "

untigenc inmobilist

par des sollutions

de:
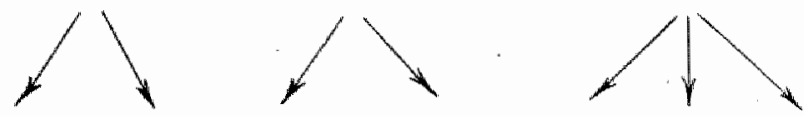

Fibrinogene

Anti th Antid Antio

Anti D Anti D Anti O, Anti D

ratargent $E$

PDF

Fragratent $D_{d}$

Fraghent $\mathrm{O}_{3}$

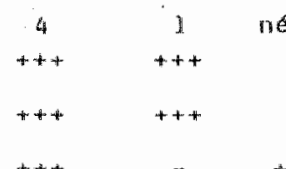

neo 3

nécol lotals

$\operatorname{anc} 2$
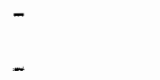

* Cunf : de conformation

Tableau WI : Classification des hybridomes obtemus hecapitulation des resultata. 
Cependant, pour interprêter les differences de réactivité de j'anticorps pour le fibrinogene d'une part, et pour le fragment de dégradation d'autre part, il faut tenir compte des poids moléculaires respectifs du fibrinogene. du fragment 0 et du fragment $E$ (respectivement $340.000,105.000$ et 55.000 ) et du fait qu'une molécule de fibrinogene renferme deux fragment $D$ et un seul fragment $E$.

Ainsi. il est établï que 100 gammasde fibrinogène correspondent approximativement à 60 gammas "équivalent 01 et seulement aे 15 gammas d'équivalent $E$. Une correspondance entre fragments de dégradation du fibrinogène et complexes de dégradation de la fibrine, est beaucoup plus difficile à établir compte tenu de la grande variété existant dans les complexes de degradation de la fibrine. Quand elle est calculee, elle est effectuee sur la base d'un complexe de dégradation $D-D-E$.

\section{A. ANTICORPS REAGISSANT AVEC LE FIBRINOGENE ET LE FRAGMENT D EN TENANT COMPTE DES CALCULS D'EQUIVALENCE}

L'anticorps DSB1 par exemple réaglt beaucoup plus avec le fragment $D$ ou les PDFb, qu"avec le fibrinogène : il faut 6 gammas/mI de fragment $D$ et de PDF pour induire une inhibition complete de Ia fixation de cet anticorps (a la dilution choisie) sur du fibrinogene immobillse, tandis qu'il faut 100 gammas/ml de fibrinogène, correspondant à 60 gammas/ml d'equivalent D pour obtenir la même inhibition, dans les meimes conditions.

De même, pour induire $50 \%$ d'inhibition de la fixation de 
1 'anticorps sur l'antigène immobilise. il faut incuber l'anticorps. soit avec $0,45 \mu g / m l$ de fragment $D$, soit avec $4 \mu g / m l$ de fibrinogène. correspondant $d 2,4$ fig /mi d"equivalent $D$.

La différence de réactivité peut être facilement expliquée par Ie fait que l'épitope réagissant avec cet anticorps doit être beaucoup plus expose dans les produits de degradation que dans la molécule native de fibrinogène.

Parmi les anticorps anti-D, deux anticorps sont particulierement intéressants car ils reagissent avec le fragment 01 (D cate) et non avec le fragment D3 (DEGTA). Il s'agit des anticorps B.4 et D4A10. Or il est connu que le fragment $\mathrm{D} 3$ est plus dégrade que le fragment D1, le fragment D1 possédant un peptide supplementaire a L'extrémité $C$ terminal de la chaine gamma, correspondant au peptide compris entre le résidu gamma 303 et le résidu gamma 411 , de la chaîne gamma du fibrinogène (86). De tels anticorps daivent donc réagir avec un épitope présent sur la portion de chaine gamma 303-g amma 411.

Toutefois, ces deux anticorps ne reagissent pas avec la chaine gamma, isolee du fibrinogene, soit que l'epltope soit masque dans cette chaine gamma solee du fait de sa conflguration tertialre, soit que la fixation de la chaîne gama au poslystyrene se fasse au niveau des épitopes specifiques de ces anticarps. Cette portion de chaine gama 303-411 a un role physiologique important dans la fonction du fibrinogène. En effet, c'est a ce niveau que sont localisês les sites de polymérisation aux monomères de fibrine, ainsí que le site permettant au fibrinogène de se ller aux plaquettes. 


\section{B. ANTICORPS REAGISSANT AVEC LE FIBRINOGENE ET LE FRAGMENT E}

Concernant les anti- $E$, des différences de réactivité de I'anticorps vis-ä-vis du fibrinogène, du fragment $E$ et des PDFb sont egalement observées avec certains anticorps et pas avec d'autres.

Ainsi, d'après les rếsultats exposés au tableau $V$, en calculant en équivalent E, 1 'anticorps ESB2 réagit approximativement de la même manière avec le fibrinogène qu'avec le fragment $E$, compte tenu que 500 gammas de fibrinogène correspondent à 75 gammas d'équivalent $E$. De même ESB3 réagit approximati vement de la même façon avec la molécule intacte et avec le fragment $E$.

Concernant la réactivité de ces deux anticorps vis-ä-vis des produits de dégradation de la fibrine, le calcul a été effectué en équivalent É par sous unité D-D-E. Là encore, ces deux anticorps semblent avoir approximativement la même réactivité pour le fragment $E$ que pour les PDFb, puisque par exemple, pour 1'anticorps ESB2, 200 gammas de PDFb correspondant à 45 gammas d'équivalent $E$, sont nécessaires pour induire $100 \%$ d'inhibition de la fixation de l'anticorps sur l'antigène immobil isé.

Au contraire, quand on calcule en equivalent E, l'anticorps E1G6 réagit mieux avec le fibrinogène, un peu moins avec les PDFb et assez mal avec le fragment $E$. Cette maukaise réactivitế de E2G6 vis-ä-vis du fragment E est expliquée par le fait que la conformation tertiaire du fragment E est telle que l"épitope qui etait accessible sur le fibrinogène ou les produits de dégradation de la fibrine, I" est moins sur le fragment $E$ isolé et purifié. 
L'anticorps ESBI est particulierement interessant, car bien qu"il rêagisse avec le fibrinogène et à un moindre degré avec le fragment $E$, il présente la particularite de ne pas réagir avec les PDFb (qu'il s"agisse des PoFb précoces, ou des complexes D-D-E). L'épitope révéle par cet anticorps au niveau du fragment $E$ est donc vraisemblablement masqué par le dimère D-D present dans les produits de degradation de la fibrine. Un tel anticorps peut etre précieux pour differencier les produits de degradation du fibrinogene, des produits de degradation de la fibrine. Cet anticorps provient vraisemblablement de l'immunisation des souris par les traces de fragment $E$ libre qui contaminaient la préparation de PDFb ayant servi à $l^{\prime}$ immunisation.

II. ANTICORPS NE REAGISSANT PAS AVEC LE FIBRINOGENE IMTACT MAIS

\section{REAGISSANT AVEC LE FRAGMENT D}

Deux types d'anticorps ant eté selectionnes :

\section{A. ANTI-D NEO ANTICORPS}

11 a eté appelé anti-D nëo anticorps, des anticorps qui ne réagissaient pas avec le fibrinogène (en solution, ou immobilise) mais possedaient une réactivité vis-a-vis du fragment $D$ ffragment isole ou inclus dans les complexes de degradation de la fibrine). Lepitope révele par ces anticorps est donc masque dans la molecule de flibrinagène non dégradé. 
Les D-néo antigênes apparaissant après clivage de la molécule ont ete localises par Plow et Edgington (160) dans la portion centrale de la châne gamma (gammid 95-gamma 264). Cinq épitopes différents ont pu etre identifies par fair (50). Tous ces êpitopes, bien que présents dans la molécule de flbrinogêne, sont peu accessibles a l'anticorps dans le fibrinogene intact. Ils correspondent aux fragments gamma 95-108, gamma 109-194, gamma 198-247, gamma $248-256$ et gamma $257-264$.

Il est difficille à I'heure actuelle de savoir si les D-néo antigeñes (gamma 160-197) décrits par Plow et a1. 166, correspondent à un des cinq epitopes de Falr.

Parmi les D-néo anticorps sélectionnés ici, aucun ne réagissait avec la chaine gamma isolée et intacte, par contre l'un d'entre eux, le DSB12 se fixalt sur la chaine $B$ beta immobilisee permettant ainsi d"affirmer pour la première fois qu'un D-néo antigène était localisé au niveau de la chaine beta. L'utilisation d'un tel anticorps est précieuse pour l'étude de la structure conformationelle du fibrinogene.

Le manque de réactivité des autres D-nêo anticorps vis-â-vis des chaines dissociees du fibrinogène et en particulier vism-vis de 1a chaine gamma, particulierement riche en néo-antigènes, peut être explique

- soit par la structure tertiaire de la chaine isolée entrainant un masquage de l"épitope normalement accessible sur le fragment $D$.

- solt par le fait que l'épitope présent au niveau de la chaine, solt enfoul dans le palystyrène lars de la fixation de la chaîne sur La plaque, la rendant de ce fait inaccessible a l'anticorps. 
L'un de ces anti-D néo, DSB14, possède la propriété de réagir beaucoup plus avec les PDFb qu'avec le fragment D. En évaluant la quantitéde PDFb en équivalent D (calcul effectue par sous unité D-D-E) dix fois plus de fragment $D$ en solution sont nécessaires pour inhiber complètement la fixation de 1 "anticorps å du fragment D immobilisé que de complexe D-D-E. Cet anticorps possède les même types de réactivité que l'hétéro-antisérum de Budzinski et al. (26). L'utilisation simultanée de cet anticorps DSB14 et d"un autre D-néo anticorps ayant la même réactivité pour le fragment $D$ et pour les PDFb, permet de differencier dans un échantillon les produits de degradation du fibrinogène de ceux de la fibrine.

Par exemple, compte tenu des résultats exposés au tableau IV, si dans un échantillon donné $A$,

- la dilution nécessaire de cet échantillon A pour obtenir $100 \%$ d'inhibition de la fixation du DSB14 sur du fragment D immobilisé est de $1 / 10$, ceci veut dire que l'échantillon renferme $10 \times 25 \mu \mathrm{g} / \mathrm{ml}$ de fragment $D$ ou $10 \times 3 \mu \mathrm{g} / \mathrm{ml}$ de PDFb ;

- la dilution nécessaire de cet echantillon pour obtenir $100 \%$ d'inhibition de la fixation d'un autre anti-D neo anticorps le DSB13 sur le fragment $D$ immobilise est de $1 / 25$, cela correspond $1,2 \times 25$ $\mu \mathrm{g} / \mathrm{ml}$ de fragment $\mathrm{D}$ ou de PoFb, la sensibilite de cet anticorps était en effet, la même pour le fragnent 0 que pour les PDFb;

- la confrontation des résultats obtenus avec ces deux anticorps permet de conclure que dans ce cas, l'echantillon A renferme principalement des PDFD.

Si dans un deuxieme echantillon B:

- la dilution nécessaire de cet echantillon $B$ pour induire $100 \%$ 
d'Inhibition de la fixation de DSB14 sur du fragment $D$ immobilise est toujours de $1 / 10$

- mais que la dilution nécessaire de l'echantillon pour induire 100 \% dinhibition de la fixation de DSB13 sur du fragment 0 immobilise soit de $1 / 250$, cela veut dire que l'échantillon renferme $1,2 \times 250=300 \mu \mathrm{g} / \mathrm{ml}$ de PDFb ou de fragment $D$

- la confrontation des resultats obtenus avec ces deux anticorps permet alor's de conclure que l'échantillon $B$ remferme principalement du fragment D.

Cette technique d'investigation utilisant les deux anticorps doit être réservếe à des cas trếs prêcis. En effet, en pratique courante, le fibrinogene n'est pas dégradé par la plasmine dans la circulation, car d'une part, l'activation du plasminogêne en plasmine par l'activateur tissulaire (tpA) nécessite de la fibrine et d'autre part, la plasmine susceptible d"être formée est neutralisée instantanément par l'alphaz antiplasmine présente en grande quantité dans le sang circulant. En revanche, lorsqu'il y a des thrombi, l"activation du plasminagène en plasmine par le tpA est potentialisé par la fibrine et de plus, la fibrine fixant tres peu dantiplasmine est facilement degradee par la plasmine ainsi formé. Ceci explique qu'en pathologie les produits de degradation du fibrinogene ne sont retrouves qu'exceptionnellement et qu'en revanche les prodults de degradation de la fibrine stabilisee constituent souvent un des criteres essentiel de diagnostic de crvo. 


\section{B. ANTICORPS ANTI-D REAGISSANT AVEC LE FIBRINOGENE IMMOBILISE SUR UN SUPPORT ET NE REAGISSANT PAS AVEC LE FIBRINOGENE EN SOLUTION}

Les anticorps DSB2 et D5H4 possèdent la propriété de se fixer aux plaques de fibrinogène immobilisé. En revanche, le fibrinogène en solution, même à des concentrations importantes (supérieur à 50 gamma/ml) est incapable d"induire une inhibition de la fixation de ces deux anticorps sur du fibrinogère ou du fragment D immobilisé. Ces anticorps révèlent donc un épitope accessible sur le fragment $D$ (immobilisé ou en solution), et sur le fibrinogène immobilisé, mais non accessible sur le fibrinogène en solution. Ces deux anticorps permettent donc de detecter un changement conformationnel du fibrinogène lors de san adsorption sur une surface, puisque le fibrinogène immobilisé contrairement au flbrinogène en solution est capable de fixer ces deux anticorps.

De tels anticorps peuvent avair une importance pratique considérable pour l'étude des bio-matériaux utilisés pour les greffes ou les circulations extra-corporelles.

En effet, l'adsorption des proteines du sang sur les bio-matériaux est la première étape d'une suite de réactions qui peuvent conduire, soit a la bio-compatibilite du materiau, soit au contraire a l'apparition de thromboses.

Le rôle de la composition des protéines fixées a la surface du bio-matériau d"une part et de leur conformation d'autre part dans I'interaction du matériau avec le sang circulant, reste toujours controversé. Le cas du fibrinogène a eté très étudié, puisqu'il est 
connu que le fibrinogéne s'adsorbe sélectivement sur des matériaux artificiels et que les plaquettes adherent secondairement au matériel recouvert de fibrinogene.

De nombreuses etudes biophysiques ont été faites concernant lies changements de conformation du fibrinogène induites par son adsorption d une surface, mais conduisent souvent a des résultats contradictoires. En general, les techniques utilisees pour etudier les changements conformationnels des proteines induites par leur absorption à urie surface, requierent un équipement spécial lourd et utilisent en genéral des proprietes optiques telles que les mesures d'adsorption de certains rayonnements infra-rouges sur des surfaces de silice, des spectres infra-rouges, des spectres Raman ou du dichroisme circulaire sur des disques en quartz. Cette dernière technique peut être utilisee pour étudier les changements conformationnels du fibrinogène adsorbé puis elué et peut donc être utilisêe quel que soit le matériau. Cependant, les resultats de cette technique après elution peuvent être différents de ceux obtenus par la technique directe (sans ellution) utillisant des disques de quartz.

D"autres methodes utilisent des techniques telle que la mi crocalorimetrie.

L"avantage de la methode proposée avec les anticorps monoclonaux est d'etre aisement réalisable. De plus elle peut être pratiquee quel que soit le materiel a tester et est independante de la surface et des proprietes optiques du bio-matêriel.

Enfin, les rexsultats mettent directemment en evidence le changement conformationnel du fibrimogène.

La technique proposee ici a en outre l'avantage de pouvoir etre appliquée a d"autres proténes. 


\section{COMPARAISON DES ANTICORPS MONOCLONAUX OB TENUS AVEC LES}

\section{AUTRES ANTICORPS DECRITS DANS LA LITTERATURE}

Compte tenu de la compléxité de la molécule de fibrinogène, de nombreux chercheurs ont préparé des anticorps destinés, d'une part à établir la cartographie de la molécule de fibrinogène, d'autre part à identifier et quantifier les produits issus de la dégradation par la plasmine du fibrinogène ou de la fibrine, ou résultant de l'attaque du fibrinogène par la thrombine.

Durant ces dix dernières annees des études immunologiques ont été développées dans ce but. Certaines ont été réalisées a l'aide d"antisérums préparés par les méthodes conventionnelles d'immunisation, puis adsorbés secondairement sur des produits dérivés de l'agent immunogène utilisé, afin de rendre l'antisêrum spécifique d'un domaine particulier de la molécule. C'est ainsi que Plow et Edgington (155, 158) ont préparé des ariticorps contre des néo-antigènes apparaissant lors de la dégradation du fibrinogène, en immunisant des animaux avec le fragment $D$ ou le fragment $E$, puis en adsorbant les antisérums obtenus sur du fibrinogène. Cependant, les anticorps ainsi obtenus ont un titre très faible.

D'autres travaux ant été réalisés a l'aide d'antisérums préparés par immunisation d'animaux avec des petits fragments de dégradation du fibrinogène, préalablement isolés ou synthétisés, afin d'abtenir des anticorps spécifiques d'un domaine donné de la molécule. 
Ainsi, des dosages radio-immunologiques du FpA et du FpB ont ete réalises par Nossel et all. (10, 141) pour l'investigation biologique des états d'hypercoagulabilité. Le dosage du FpA est devenu maintenant un examen d'investigation biologique courante et uni dosage immuno-enzymologique a ete mis au point.

Puls ont éte realises, le dosage du peptide $B$ beta $1-42$ et du peptide $B$ beta 15-42, qui sont respectivement tênoins de la thrombolyse de la fibrine I et de la fibrine II $(108,145,146)$. En effet, comme 11 a étée wu dans le premier chapitre, l"attaque du fibrinogène par la thrombine se fait en deux étapes. La première étape est llée au dépant du fpA et conduit à la fibrine I, la deuxième étape étant Lee au dêpart du foB et aboutissant à la formation de la fibrine II, d'une structure plus compacte que la fibrine I.

L'antisérum préparé par immunisation avec le peptide $B$ beta 1-42. reagit en outre avec le fibrinogène, avec le fpB (B beta 1-14) et avec le peptide $B$ beta $15-42$.

L'antisérum preparé par immunisation avec le peptide B beta 15-42 réagit également avec le $B$ beta $1-42$ et avec le fibrinogène (108). Pour differencier f $p B$, peptide $B$ beta $1-42$ et $B$ beta 15-42, outre la determination de l'antigênicite de l'echantillon vis-à-vis des trols anticorps correspondants a ces trois peptides. Nossel a utilise la difference d'antigenicite entre le fpB libre et le fpB present au niveau du peptide $B$ beta $1-42$. La reactivité du fpB vis-a-vis de I'antisêrum anti fpB est en effet dix fois plus importante avec le fpB libre, qu'avec le fpB inclus dans le peptide $B$ beta 1-42. Il etudie donc 1 'augmentation de l'antigénicite du fpB liée a l'action de la thrombine (145). Toutefois, tous ces anticorps réagissant également avec le fibrinogène, il est nécessaire pour 
évaluer la concentration plasmatique dans ces differents fragments, d"éliminer au préalable le fibrinogene par la bentonite ou par traitement par l'alcool à $50 \%$.

Enfin, Gollwitzer et al. ont mis au point un dosage radio-immunologique du FCB3, fragment de degradation du fibrinogene par le bromure de cyanogène. En effet, ce peptide correspondant au peptide alpha $241-476$ est très voisin du peptide situé a la moltie $C$ terminal de la chaîne alpha, libếé très précocément lors de l'attaque du fibrinogène par la plasmine. Le dosage du FCB3 dams le sérum permet donc la détection de fragments très précoces de la fibrinolyse, car il est complementaire du fragment $x$ précoce, encore coagulable par la thrombine et de ce fait non retrouvé dans le sérum.

De plus, pour tous ces antisérums préparés par des méthodes conventionnelles, des différences d'immuno-réactivité peuvent être observêes d'une immunisation à l'autre, en particulier vis-à-vis du FpA et du $F p B(92,143)$ comme $\mathbb{1}$ a eté vu au chapitre $\mathbb{I}$.

Les études récentes basees sur la production d'anticorps monoclonaux permettent de caracteriser des fragments du fibrinogene ou de la fibrine ou de mettre en evidence des modifications conformationnelles de la nolecule, come le montre le tableau récapitulatif des anticorps monoclonaux publiés à notre connaissance jusqu'ầ ce jour (tableau VII). 
Tableau V11: Comparaison des anticorps monoclonaux obtenus avec les autres anticorps decrits dans la literature.

SOBEL et a1. (167):

A I. Fragments obtenus par digestion par le BrCN de la chaine de la flbrine et renfermant les peptides $241-476$ et $518-584$.

Type 11 Anticorps rểagissant avec des ëpltope présents sur les framents de chaine isolés.

2) Anticorps rểagissant avec des déterminants conformationnels de la chaine polymêrisée et ayant peu de reactivite vis a vis des peptides constitutionnels.

Mode ?

In. Dëtection de déterminants spëcifiques de la fibrine stabllitsëe. Dếtection prëcoce des thromboses?

WILNER et a 1. (189):

A I. Fibrinogène.

Type 2 anticorps rẹagíssant avec le fibrinogène et le fragment D1, mais ne réagissant ni avec le fragment D-D ni avec le fragment D3. Ils révèlent donc un êpltope localisé à 1 'extrêmitế $C$ terminal de la chaine, masque dans D-D.

Mode - R.I.A.

- Inhibition de la fixation d'anticorps.

In. Différenciation entre produits de dégradation de la fibrine et produits de dëgradation du fibrinogène.

KUDRIJK et a 1. (109):

A I. N-DSK; A $1-51$, B $1-118,1-78$.

Type 1 antlicorps réagissant avec le fibrinogène le NDSK, le B 1-118, et le des A-NDSK, mals ne rëagissant ni avec le des A-des $B$ monomère, ni avec le des $A$ des $B$ NDSK, ni avec le B 15-42. Il detecte donc un epltope localisë au voisinage de 1 a 1 ialson B Arg 14- G1y 15.

Mode - id à WILNER.

In. Investigation de la fibrino(gënollyse après sëparation des peptides par HPLC. Confontration des résultats obtenus avec ceux du fpA et du B 15-42. 
KWAN et a 1 (110):

A I. Heptapeptide synthétique analogue au peptide $N$ terminal de la chaine $B$ (après élimination du foB).

Type Anticarps rëagissant avec la fibrine, mais ne rếagisant pas avec le fibrinogène.

Mode Dëtection des anticorps fixës sur des monomères immobilisés.

In. Détection de dépots de fibrine (ex vivo). La dếtection du peptide B 1-42 n'a pas été effectuée.

RYLATT et a l. (161):

A I. D Dïmère

Type 2 types d'anticorps: 1) anti D complets, rëagissant avec le fübrinogène, le fragment $D$ et le $D-D$.

2) anti D-D, rểaissant avec le $D-D$ et les PDFb, mais ne réagüssant pas ou très peu avec le fragment $D$ ou le fibrinogène.

Mode Elisa.

In. Dëtection des POFo dans le plasma, par le test cap-tag test: fixation anti DD monoclonal sur un support captant 1 'antigène, qui sera révélé secondairement par un antí $D$ complèt monoclonal marqué à la peroxydase. Permet la détection des PDFb dans le plasma.

BOUCHEIX et a1(23); SORIA et a1(172); SORIA et al(173); MIRSHAHI et at (132):

A I. Complexes de dëgradation de la fibrine.

Type 1) anti D complets.

2) anti $D$ de conformation réagissant avec le flbrinogêne immobilisę mais non avec le fibrinogène en solution, rëagissant avec le fragment d en solution ou fmmobilisë. 3) Anti $E$ complets. L"un d'entre eux ne rểigit pas avec les PDFb.

4) Anti D néo 1 des antï D néo est plus rëactif avec les PDFb qu'avec 1 e fragment $D$.

Mode Immuno-enzymologie.

In. 1) Anti D conformationnels. Détection de modification de structure du fibrinogène lors de son immobllisation en vue de tester les biomatériaux.

2) Anti D nëo.-utilisés pour doser les pofb dans le plasma -utilisés pour la míse au point d'une technique quantitative d'évaluation de la polymérisation des monomères.

3) Anti D reconnaissant le fragment D1 et non le fragment 03.

A I = Agent Immunogène. Type= Type d"anticorps selectionné.

Mode $=$ Mode de détection. In $=$ Intểêt. 
CHAPITRE V

APPLICATIONS DES ANTICORPS MONOCLONAUX SELECTIONNES 
ETUDE ANALYTIQUE DE L"INTERACTION ENTRE LES DIFFERENTS MONOMERES PAR UTILISATION D"ANTI D-NEO ANTICORPS. APPLICATION A L'ETUDE DES TROUBLES DE L'AGREGATION DES MONOMERES.

Mise en éwidence d"une anomalle du site de polymérisation "a" de la chaine ganma dans une dyfibrinogénémie homozygote.

Jusqu'ả présent, I'agrégation des monomëres de fibrine etait étudiée par mesure cinétique de la variation de densité optique, traduisant l'opacification du milieu lors de la formation du callot de fibrine. Cette étude était effectuée à partir de monomères purifies de fibrine en solution dans l'acide acétique a $1 \%$, lesquels après dilution importante dans un tampon approprie (permettant aux forces attractives de se constituer) agregent ce qui est objectivế par une augmentation de DO à $350 \mathrm{~nm}$ (7). Toutefois, la technique proposée présente l'inconvênient de ne pas différencier entre anomalie quantitative d"agrégation des monomères avec diminution de formation de caillot et anomalie qualtative lié a la formation d'un caillot translucide de structure anormale.

Dans les dysfibrinogénemies acquises par exemple, un caillot est formé, mais 11 est translucide $(126,168,171)$. Dans ces cas, 1 'agrégation des monomères par mesure de la variation de Do a $350 \mathrm{~nm}$ ne se traduisant pas par une augmentation de la densité optique, il est difficile de faire la part entre anomalie qualitative d"agregation des monomeres et diminution d'agregation. 
Pour tenter de mieux analyser le stade d'agrégation des monomères, il a été utilisê la propriété du fragment D1 a s"associer aux monomères de fubrine par formation de liaisons entre les sites "A" et "B" démasqués dáns les monomères et leurs sites complémentaires respectivement "a" et "b" présents dans, le fragment 01 . En effet, ainsi à des doses bien déterminées, le fragment 01 qui posséde les sites $a$ et $b$ en se liant aux monomeres de fibrine au niveau des sites $A$ et $B$ empeche de ce fait l'interaction des monomères entre eux, du fait du bloquage des sites $A$ et des sites $B$ par les sites a et $b$ presents sur le fragment 01 , ce qui se traduit par une inhibition de I" agrégation des monomères.

Certains auteurs ont donc etudie l'allongement du temps de coagulation par la thrombine d'une solution de fibrinogène induit par I'addition de quantite croissante de fragment $D$. Toutefois, cette technique est relativement peu sensible.

\section{MISE AU POINT D' UNE TECHNIQUE D'ETUDE DE L'INTERACTION MONOMERES-FRAGMENT D1}

Nous avons réalisé au laboratoire une technique très sensible et très analytique de l'étude de l'interaction entre monomères de fibrine et fragment D1, grâce à l'utilisation des anticorps monoclonaux. In vivo, la fibrine formee étant souvent de la fibrine I résultant uniquement des interaction $A-a$, nous avons étudié 1 'interaction de des $A$ monomères de fibrine (où seuls les sites $A$ sont accessibles) avec le fragment 01 . Cette technique permet d'analyser le 
mode d'action de certains inhibiteurs de la fibrinoformation et de quantifier leur activité.

\section{A. PRINCIPE DE LA TECHNIQUE}

A une quantite fixe de des A-monomères de fibrine immobilises sur une plaque de polystyrène, sont ajoutées des quantités progressivement decroissantes de fragment $D_{1}$ (en présence et en l"absence de l'inhibiteur à étudier). Après élimination du fragment D1 en solution, donc non fixé aux monomères, la quantitế de fragment $D 1$ lié aux monomères est évaluée en ajoutant successivement à la plaque un anticorps anti-D néo (qui ne réagit pas avec les monomères), puis de l'immunoglobuline de chèvre anti-immunoglobuline de souris marquee à la péroxydase. La quantité de péroxydase liée à la plaque dépend donc de la quantité de fragment D1 lié aux des A-monomères de fibrine.

Des réactions contróles ont été effectuées en étudiant la fixation du fragment 01 sur du fibrinogène immobilisé dans les mêmes conditions.

\section{B. MATERIEL ET METHODES}

1) Obtention de fragment D1 (voir 2e chapitre)

2) Préparation des des A-monomères de fibrine, c'est à dire des monomères de fibrine dépourvus en fibrinopeptide $A$, mais possédant encore le fibrinopeptide $B$ : 
- A 1 m de solution de fibrinogene humain Kabi a $5 \mathrm{mg} / \mathrm{ml}$ de protéine coagulable, est ajouté $0,2 \mathrm{ml}$ de reptilase (FTH 50 , Stago)

- Apres 30 minutes d'incubation a $37^{\circ} \mathrm{C}$, le caillot est soigneusement lavé, essoré, puis dissous dans $1,5 \mathrm{ml}$ d'urée $4 \mathrm{M}, \mathrm{pH}$ 7,5 .

- La solution obtenue consiste en des monomères dépourvus de $F p A$, mais possedant encore le $F p B$.

- La teneur par monomeres de la solution est évaluée par mesure de la 00 a $282 \mathrm{~nm}$ en utilisant le coefficient d"extinction du fi brinogène.

3) Fixation de la solution de monomères sur la plaque de polystyrêne ELISA à 96 puits. Elle est réalisêe selon la technique exposée pour la fixation d'antigène insoluble à partir d'une solution de monomëres a $5 \mathrm{Jg} / \mathrm{ml}$.

Dans un expériance prêliminaire, afin de dêterminer la quantité de monomeres fixés, Ia solution surnageante a eté recuperée, avant le lavage des plaques et dilué au $1 / 50$, puis la teneur en monomeres evaluee par dans cette dilution ELISA à l"aide d'Ig anti-fibrinogène (dans ces conditions, les concentrations d'urêe ne gênent pas le dosage et la concentration en monomeres est trop faible pour que les monomères agregent). La solution surnageante diluee renfermant moins de $10 \mathrm{ng} / \mathrm{ml}$ de monomères, 11 est considere que la totallte des monomères est fixêe à la plaque de polystyrène.

Deux réactions controles ont été effectuees. La première consiste à utiliser des plaques sensibilisees à la glutaraldehyde et sur lesquelles aucune fixation de proteine n'a ete pratiquée. La deuxième consiste à fixer du fibrinogène dans les mêmes conditions 
que celles utilisêes pour la fixation des monomeres. Comme pour les monomères, dans une expêrience préliminaire, la quantite de fibrinogène fixé sur la plaque a été dêterminée et il a eté conclus que la totalité du fibrinogène etalt fixé dans ces conditions, puisque le fibrinogène n'a pas êté retrouvé dans le surnageant.

En pratique, afin que les conditions soient rigoureusement identiques pour la fixation du fibrinogène et pour la fixation des monomeres, une moitié de la plaque préalablement activêe par la glutaraldehyde sera incubee avec le fibrinogène et I'autre moitie sera incubée avec les monomeres.

4) Interaction entre monomères des A de fibrine lou fibrinogène) et fragment D1 - Les conditions retemues pour cette interaction consistent à introduire dans chaque puits, $100 \mu l$ de fragment D1 à des concentrations progressivement decroissantes, allant de $25 \mu \mathrm{g} / \mathrm{ml}$ à $1,5 \mu \mathrm{g} / \mathrm{ml}$.

Afin d'éviter une fixation non spécifique du fragment 01 sur la plaque, le fragment D1 a été dissous dans du PBS, contenant $0,5 / 1000$ de tween 20 et $1 / 1000$ d'albumine.

De plus, afin d'eviter lors de l'incubation une dégradation des monomères par des traces de plasmine susceptibles d"etre présentes dans la solution de fragment D1, de l'inhibiteur de Kunitz est ajoutê à la solution de fragment $01(20000 \mathrm{U} / \mathrm{ml})$.

Une réaction controle est pratique en remplaçant la solution de fragment D1 par du tampon PBS tween.

L'interaction monomeres ou fibrinogène et fragment 01 est réal isée par incubation de 2 heures a $37^{\circ} \mathrm{C}$. Au bout de ce temps d'incubation, la 
plaque est lavee 4 fois dans du CINa contenant $0,5 / 1000$ de tween 20 , afin d'éliminer le frAgment $D 1$ non combiné aux monomères lou au fibrinogène).

5) Mise en evidence du fragment D1 lié aux monomères fou au fibrinogène)

Elle est pratiquee par deux incubations successives de 1 heure 30 a 37 C sêparées par 4 lavages avec du chlorure de sodium $0,15 \mathrm{M}$ contenant $0,5 / 1000$ de tween 20 : la première avec de $I^{\prime}$ anti-D néo utillisé a une dilution préalablement déterminée telle que la fixation de I'anticorps sur le fragment $D$ immobilisé soit maximale (voir chapitre: Resultats des anticorps monocionaux), la deuxième avec de $l^{\prime} \mathrm{Ig}$ de chèvre anti-Ig de souris marquee à la péroxydase diluée au $1 / 1000$.

Après 4 lavages de la plaque dans les mêmes conditions, la péroxydase immune est révélée par addition de $200 \mu l$ du réactif à l'orthophénylène diamine. Après $4 \mathrm{mn}$ d'incubation la réaction est bloquée par addition de $50 \mu \mathrm{l}$ de $504 \mathrm{H} 22,5 \mathrm{~N}$.

La densité optique a $492 \mathrm{~nm}$ au niveau de chaque puits révélant la peroxydase dépend de la quantité de fragment Di fixé aux monomères (ou fibrinogène).

\section{RESULTATS}

II y a une relation semi-logarithmique entre la quantité de fragment D1 incubé avec les monomères (ou le fibrinogène) et la Do 
Fig. 25: Fixation du fragment D1 sur le fibrinogène et les monomères inmobilisès.

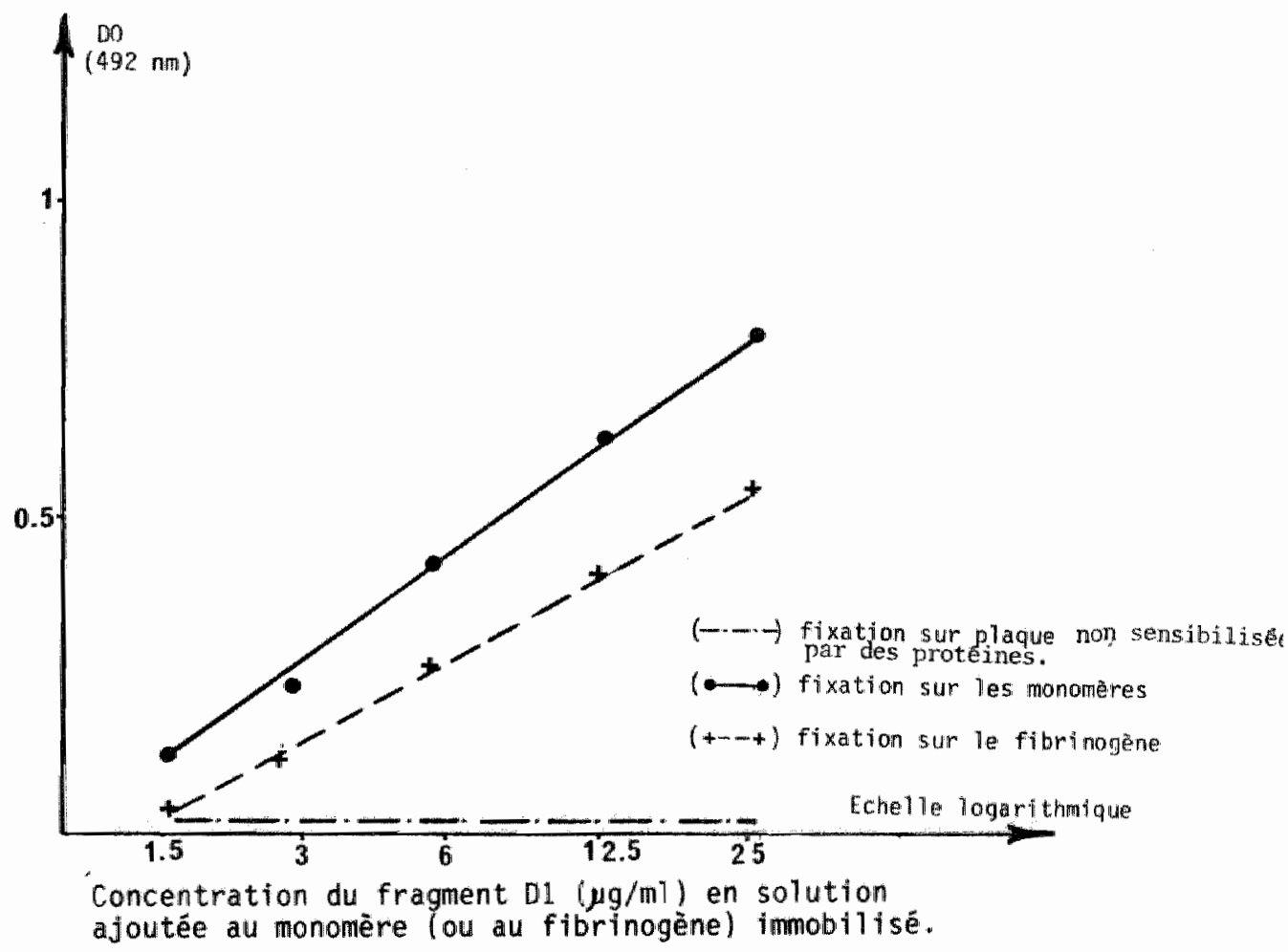


aprếs révêlation de la péroxydase (Fig. 25). La quantité de fragment D1 fixee aux des A monomeres est beaucoup plus importante que celle fixée au fibrinogêne. Aucune fixation de fragment 01 n'est observée lorsque les plaques sont uniquement traitees par la glutaraldehyde. De plus, un contróle a été réalisé, montrant qu'aucune immunoréactivité n'est observée lorsque le fragment 01 est remplacé par du tampon.

D. DISCUSSION

La technique réalisée lici constitue une méthode simple, sensible, reproductible et quantitative de la fixation du fragment 01 sur les monomères des. A de fibrine.

- La fixation du fragment D1 au fibrinogène est toutefois controversée dans la litterature. Olexa et Budzinski. par exemple, ont trouvé que le fragment 01 ne $5^{\prime \prime a c c r o c h a i t ~ p a s ~ a u ~ f i b r i n o g e ̀ n e ~ i m m o b i l i s e ~ s u r ~ d u ~}$ sépharose activé par le bromure de cyanogene (149).

En revanche, Pasqua et Pizzo (151) ont note une fixation du fragment D sur le fibrinogène immobilisé sur le sépharose. Pour ces auteurs, la discordance observee entre leurs résultats et ceux d'0lexa et Budzinski serait liée au falt que ces derniers, pour séparer le fragment 0 libre du fragment 0 combiné au fibrinogene, utilisent des lavages extensifs du sepharose fibrinogène ne permettant pas de mettre en evidence des attractions faibles entre fibrinogene et fragment 0 . En revanche, par leur technique utilisant une dialyse a l'équilibre, les liaisons faibles ne sont pas dissociêes. 
- La fixation du fragment ol au fibrinogène observee par notre technique peut être liêe :

- soit à la présence de forces attractives faibles entre fibrinogène et fragment $D 1$, comme le pensent Pasqua et Plzzo,

- soit à une fixation du fragment D1 sur du fibrinogène légèrement modifié par sa fixation sur la plaque de polystyrène. En effet, dans le chapitre précédent, grace à l'utilisation de deux anticorps monoclonaux, nous avons pu montrer que lors de la fixation du fibrinogène sur le polystyrène, il $y$ avait un changement de conformation de la molécule, rendant accessible certains épitopes masqués dans le fibrinogène natif en solution.

- soit à une fixation non specifique du fragment 01 sur les protéines immobilisées.

Quoi qu'il en soit, afin de calculer la fixation spécifique du fragment D1 aux monomères, sur le diagramme, il est mis en abcisses la quantité de fragment 01 en solution incubée avec les monomères (ou le fibrinogène immobilisé) et en ordonnées la différence entre la do obtenue lorsque l'incubation a lieu avec les monomères et la Do obtenue après incubation avec le fibrinogène (Fig. 26). 


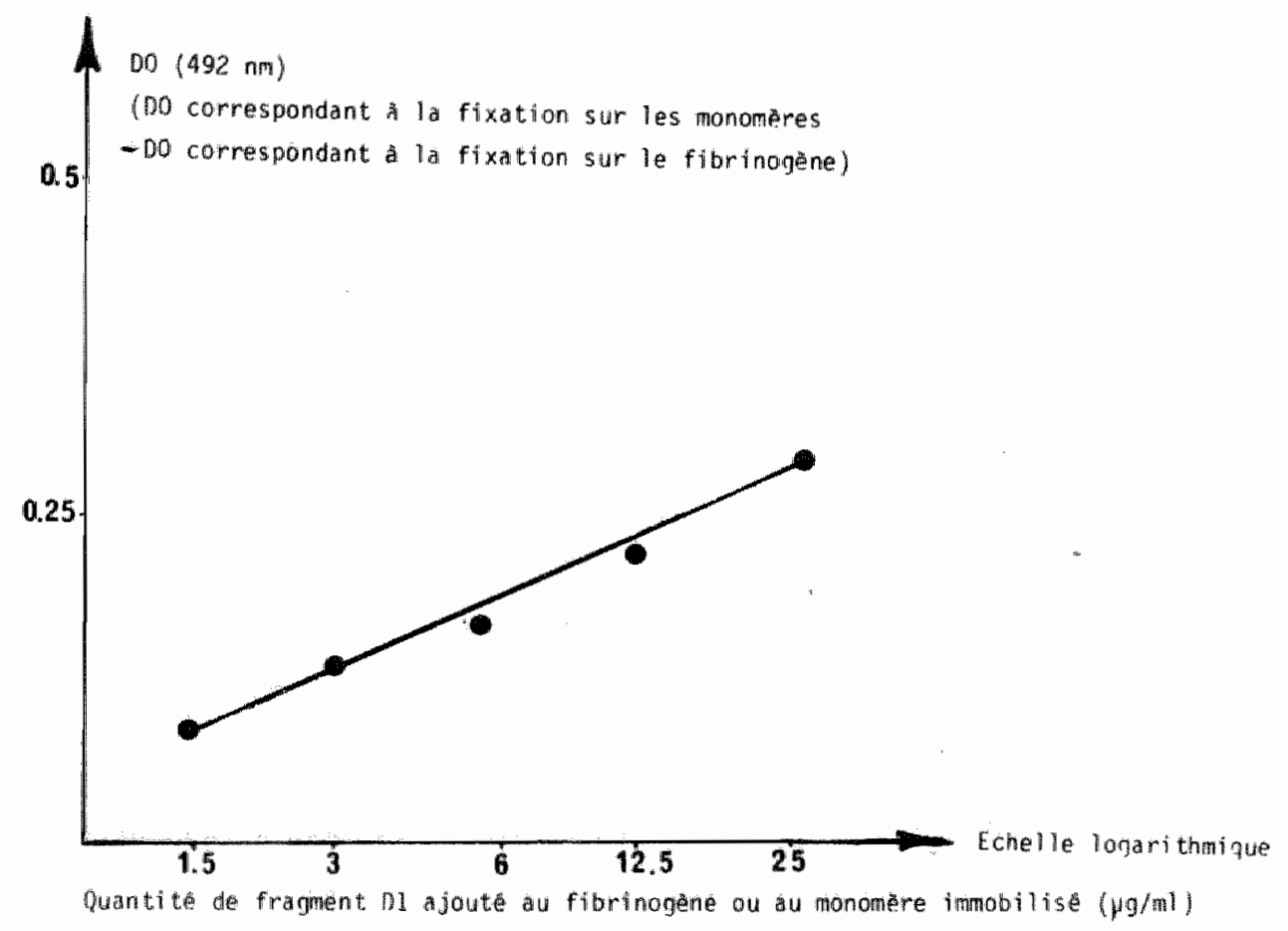

Fig. 26 : Fixation specifique du fragment 01 sur les monomères immobilitisés. 


\section{APPLICATION DE LA METHODE}

\section{A. ETUDE PHARMACOLOGIQUE DE CERTAINES SUBSTANCES INHIBANT \\ L"AGREGATION DES MONOMERES. DETERMINATION DE LEUR REACTIVITE}

Elle est réalisée en incubant les monomères immobilisés avec une quantite donnée de fragment $D 1$ en présence de quantites croissantes de la substance à étudier. Pour évaluer l'activité de l'inhibiteur, l'inhibition de la fixation du fragment 01 sur les monomères est déterminée en fonction de là dose de substance inhibitrice ajoutée au fragment 01.

Cette étude quantitative est très reproductible, et peut rendre de précieux services dans l'étude du mécanisme d'action de certaines drogues et dans la détermination de leur activité.

B. APPLICATION PARTICULIERE A L'ETUDE D'UN FIBRINOGENE ANORMAL HOMOZYGOTE, LE FIBRINOGENE ALES. MISE EN EVIDENCE D' UNE ANOMALIE OU SIGE DE POLYMERISATION "a" LOCALISEE SUR LA CHAINE GAMMA

Cette étude a été effectuee en collaboration avec $P$. Desvignes et $P$. Bonnet.

De nombreux cas de dysfibrinogénémie ont été rapportés dans la littérature. Toutefois les cas homozygotes sont très rares. Du falt de la seule présence de fibrinogène anormal, l"étude de tels cas 
homozygotes est tres important pour etudier les relations entre anomalies de structure et de fonctions du fibrinogène.

Jusqu"a présent seulement deux cas de dysfibrinogénémie homozygote ont eté publiés. $11 \mathrm{~s}^{\prime}$ agit des fibrinogènes Detrait (21) et Metz $(164)$.

Le cas présenté ici a été decouvert par hasard chez un polytraumatise et pour lequel un bilan de coagulation de routine a éte effectué. Le patient ne prêsentait pas de tendance hémorragique anormale. De meme, ni la soeur, ni les parents, qui sont cousins germains ne presentaient de tendance au saignement, ni de tendance thrombotique.

1) Matêriel et méthodes ayant servi à étudier cette dysfibrinogénémie

a) Examens d'investigation biologique en coagulation

Le temps de saignement (Duke), le temps de recalcification plasmatique (Howell), le temps de Quick, l'évaluation différencielle des facteurs $I I, V$ et VII 10 , le temps de céphaline-kaolin ont éte realises selon les techniques présentées par Can, Larrieu et Samama (29).

L'agregation plaquettaire induite par l'ADP, le collagene, l'acide arachidonique a été étudiée à l"aide d"un agrëgomètre coultronic. L'activite cofacteur du fibrinogene dans L'agrégation plaquettaire induite par L'ADP a êté déterminée en etudiant l'agrégation a l'ADP de plaquettes lavees normales obtenues selon Patscheke (152) en présence de quantitê wariable de fibrinogène normal ou anormal.

La concentration plasmatique en fibrinogène (29) a été 
determinée par diffëremtes methades : chronométriques (Von clauss). immunologiques (Mancini), utilisant les plaques Partigen (Laboratoires Behring; et par précipitation a $56 \mathrm{C}$.

- Le temps de thrombine et le temps de reptilase ont eté mesures par addition à un volume de plasma, d'un volume egal de thrombine (de différentes origines) ou de reptilase utilisees à differentes concentrations et en solution dans le chlorure de sodium 0,15 M ou le chlorure de calcium M/40.

- La courbe de polymérisation a été effectué selon la technique de Bouvier et Gruedlinger (24) par enregistrement cinétique de la variation de la DO a $350 \mathrm{~nm}$ d'une dilution de plasma induite par addition de thrombine. La dilution du plasma utilisée dans ces cas a été de $1 / 3$ (au lieu de $1 / 10$ normalement).

- La teneur dans le sérum de substances ayant l'antigénicité du fibrinogène a eté déterminé à l'aide de particules de latex sensibilisees avec de l'antifibrinogène (thrombo-walcotest. Laboratoires Well come).

- Le facteur XIII a eté dosé par la technique de Josso en utilisant du fibrinogène dépourvu de facteur XIII (Laboratoire Behring) (29).

b) Analyse de la molecule de fibrinogène

Elle a été réalisée sur du fibrinogène purifié obtenu par a méthode de Blomback et Blamback (11). Le fibrinogene purifie est dissous dans du CINa $0,15 \mathrm{M}$ afin d'abtenir une solution a $10 \mathrm{mg} / \mathrm{ml}$ de protëines. Cette solution est lyophil isëe en fractions de $1 \mathrm{ml}$.

- Le fibrinogène ainsi isolế est analyse par electrophorèse en gel de polyacrylamide en présence d'urée et de SDS (63) 
- Les chaînes dissaciées de ce fibrinogène ont été étudiées par électrophorèse en gel de polyacrylamide à $5 \%$ en présence de SDS selon 1a technique de Schwartz et al. (163), et par isofocalisation en gel de polyacrylamide a $4,5 \%$ (selon le premier stade de la technique de a'Farel1) (147) en présence d'un mélange à parties égales de pharmalytes pH 4-6 et pH 4-8 (Laboratoire Pharmacia).

La dissociation du fibrinogène en ces trois chaînes a été réalisée selon la technique de Schwartz et al. (169) par incubation pendant 18 heures à $37 \mathrm{C}$ de l'echantillon dans une solution d'uree $8 \mathrm{M}$ et de mercapto éthanol à $3 \%$. L'incubation est réalsêe en l'absence de SDS pour 1'isofocalisation et en présence de $3 \%$ de SDS en concentration finale pour I "électrophorèse en gel de polyacrylamide-SDS.

- Les produits de dégradation du fibrinogène par la plasmine non réduits ou réduits par le mercapto éthanol, ont été étudiés par électrophorèse en gel de polyacrylamide-SDS selon la technique de Schwartz. La dégradation du fibrinogène par la plasmine est réalisée en présence de calcium et en présence d."EDTA selon le protocole décrit par Haverkate (84).

c) Analyse de la fibrinoformation

Les trois etapes de la fibrinoformation ont été étudiées séparément.

- La liberration des fibrinopeptides A et B après addition de thrombine au fibrinogène purifié, a été étudiée par HPLC selon la technique de Kehl et Henschen (104) à l'aide d'un appareil Waters. La liberation du fpA après addition de reptilase au fibrinogène 
purifié a également été mesuré par immunoenzymologie selon la technique de soria et all. (170) en utilisant les reactifs stago (Asnières, France).

- L'agrégation des monomeres de fibrine a eté appréciee par la technique de Belitser (7) : la solution de monomeres dans l"acide acétique à $1 \%$ est diluée dans du tampon tris-HCl pour induire l'agrégation des monomères, qui est suivie par enregistrement de la variation de densité optique a $350 \mathrm{~nm}$.

- La stabilisation de la fibrine a éte appréciée par la formation de dimères de chaines gamma et de polymeres de chaine alpha. Cette analyse a été réal isée par électrophorêse en gel de polyacrylamide a 5 \% en présence de SDS, après dissociation du caillot par I "urée et mercapto éthanol, selon la technique de schwartz (163). Ont eté parallèlement étudiés, le caillot provenant de la coagulation du plasma natif obtenu par centrifugation immediate a 4 C du sang natif recueilli sans anticoagulant et celui provenant de la coagulation par la thrombine calcique d'un échantillon de fibrinogene purifié additionne de facteur XIII (fibrogamine, Laboratoires Hoescht) d une concentration finale egale à celle presente dars le plasma "selon le protocole de Schwartz et al.

Conjointement le calllot non stabilisé provenant de la coagulation du fibrinogène par de la thrombine en présence d'EDTA a été analysé dans les mêmes conditions.

Conjointement a cette etude des trois stades de la fibrinoformation, la liaison du fragment 01 issu du fibrinogene anormal a des (des A)monomẻres de fibrine provenant d"un fibrinogène normal a été étudiée. 
2) Resultats

a) Investigation biologique de la coagulation

Elle est rếsumée dans le tableau VIII. Ell a permis de déceler chez ce mallade un allongenent important du temps de thrombine. Ce trouble de la fibrinoformation retentit sur le temps de Quick, qui est très allongé, malgré un taux normal des facteurs II, V, VII+10. Le temps de reptilase est infini, même lorsque la reptillase est utilisee 10 fais plus concentrée que nomalement.

La concentration plasmatique en fibrinogène est wariable selon la technique utilisée, normale par les méthodes immunologiques ou par précipitation à $56^{\circ} \mathrm{C}$, très diminuée en revanche dans les méthodes chronometriques.

La soeur du malade présente les mêmes anomalies que celles de son frère, tandis que leur père et leur mère, qui sont cousins présentent aussi une anomalie de la fibrinoformation, mais beaucoup moins intense que celle observée chez leurs deux enfants.

b) Analyse du trouble de la fibrinofornation

- La courbe de polymérisation faite avec le plasma dilué de malade montre d'abord un allongement tres important du temps de latence, puis une augmentation de la densité optique très lente. Toutefois, compte tenu de la concentration plasmatique en fibrinogène, la Do finale du caillot est normale (figure 27 ).

- L'addition de chlorure de calcium à la thrombine n'induit aucun racourcissement du temps de thrombine. 
Tableau VIII : Investigations biologiques de routine permettant d'explorer la coagulation.

\begin{tabular}{|c|c|c|c|c|c|}
\hline & Patient & Soeur & Pare & Mere & Controle \\
\hline Temps de saignement ( $\mathrm{mn})$ & 3 & 1,30 & ND & ND & $2-4$ \\
\hline Plaquettes $\left(\times 10^{3} / \mu l\right)$ & 200 & 280 & $\mathrm{ND}$ & $N D$ & $200-400$ \\
\hline Agrégation plaquettaire & $\mathrm{Nl}$ & N1 & NI & $\mathrm{Nl}$ & \\
\hline Temps de coagulation (mn) & 8 & 9 & 7 & 7 & $5-9$ \\
\hline Temps de Quick (sec) & 180 & $>180$ & 16 & 15.5 & 13 \\
\hline Facteur II $(\%)$ & 100 & 100 & 100 & 100 & $80-100$ \\
\hline$V I+10(\%)$ & 100 & 100 & 100 & 100 & $80-100$ \\
\hline$V(x)$ & 100 & 100 & 100 & 100 & $80-100$ \\
\hline Temps de cephaline & & & & & \\
\hline Kaolin $(\sec )$ & $2^{180}$ & $>180$ & 34 & 36 & 32 \\
\hline Temps de thrombine ( $\mathrm{sec}$ ) & & & & & \\
\hline$/ \mathrm{ClNa}$ & 600 & 780 & 30 & 30 & 20 \\
\hline$/ \mathrm{Cl} 2 \mathrm{Ca}$ & 60 & 60 & 10 & 10 & 10 \\
\hline Temps de reptilase (sec) & & & & & \\
\hline reptilase $\times 1$ & & & ND & ND & $\| 7$ \\
\hline reptilase $\times 10$ & & & $\mathrm{ND}$ & ND & 10 \\
\hline Fibrinogẹne mg/100 ml & & & & & \\
\hline - technique chronométrique & $e<20$ & 20 & 80 & 80 & $200-400$ \\
\hline - précipitation à $56^{\circ} \mathrm{C}$ & 315 & 330 & 370 & 400 & $200-400$ \\
\hline - technique imunol. & 305 & 302 & 400 & 400 & $200-400$ \\
\hline Matériel ayant 1'anti- & & & & & \\
\hline génicité du fibrinogène & & & & & \\
\hline dans le sérum : $\mu g / m l$ & 20 & 20 & ND & ND & 20 \\
\hline
\end{tabular}

N1 : Norma 1 


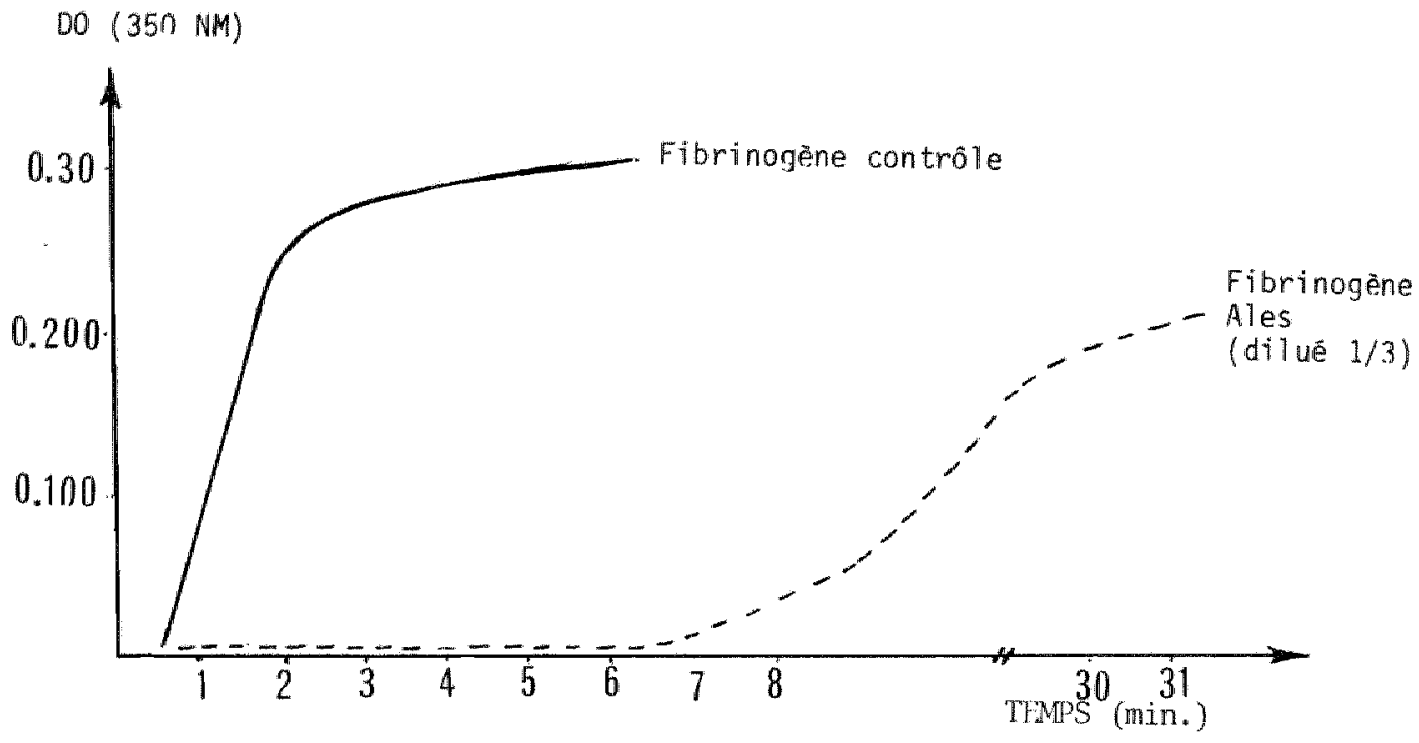

Fig. 27 :

Courbe de polymérisation du fibrinogène Mles après addition de thrombine. 


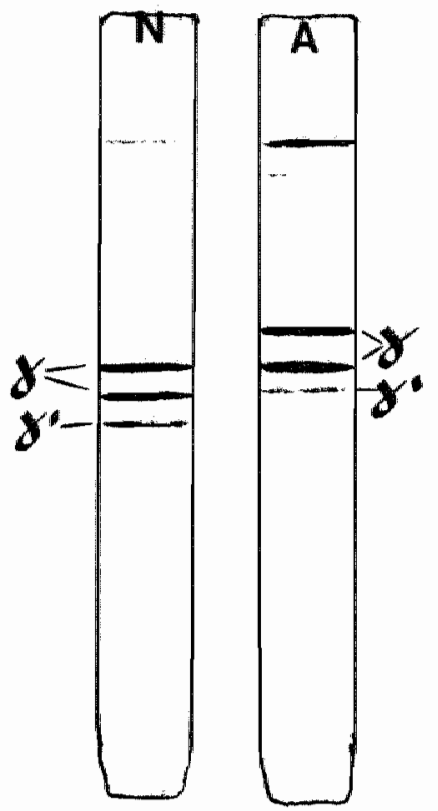

Fig. 28

Isofocalisation des chaînes dissociées du fibrogène ( $N$ : fibrinogène norma 1 )

(A: fibrinogène Ales). 
- Le même allongement du temps de thrombine que celui observé avec le plasma du malade et l'absence de coagulation par la reptilase (mếme à une concentration 10 fois superieure à celle utilisée normalement) s'observe aussi avec le fibrinogène purifié.

c) Analyse de la molécule de fibrinogène

- Par électrophorése en gel de polyacrylamide-SOS (SDS-PAGE) du fibrinogène non réduit, le fibrinogène anormal possède le même poids moléculaire apparant que celui du fibrinogène normal isolé dans les mêmes conditions.

- Par SDS-PAGE des trois chânes dissocices du fibrinogène, aucune anomalie n'a été décelée,

- Par isofocalisation des trois chaines du fibrinogène en revanche, lá migration de la chaine gamma-gamma' du fibrinogène anormal est bien anodique que celle de la chaîne gamma-gamma' du fibrinogène normal, comme le montre la figure 28 .

- Par SDS-PAGE des produits de dégradation du fibrinogène anormal obtenus par dégradation du fibrinogène par la plasmine en présence de calcium et en présence d'EDTA, aucune anomalie n'a pu être décelée : en présence de calcium obtention de fragment $D 1$ et $E$, en présence d" EDTA obtention des fragments 03 et $E$.

d) Etude des differents stades de la fibrinoformation

- Les fibrinopeptides $A$ et $B$ ont étê libérés normálement après action de la thrombine sur le fibrinogène. Aucune anomalie de structure des fibrinopeptides n'est décelable. En effet, le profil d'elution en HPLC des FPA et FPB provenant du fibrinogène anormal 
s'est révélé identique à celui issu du fibrinogène normal. De plus, les quantités de FPA et de FpB liberés du fibrinogène anormal sont identiques à celles libérées à partir du fibrinogène normal (Fig. 29).

De même le fibrinopeptide A est libéré normalement du fibrinogène anormal après action de la reptilase, comme il a été déterminé par dosage immunoenzymologique. En effet, $30 \mu \mathrm{g} / \mathrm{ml}$ de FpA ont été libérés d'une solution de fibrinogène à $3 \mathrm{mg} / \mathrm{ml}$ traité par la reptilase, qu"il s'agisse du fibrinogène normal ou du fibrinogène anormal.

- L"agrégation des monomères de fibrine est très anormale puisque dans les conditions décrites par Belitser aucun calllot ne se forme à partir des monomères issus du fibrinogène anormal, alors qu'un calllot se forme en moins de 5 minutes à partir des monomères normaux.

- La stabilisation de la fibrine est normale dans cette dysfibrinogénémie, puisque l'analyse par SDS-PAGE du caillot dissocié a montré la présence de dimères de chaines gamma et de polymères de chaînes alpha (Fig. 30).

e) Etude de l'interaction du fragment 01 à des monomères (des A) de fibrine normaux.

Comme 11 est objectivé dans la figure 31 , la fixation du fragment $D 1$ issu du fibrinogène normal aux des $A$ monomères normaux est très supérieure à la fixation du fragment dy provenant du fibrinogène anormal aux mêmes des A monomères normaux de fibrine. 




Ales

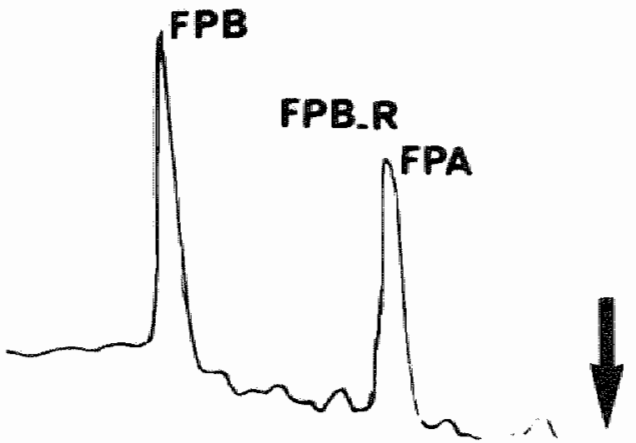

Normal

Fig 29 Etude par HPLC de la liberation des fibrinopeptides A et B après addition de thrombine au fibrinogène. 


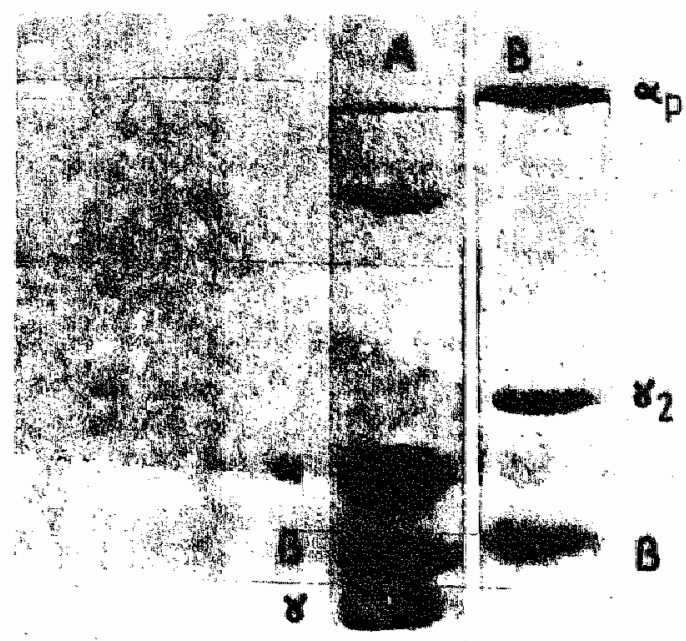

Fig 30

Etude de la stabilisation de la fibrine Ales

A : calllat non stabilisé

B : caillat s.tabilisé

Electrophorèse en gel de polyacrylamide + SDS avec callilot dissocië par l'urée et le marcapto-êthanol. 
Fig 31: Fixation des fragments 01 provenant du fibrinogène nomal et du fibrinogêne Ales sur le fibrinogène et les monomères normaux immobllisês.

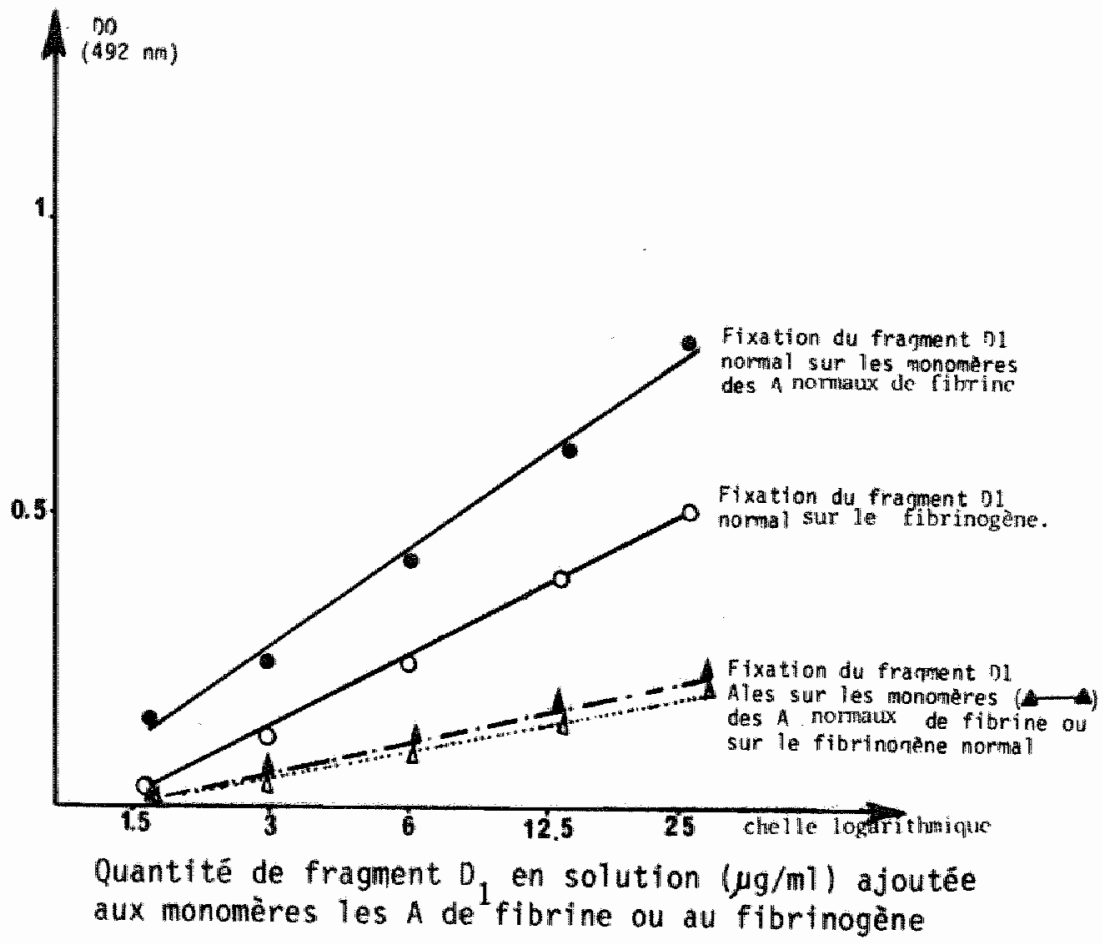


Fig 32: Fixation spécifique des fragments $D 1$ provenant du fibrinogène normal et du fibrinogène Ales sur des monomères (des A) normaux de fibrine.

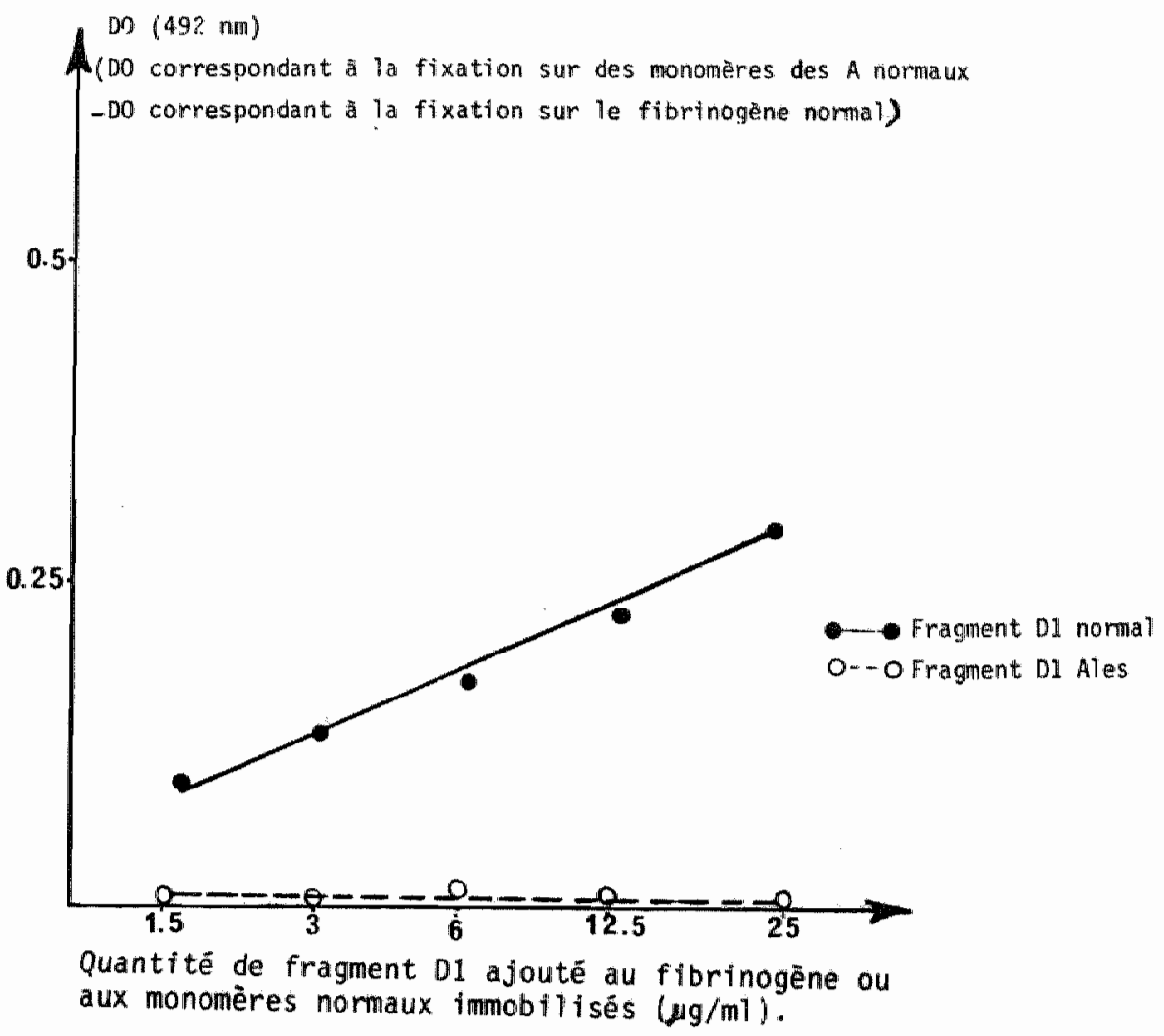


De plus, contrairement à ce qui est observé avec le fragment D1 normal, l'interaction du fragment 01 provenant du fibrinogène anormal, avec les (des $A_{4}$ ) monomères normaux est identique à celle abservée avec le fibrinogène normal.

Ainsi 11 ne semble y avoir aucune fixation specifique de fragment DI à des monomères (des A) de fibrine (Fig. 32).

f) L'activité cofacteur d'agrégation plaquettaire du fibrinogène anormal dans l'agrégation plaquettaire induite par l'ADP est strictement superposable à celle du fibrinogène normal.

3) Discussion

La dysfibrinogénémie homozygote présentée ici est particullêrement intéressante. En effet, 11 y a un grand retard a la coagulation du fibrinogène par la thrombine, mais il n'y a pas de coagulation du fibrinogène par la reptilase. La coagulation du fibrinogène par la thrombine est uniquement retardée, puisque la quantité de matériel ayant l'antigéniçite du fibrinogène dans le sérum est inférieure a $20 \mathrm{gamma} / \mathrm{ml}$, témoignant de l'absence de fibrinogène non coagule dans le sérum, ou l'absence de monomères.

- Concernant l'anomalie de structure de la molécule, elle a pu être localisée sur la chaine gamma de la molécule puisque que par isofocalisation des chaînes dissociées du fibrinogène, il a puêtre montre que la chaîne gamma-gamma' issue du fibrinogène anormal, avait un point isoélectrique supérieur à celui de la chaîne gamma-gamma' normale. De plus, la dégradation du fibrinogène anormal par la plasmine est identique à celle du fibrinogène normal, puisque en 
présence de chlorure de calcium il y a formation de fragment $D 1$ et $E$ et que en présence d'EDTA il y a formation de fragment $D 3$ et $E$.

- Concernant l'anomalie de la fibrinoformation, elle a pu être liẻe à un trouble important de l'agrégation des monomeres de fibrine, tandis que la liberation des fibrinopeptides et la stabilisation de la fibrine sont normales.

Compte tenu que :

1) I"anomalie est localisée à la chaîne gamma de la molécule

2) que le trauble de la fibrinaformation est lie a une agrégation défectueuse des monomères de fibrine,

3) que le fragment $D 1$ issu du fibrinogène anormal ne se lie pas aux monomeres (des $A$ ) de fibrine normaux ayant disponibles les sites de polymérisation "A" (et non " $B$ ", puisque le $\mathrm{fpB}$ n'a pas été liberé), il en a été conclu que l'anomallie devait être localisee au niveau du site "a", localisế dans le fragment $D 1$, a l'extrémité $C$ terminal de la chaîne gamma, site complémentaire du site "A" présent dans les (des A) monomères de fibrine.

Cette constatation explique donc la discordance observee entre la coagulation de ce fibrinogène par la thrombine d'une part, et son incoagulabilite par la reptilase d'autre part. En effet, lors de 1'attaque du fibrinogène par la thrombine, libérant le fpA et le $f p B$, les sites" $A$ et $B^{\prime \prime}$ deviennent accessibles, mais du fait de l'anomalie localisee au niveau des sites "a", entrainant de ce fait l'absence d'interaction A-a, la coagulation du fibrinogène par la thrombine est uniquement liée à l'interaction des sites " $B$ " et des sites " $b$ ". Au contraire, lors de l'attaque du fibrinogène par la reptilase, le 
fpA est libere normalement, rendant accessible le site "A" tandis que le fpB n'btant pas liberé, le site "B" reste masqué. De ce fait, alors que pour le fibrimogene normal, IInteraction A-a suffit pour former un calllot, pour le fibrinogene anormal, du fait de l'absence d"interaction A-a liée à l'anomalle du site "a" ce fibrinogène anormal ne peut pas coaguler par la reptilase.

De telles experiences ont donc permis de mettre en evidence une anomalie au niveau du site a de polymerisation. Cette anamalie est particulièrement intêressante car jusqu'a ce jour la nature du site a était encore inconnue et l'étude d'un tel fibrinogêne anormal devrait permettre de localiser ce site sur la chaine gamma. 
DOSAGE DES PRODUITS DE DEGRADATION DE LA FIBRINE OU DU FIBRINOGENE DIRECTEMENT DANS LE PLASMA

Les dosages des produits de dégradation de la fibrine (PDFb) constituent actuellement (en assaciation avec la recherche de complexes solubles dans le plasma) une investigation blologique courante pour le diagnostic des coagulations intra-vasculaires. Plusieurs méthodes de dosage des PDFb ont été décrites, le fibrinogêne interférant il faut donc pratiquer le dosage dans le sérum.

\section{RAPPEL DES TECHNIQUES UTIILISEES ACTUELLEMENT} EN BIOLOGIE CLINIQLLE

\section{A. METHODES BASEES SUR UNE REACTION ANTIGENE-ANTICORPS}

Les méthodes les plus courantes utilisent une reaction antigène-anticorps. Elles sont toutes effectuees d'aide d'antiserum polyclonaux antifibrinogène ou anti $D+$ anti E. Les techniques les plus couremment utilisees sont : la technique de Merskey d'une part, la technique au latex d'autre part.

1) La technique de Merskey (134). Elle est baste sur le fait que l'hémagglutination de globules rouges sensibilisés par du fibrinogene lie aै l'addition d'un antiserum anti-fibrinogene est inhibee par l'incubation préalable de l'anticorps avec une quantite suffisante de 
produits de dégradation de la fibrine. De la plus grande dilution de l'échantillon analysé incubé avec l'anticorps induisant une inhibition de l'hémagglutination. Il est déduit la concentration en POFb dans le prélèvement. Cette technique est sensible et reproductible, toutefois, les réactifs sont longs a préparer et ont une durée de conservation limitée ( 6 semaines). De plus, lors de la détermination des PDFb, deux incubations de 30 minutes chacune sont pratiquées, la technique ne peut donc être réalisêe rapidement, ce qui limite son utilisation. Par cette technique „le fragment $E$ n'est pas révélé (171).

2) La technique au latex sensibilisé par un mélange d'Ig anti-D et d'Ig anti-E est en revanche très utilisée. Elle consiste à déterminer la plus grande dilution de l'échantillon à analyser quỉ induit en 2 minutes l'agglutination des particules de latex sensibilisé. La réaction est donc très rapide à effectuer, de plus, des réactifs commerciaux de bonne conservation sont disponibles.

B. LE STAPHYLO CLUMPING TEST

Le "staphyloclumping test" est une méthode basée sur l'agglutination de certaines souches de staphylocoques par le fibrinogène et certains de ces dérivés $(2,116)$. Il suffit donc de déterminer la plus grande dilution de l'échantillon à analyser qui induit encore l'agglutination de la suspension de staphylocoques. Cette technique mise au point par Hawiger et al. (85) ne décèle que les prodults très précoces de dégradation. En effet, Strong et al. ont montré que c'était le peptite gamma 397-411 éliminé lors de la 
conversion du fragment 01 en fragment 03 qui se fixait sur les souches de staphy locoque (177). Cependant, pour que l'agglutination apparaisse il faut que ce peptide soit expoxe symétriquement de chaque côté de la molécule, le fibrinogene realisant ainsi des ponts entre deux staphylocoques (32). En revanche, les prodults de degradation asymétriques ne renfermant qu'un seul peptide gamma 397-411 bloquent les récepteurs au niveau des souches de staphylocoques, sans entrainer" d"agglutination.

Pour toutes ces techniques, quand la coagulation du sang est très retardée ou incomplète, deux heures après l'obtention du caillot, il peut rester en solution du fibrinogène non coagule ou des monomères ne polymérisant pas interférant donc avec le dosage des POFb.

L'obtention d'anticorps réagissant avec les POFb et ne réagissant pas avec le fibrinogène est donc particulièrement intéressante. Une technique de dosage des PDFb utilisant de tels anticorps, présente en outre l'avantage de pouvolr réaliser toute 1 "investigation biologique de la coagulation sur un seul prélevement de sang recuellli sur citrate trisodique 0,13 M ( 1 volume pour 9 wolumes de sang) et permet en outre de réaliser l'exärien souvent urgent sitót le prélèvement effectue, puisqu'il n"est plus necessaire alors d'attendre la coagulation complete du sang.

Les anticorps monoclonaux anti-D néo peuvent donc être utilisés dans ce but. 


\section{TECHNIQUES DE DOSAGE DES PRODUITS DE DEGRADATION DE LA FIBRINE PAR UTILISATION D'ANTICORPS}

\section{MONOCLONAUX ANT1 D-NEO}

\section{A. TECHNIQUE IMMUNO-ENZYMOLOGIQUE DE RYLATT ET AL.}

Les premiers Rylatt et al. (161) ont utilisés une technique de dosage des PDFb directement dans le plasma, puisque leur anticorps rêvèle un épitope présent dans le dimëre $D-D$ maís masqué dans le fibrinogène intact et le fragment $D$, permettant en outre de differencier les produits de degradation de la fibrine PDFb, des produits de dégradation du fibrinogène PDFg. La technique qu'ils utilisent pour doser les POFb dans le plasma, bien qu'intéressante, est une technique ELISA longue à réaliser et donc non applicable en laboratoire de routine. Elle consiste à capter de façon spécifique les PDFb de l"échantillon par leur anticorps monoclonal purifié fixé sur une plaque de polystyrène spécifique du fragment $D-D$ et ne révélant pas le fibrinogène. Puis, dans un deuxième temps les PDFb liếs au polystyrène sont révelés par un deuxième anticorps monoclonal marqué à la péroxydase, révèlant aussi bien le fibrinogène que les PDFb. Le deuxième anticorps monoclonal doit révéler un épitope assez éloigné de l'épitope détecté par le premier anticorps, afin de ne pas avoir de problème d'encombrement stérique. 


\section{B. TECHNIQUE PERSONNELLE AUI LATEX}

La technique réalisée dans notre laboratoire est un test au latex. Sur la suggestion des laboratoires Diagnostica Stago (Asmieres, France), nous avons envisagé de fixer les anticorps monoclonaux anti-D néo sur des particules de latex afin de développer un test pratique de dosage des PDFb dans le plasma.

\section{1) Principe}

Des particules de latex sensibilisees avec des Ig purifiées anti-D néo ont été préparées. Les particules agglutinent en présence d'une quantité suffisante de PDFb ou de fragment $D$.

2) Matériel et méthodes

- Plasma citrate obtenu par centrifugation à $1000 \mathrm{~g}$ de sang recueilli sur citrate dissodique $0,13 \mathrm{M}$ ( 1 volume pour 9 volumes de sang)

- Particules de latex en polystyrène stabili sé de $0,3 \mu$ de diamètre (Rhone Poulenc).

- Obtention des Ig purifiées à partir de l"ascite de souris injectée avec les hybrides DSB14. Elle a été réalisée selon la technique de Boschetti et al. (22) : apres précipitation des Ig par le sulfate d'ammonium, le précipité est dissous, filtrế sur une colonne de CFO5 (laboratoires IBF) puis le pic de proteine est soumis ane double chromatographie échange d'ions, la première sur DEAE tris acryl 
(IBF) avec elution en gradient de 0 à 0,3 M de $\mathrm{NaCl}$ en tampon phosphate 0,01 M pH 8. La deuxième sur CM tris acryl (IBF) en tampon phosphate $0,01 \mathrm{M} \mathrm{PH} 6$, suivie d'une elution par du $\mathrm{ClNa} 0,5 \mathrm{M}$ dans le tampon pH 6. La fraction protéique correspondant aux $\mathrm{lg}$ est repérée par la technique immunoenzymologique directe utillisée pour la mise en évidence de lá sécrétion đ'hybridomes.

Par électrophorèse en gel de polyacrylamide SDS, selon Weber et osbơrn (185) il a pu être montrê que cette fraction renferme au moins $95 \%$ d'immunoglobulines.

- La sensibilisation du latex avec les Ig provenant de l'ascite de souris qui avait été injectée avec des hybridomes anti-D néo a été pratiquée selon Singer et Plotz (166).

- Le dosage des PDFb s'effectue directement dans le plasma : la plus petite dilution du plasma en tampon glycine $\mathrm{pH} 8,35$ induisant encore l'agglutination des particules de latex sensibilisées est déterminée. L'étalonnage de la technique est effectué avec du fragment D purifie et avec des PDFb isolés.

Sur une plaque de verre sont deposés successivenient $0,1 \mathrm{ml}$ de dilution de plasma et $0,025 \mathrm{ml}$ de suspension de latex. Après mélange des particules de latex à la dilution de plasma, à l'aide d'un agitateur, la plaque est soumise à une oscillation douce pendant 5 minutes. Le temps nécessaire a l'apparition de l'agglutination est mesure. Seules les agglutinations n'apparaissant en moins de 5 minutes doivent être retenues.

- Les résultats obtenus ont été confrontés avec le bilan d'investigation biologique de coagulation et en particulier aux 
fibrinogène n'interfère pas avec le dosage des PDF, aucune cause d'erreur n"a êtê abservêe, même chez les sujets présentant une hyperfibrinemie à $8 \mathrm{~g} / 1$. De plus, les resultats obtenus par agglutination des particules de latex sensibilisees a 1 'anti-D né sont comparables avec ceux obtenus avec le thrombo Welco test. Les calculs statistiques n'ont pas eté réalises. En effet, les dilutions effectuées de l'échantillon a analyser sont des dilutions arithmetiques pour determiner la plus grande dilution de cet échantillon entrainant encore une agglutination des particules de latex.

Ceci explique que la concentration des pof dans 1"échantillan est comprise entre deux concentrations, allant du simple au double.

La différence de réactivitế de l'anticorps monoclonal DSB 14 pour le fragment 0 et paur les produits de dégradation de la fibrine PDFb, qui avait été observé dans le test immonoenzymologique par compétition, n'apparait pas dans le test au latex. Cette différence de réactivité de l'anticorps selon la technique utilisée peut être expliquée aisement par le fait que les durées d'incubation des produits de dégradation de la fibrine ou du fibrinogéne avec l'anticorps sont tres differentes. Moins de 5 minutes la temperature du laboratoire pour le test au latex et 18 heures a $4 \mathrm{C}$ pour le test immunaenzymologique.

La mise au point de techniques utilisant ces particules de latex est três délicate, comme l'ont souligné Daniel (41) et Grémy (78).

En particulier, le choix des particules de latex doit etre très rigoureux. En effet, les particules de latex sont constituees par 
complexes solubles effectues avec le kit Stago FSPrest.

3) Résultats

a) Contróle de la validité des particules de latex sensibilises

- le fragment $\mathbb{D}$ a une concentration de $5 \mu \mathrm{g} / \mathrm{ml}$ induit l'agglutination des particules de latex en moins de 3 minutes.

- les POFb aे une concentration de $5 \mu \mathrm{g} / \mathrm{ml}$ induisent également l"agglutination des particules de latex dans les mêmes conditions.

- les plasmas citrates provenant de 50 sujets témoins normaux dilués au $1 / 4$ dans le tampon glycine $\mathrm{pH} 8,35 \mathrm{n}$ 'ont jamais induit d'agglutination des particules de latex, ce qui correspond ane concentration en PDFb inférieure à $20 \mu \mathrm{g} / \mathrm{ml}$.

b) Etude des prélèvements de malades

Le tableau IX expose les principaux résultats de prélèvements de malades et montre que, chaque fois que les complexes solubles sont positifs, la teneur plasmatique en produits de dégradation de la flbrine est assez elevée. Il y a donc une bonne correspondance entre les deux tests. De plus, il y a également une bonne correspondance entre lá technique classique utilisant le thrombo-welco-test, effectuée dans le sérum et notre technique utilisant un anticorps monoclonal anti-D néo effectuée dans le plasma.

4) Discussion

La technique que nous avons mise au point est très utile dans l'investigation biologique de routine pour dépister les coagulations intra vasculaires. Des résultats obtenus, il ressort que le 


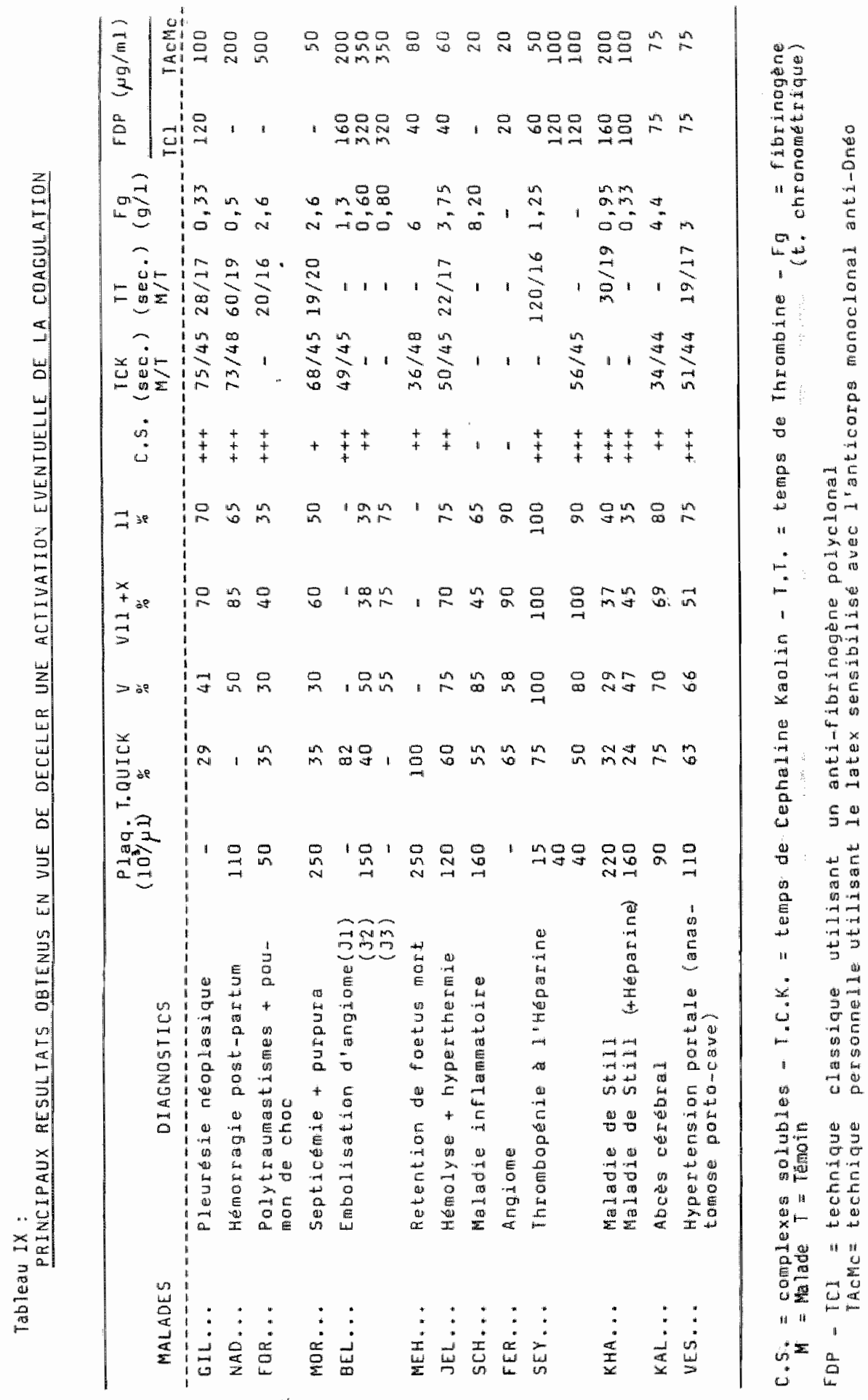




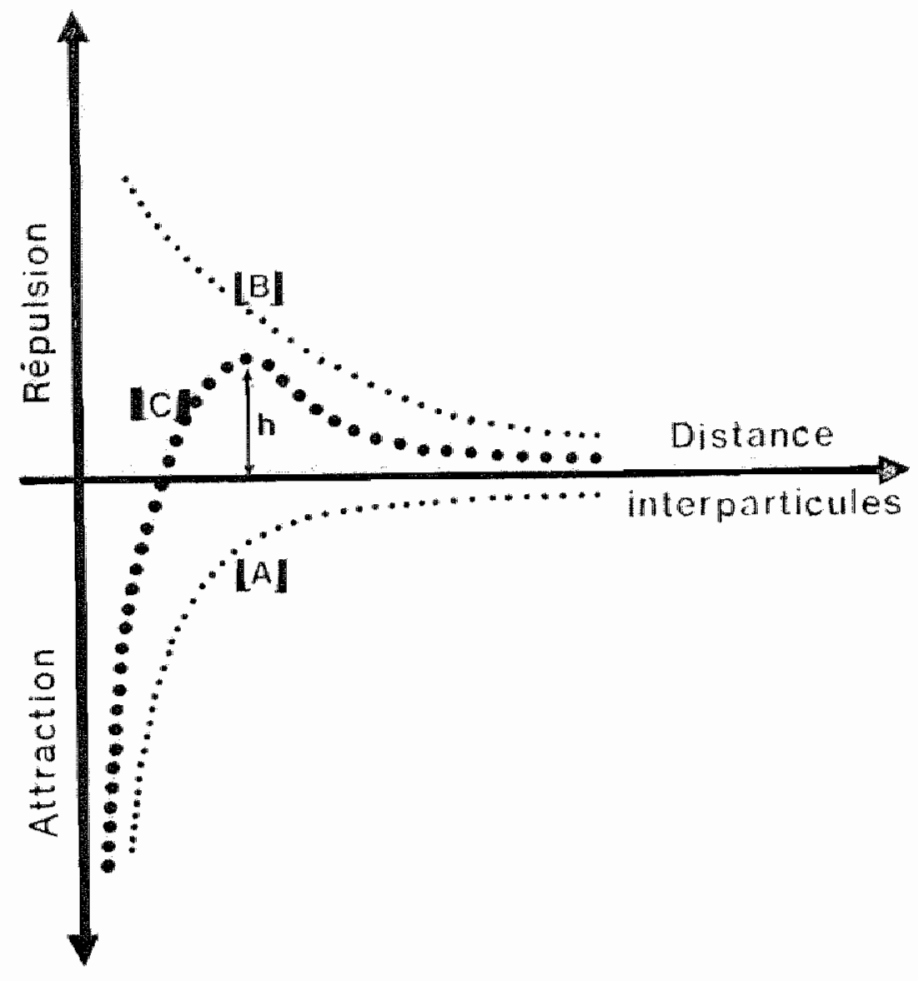

Fig. 33 : Differentes forces d'attraction entre les particules de latex, responsables de 1 "agglutination des particules. 
un ensemble de particules de polymères monodispersees dans une phase aqueuse. Ces particules de latex soumises a l'action de deux types de force qui agissent en sens inverse (Fig. 33)

- des forces d'attraction de type London-van der Waals qui s'exercent à très courte distance (courbe A)

- des forces de répulsion d'origine électrostatique dont l'intensité en fonction de la distance varie selon une loi différente (courbe B).

Il en résulte que les particules sont soumises à un potentiel dont la valeur dépendra de la distance interparticulaire (courbe c). De cette courbe $c$, il ressort que pour que les particules soient maintenues éloignées les unes des autres (latex stable) la barrière de potentiel doit être de $h$. La valeur de $h$ est en relation avec la stabilité du système. "h" dépend de paramètres variés comme :

- la densité des charges a la surface des particules

- la force ionique du milieu aqueux

- la constante diélectrique de la phase aqueuse. Toute action sur ces paramètres modifie donc la stabilite du système.

En outre, les particules de latex sont stabilisees par un agent émulsifiant. Les emulsifiants non ianiques sont constitues de molécules comportant une partie hydrophobe leur permettant de se fixer fortement sur les particules et de longues séquences hydrophiles qui se déploient dans la phase aqueuse. L'effet stérique introduit par de longues séquences hydrophiles de l'émulsifiant empếche les particules de se rapprocher suffisamment. Les quantités d'êmulsifiant doivent être aussi faibles que possible, car l'émulsifiant entre en competition avec les molécules biologiques dans le processus 
d"ad sorption.

Lorsque le latex est recouvert d'Ig, il constitue le latex "sensibilise". Ce latex sensibilise mis en presence de l'antigène correspondant est destabilisé du fait de la modification de charge induite par la formation de complexas antigêne-anticorps. Cette destabilisation crée des liaisons entre les différentes particules se traduisant par l'apparition d'agglutinats.

Cecl explique dont que la qualité du latex à utiliser doit être bien standardisée, en particulier,

- Les particules doivent etre de taille bien definie et la distribution granulametrique doit être la plus étraite possible, afin que la surface specifique soit bien connue et identique d'une particule à l'autre. En effet, le fat de disposer de particules identiques implique que toutes les particules précipitent en même temps lors de la formation du complexe antigène-anticorps. Cette précipitation brutale facilite la lecture du résultat.

- La stabilite du latex doit egalement être suffisante pour permettre d'analyser des milieux biologiques, en général riches en electrolytes.

Compte tenu de toutes ces précautions a prendre, qui dépendent donc surtout de la qualite de latex utilise, la technique au latex est une technique facile a réaliser en laboratoire.

Il est toutefois interessant de noter que c'est la premiere fois a motre connaissance qu um anticorps monoclonal est utilise dans un test au latex.

Le fait que l'agglutination des particules de latex sensibilisees soit lie a une destabilisation de charge des particules 
lors de la formation du complexe antigène-anticorps, nous a conduit a mettre au point ce test, qui nous semble particulierement intéressant. En effet, par une technique rapide il est possible de doser les produits de degradation de la fibrine directement dans le plasma, evitant ainsi de nombreuses causes d'erreurs liées a une coagulation incomplète du fibringgène. 
CONCLUSION 
Les anticorps monoclonaux sont tress utiles en biologie fondamentale pour étudier la configuration d"une molécule. En biologie appliquée, ils sont particulièrement intéressants pour différencier différents produits du métabolisme d'une protéine, ou pour doser spécifiquement une molécule incorporée dans un complexe protếique et douée d'une propriété particulière. C'est ainsi que differentes méthodes ont été décrites pour doser le facteur VIII coagulant immunologiquement sans doser le facteur VIII Willebrand associe a cette molécule ( $f$. VIII, Cag).

Au cours de ce travail nous avons préparé des anticorps monoclonaux à partir de lymphocytes de souris immunisées avec des produits de dégradation de la fibrine.

Nous avons sélectionné diffërents clones qui ont puêtre classés en différents groupes :

1) Anticorps reconnaissant un épitope accessible sur la molécue de fibrinogène et sur un de ses fragments de dégradation ( $D$ ou $E$ ). Parmi ces anticorps, nous avons sélectionné des anticorps capables de différencier le fragment de dégradation 01 du fragment 03 plus dégrade.

2) Anticorps capable de déceler un épitope accessible sur le fibrinogène fixé sur un support de polystyrène mais non accessible sur le fibrinogène en solution.

Ces anticorps permettent donc de déceler une modification de conformation secondaire à la fixation du fibrinogène sur un support solide. 
3) Anticorps reconnaissant un épitope inaccessible sur la molécule de fibrinogene et qui ne devient accessible qu'après dégradation de la molecule.

4) Anticorps reconnaissant un épitope accessible au niveau du fragment $E$ isolé et de la molécule de fibrinogène et inaccessible au niveau du complexe D-D-E issu de la dégradation de la fibrine stabillisée.

A l'intérieur de ces groupes differents sous-groupes ont pu etre définis

- selon que l'épitope reconnu est localisé sur une chaîne isolée de la molecule de fibrinogène ou au contraire représente un épitope de conformation

- selon que l'anticorps monoclonal révèle plus les produits de degradation de la fibrine que les produits de degradation du fibrinogène.

L'obtention de ces anticorps nous a permis :

1) De mettre au point une technique originale immunoenzymologique de la polymerisation des monomères de fibrine. Elle consiste à étudier la fixation du fragment D1 contenant le site de polymérisation "a" sur des monomeres de fibrine contenant des sites complémentaires " $A$ " de polymerisation.

Cette technique aura de nombreuses applcations, tant sur le plan pharmacologique, que sur l'etude d'anomalies du fibrinogène. Ce travail nous a permis de montrer que dans le fibrinogène Ales, le 
site "a" n'était pas fonctionnel car il n"y avait pas de fixation du fragment D1 Ales sur des monomères normaux (des A) de fibrine. Cette étude associée à l'étude structurale du fibrinogene Ales devrait nous permettre d'apporter des precisions sur la nature du site "a" de polymérisation au niveau de la fibrine.

2) D'étudier l'interaction du fibrinogene avec les biomateriaux grace a l'utilisation de certains anticorps de conformation.

3) De doser les produits de dégradation de la fibrine directement dans le plasma grace à l'utilisation d'anticorps anti D-néo.

Cette nouvelle technique pourra avoir des implications pratiques très importantes car elle apporte une modification fondamentale dans le dosage des PDF. En effet, par la technique traditionnelle, les causes d'erreur en excès sont fréquentes attribuables à la présence dans le sérum de petites quantités de fibrinogène non coagulé. De plus, nous avons montré que contrairement aux réactions de précipitation, cette technique utilisant 1 agglutination de particules de latex était tout a fait realisable avec les anticorps monoclonau*. 


\section{SAMENVATTIMG.}

Monoclonale antilichamen zijn van groot nut in de fundamentele biochemle om de configuratie van een molecuul te bepalen. In de toegepaste biochemie zijn het buitengewoon interessante hulpmiddelen om verschillende afbraak-en metabole producten van een elwit te onderscheiden of om specifiek éên molecuulsoort te bepalen ook al bevindt hij zich in een complex mengsel of als hil gebonden is a an andere moleculen. Zo zijn er bijvoorbeeld verschillende methoden beschreven om stolfactor VIII immunologisch te bepalen zonder de von Willebrandfactor, die darmee geassocieerd is, de bepaling stoort. In het voorliggende werk hebben wij beschreven hoe monocionale antilichamen werden gemakt uitgaande van lymphocyten wan mulzen die geimmuniseerd waren met afbraakproducten van fibrine.

Wij hebben kionen uitgezocht die antilichamen gaven die in verschillende groepen onderverdeeld kunnen worden:

1) Antilichamen die een epltoop herkenmen dat toegankelijk is op het fibronogeenmolecul en op zijn fragmenten $D$ of $E$. Van deze antilichamen hebben wijer uitgezocht die in staat waren het afbrakproduct 01 van het verder afgebroken product D3 te ondersicheiden.

2) Antilichamen die een epitoop aan het licht brengen dat a nwezig is op fibrinogeen dat zich aan polystyreen heeft gehecht mar niet op fibrinogeen in oplosing. Deze ant lichamen maken het dan mogelijk de conformatieverandering van het fibrinogeen te detecteren die het gevolg is van hechting an een vaste fase.

3) Antilichamen die een epitoop herkennen dat niet toegankelijk is op het intacte fibrinogeenmolecuul mar dat slechts toegankelijk wordt als het molecuul wordt afgebroken.

4) Antilichamen die een epitoop herkennen dat beschikbaar is in het geisoleerde $E$ fragment en het intacte fibronogeen- 
molecuul mar dat ontoegankelijk is in het D-D-E complex dat uit afbrak van gestabiliseerd fibrine ontstat.

Binnen deze verschillende groepen hebben wij sub-groepen kunnen onderscheiden naar gelang

- het epitoop dat herkend wordt, gelocaliseerd is op een geĩsoleerde keten van net fibrinogeen molecuul of juist een conformatie-epitoop is.

- het monoclonale antilicham afbrakproducten van het fibrine of van fibrinogeen aantoont.

Het verkrijgen van deze antilichamen heeft ons in stat gesteld om:

1) Een oorspronkelijke immunologische techniek te ontwikke1 en die de polimerisatie van fibrine monomeren a a toont.

De grondslag van deze technilek is het aantonen van de hechting van 01 fragmenten die het polymerisatiecentrum "a" bezitten op fibrinemonomeren die de complementaire polymerisatiecentrum "A" bevatten. Deze techniek belooft vele toepassingen te hebben, zowel op pharmacologisch gebied als bij de studie van afwijkingen van het fibrinogeenmolecuul. Met deze techniek zijn wij in stat geweest aan te tonen dat in het afwijkende fibrinogeen "Ales" het polymerisatiecentrum "a" niet functioneel is omdat het fragment D1 Ales niet hecht op normale fibrinemonomeren. Dit werk moet ons, samen met structuurstudies van het fibrinogeen "Ales" in stat stellen met enige verfijning het wezen van het polymerisatie centrum "a" van het fibrine te bepalen.

2) De interactie tussen fibrinogeen en biomaterialen te bestuderen dankzij het gebruik van antilichamen die reageren op conformatieveranderingen bij fibrinogeenadsorbties.

3) Direct fibrineaforaakproducten in het plasma te bepalen door het gebruik van anti D-nëo antilichamen.

Deze nieuwe techniek kan heel belangrijke practische consequenties hebben. Zij makt een fundamentele verandering mogelijk bij de bepaling van fibrineafbraakproducten door 
het uitschakelen van de vaak voorkomende overschatting die het gevolg is van de aanwezigheid van lage concentratie niet gepolymeriseerd fibrine. Ook hebben we kunnen aantonen dat, war precipitatietechnieken met behulp van de gebruikte monoclonale antilichamen niet mogelijk zijn, de agglubtinatie van latexpartikels een goede alternatieve techniek is. 
B IBL IOGRAPHIE 
1. Alkjaersig N., Dawies A., Fletcher A. Fibrin and fibrinogen proteolysis products: comparison between gel filtration and SDS polyacrylamide electrophoresis analysis. Thromb. Haemost., 38 : $524,1977$.

2. Allington M.J. Fibrinogen and fibrin degradatian products and the clumping of staphilococci by serum. Br. J. Haemotal., $13: 550-567$, 1967.

3. Alving B.M., Bell W.R., Evatt B.L. Fibrinogen synthesis in rabbits. Effect of all altered levels of circulating fibrinogen. Am. J. Physiol., $232: 478-484,1977$.

4. Avrameas 5 . Coupling of enzymes to protein with glutaraldehyde. Use of the conjugates for the detection of antigen and antibodies. Immunochemistry, $6: 43-52,1969$.

5. Bachmann L." Schmitt-Fuman W., Hammel R. Lederer K. Size and shape of fibrinogen. Electron microscopy of the hydrated molecule. Makromolekulare Chemie, 176 : 2603-2618, 1975.

6. Barski G., Sarioul S., Cornefer T. Production dans des cultures (in vitro) de deux souches cellulaires en association, de cellules de caractère hybride. C.R. Acad. Sci.. 1960.

7. Bellitser V.A., Varetskaja T.V.. Malvena G.V. Fibrinagen-fibrin interaction. Blochim. Biophys. Acta, $154: 367-375,1968$.

8. Belloc F., Hourdille P., Fialon P., Boisseau M.R., Soria J. Fibrinogen synthes is by isolated human megakaryocytes. Thrombosis and haemostasis, $50: 1-18,1983$.

9. Bettelheim F.R., Bailey K. The praducts of the action of thrombin on fibrinogen. Biochim. Biophys. Acta, 9: 578-579, 1952.

10. Bilezikian S.B., Nossel H.L., Butler Jr V.P., Canfield R.E. Radioimunoassay of human fibrinopeptide $B$ and kinetic of fibrinopeptide cleavage by different enzymes. J. Clin. Invest., 56: $438-445,1975$.

11. Blomback B., Blomback M. Purification of human and bovine fibrinogen. Arkiv. Kemi., 10:415-443, 1956.

12. Blomback B., Blomback M., Henschen A., Hessel B., Iwanaga $S$, Woods R. The $\mathbb{N}$-terminal disulphide knot of human fibrinogen. Nature, 218 : 130. 134.

13. Blomback B., Yamashina I. On the $\mathbb{N}$-terminal amino acids in fibrinogen and fibrin. Arkiv. Kemi, $12: 299,1958$.

14. Blomback B. Studies on the action of thrombotic enzymes on bovine fibrinogen as measured by N-terminal analysis. Arkiv. Kemi., 12 , $321-335,1958$.

15. Blomback B., Blomback M., Edman P. et al. Human fibrinopeptides. 
Isolation, characterization and structure. Biochim. Biophys. Acta. 115 : $371-396,1966$.

16. Blomback B., Blomback M., Hessel B. et al. Structure of N-terminal fragments of fibrinogen and specificity of thrombin. Nature (Lond)., $215: 1445-1448,1967$.

17. Blomback B. Fibrinogen to fibrin transfomation. In blood, clotting enzymology, Seegers W.H, ed. Academic Press New York, 4 : $143-215,1967$.

18. Blomback B., Hessel B., Hogg D. Disulfide bridges in NH2-terminal part of human fibrinogen. Throm. Res. 8 : 639-658, 1976.

19. Blomback B., Hessel B., Hogg D. et al. A two fibrinogen-fibrin transition in blood coagulation. Nature $275: 501-508,1978$.

20. Blomback B., Hessel B., Steada M., Egberg N. Mechanism af fibrin formation and its regulation. Ann. N.Y. Acad. Sci., 370:536-544, 1981.

21. Blomback M, Blomback B., Mammen E.F., Prasad A.S. Fibrinogen Detroit - a molecular defect in the $\mathbb{N}$-terminal disulphide knot of human fibrinogen? Nature, $218: 134-137,1968$.

22. Boschetti E., Corthier G., Monsigny M. An improved chromatographic

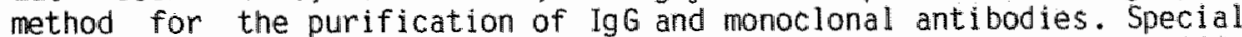
febs Meeting on cell function and differentiation. Athenes 1982, Abstract p 146.

23. Boucheix C., Mirshahi M., Soria J, Soria C., Perrot J.Y., Bernadou A., Rosenfeld $C$. Monocional amtibodies for domains which are differentialy exposed in fibrinogen, in fibrinagen degradation products or in fibrin degradation products. Protides of Blological fluids. H. Peeters ed. (Pergamin Press), 30: 399-452, 1982.

24. Bouvier C. Gruedlinger J. Etude des phenomenes de coagulation et de fibrinolyse par une méthode simple d'enregistrement optique. Schweiz. Med. Wschr., 93 ". 1441-1443, 1963.

25. Budzynski A.Z., Marder V.Jl., Shainoff J.R. Structure of plasmic degradation products of human fibrinogen. Fibrinopeptide and polypeptide chain analysis. J. Biol. Chem., 249:2294-2302, 1974.

26. Budzynski A.Z., Marder V.J., Parker M.E. et al. Antigenic markers on fragment $D D$, a unique plasmic derivative of human crosslinked fibrin. Blood, $54: 794-804,1979$.

27. Budzynski A.Z., 0lexa S.A., Pandya B.V. Fibrin polymerisation: sites in fibrinogen and fibrin fragments. Ann. N.Y. Acad. Sc1., 408 : $301-314,1983$.

28. Buttin G., Cazenave P.A. L"hybridation des cellules lymphocytaires. Buil. Inst. Pasteur, $78: 7-47,1980$.

29. Caen J., Larrieu M.J., Samama M. L'hemostase. Methodes 
d'exploration et diagnostic pratique. Exposition Scientifique (Paris), 1975.

30. Canfield R.E., Dean J., Nossel H.L. et al. Reactivity of fibrinogen and fibrinopeptide A-containing fibrinogen fragments with antisera to fibrinopeptide A. Biochemistry $15: 1203-1209,1976$.

31. Chen R., Doolittle R.F. Isolation, characterization, and location of a donnor-acceptor unit from cross-linked fibrin. Proc. Natl. Acad. Sci.USA, $66: 472-479,1970$.

32. Chen R., Doolittle R.F. Cross-liking sites in human and bovine fibrin. Biochemistry, 10: 4486-4491, 1971.

33. Christensen V., Clemmensen $\mathbb{I}$. Kinetic properties of the primary inhibitor of plasmin from humar plasma. Biochem. J., 163:389-391, 1977.

34. Cierniewski C., Plow E.F., Edgington T.S. An immunochemical hamology between the $A \propto$ and a $D E$ complex-dependent site of the chains of fibrinogen. J. Biol. Chem., 252: 8917-8923, 1977.

35. Cierniewski C.S., Edgington T.S. Internalization of the amino terminal $\|-78$ sequence of the $\gamma$ chain of native fibrinogen and exposure associated with catabolism and plasmin cleavage. Biochim. Biophys. Acta, $580: 32-43,1979$.

36. Cierniewski C.S., Edgington T.S. Surface exposure of the NHi-terminal regions of the $B \beta$ chain of the human fibrinogen. Thromb. Res., $14: 747-764,1979$.

37. Collen D. Identification and some properties of a new fast reacting plasmin inhibitor in human plasma. Eur. J. Biochem., 69 : 209-216, 1976.

38. Corthier G., Boschetti E., Charley-Poulain J. Improved method for Ig purification from varlous animal species by unic exchange chromatography. J. Immunol. Methods., $66: 75-79,1984$.

39. Cottrell B.A.. Doolittle R.F. The amino-acid sequence of a 27 residue peptide released from the $\alpha$-chain carboxy-terminus during the plasmic digestion of human fibrinogen. Biochem. Biophys. Res. 71 : $754-761,1976$.

40. Cottrell B.A., Strong D.D., Watt K.W.K. et al. Amino acid sequence studies of the $\alpha$ chain of humen fibrinogen. Exact location of crosslinking acceptor sites. Biochem., $18: 5405,1979$.

41. Daniel J.C. Utilisation de dispersions aqueuses de polymères colloque international sur les polymères à usage médical et pharmacologique. Montpelier, 1978.

42. Davies B.J. Disc electrophoresis. II. Method and application to human serum proteins. Ann. N.Y. Acad. Sc I., 124 : 404-427, 1964.

43. Doolittle R.F. Structural aspects of the fibrinogen to fibrin 
conversion. Adv. Protein. Chem. $27: 1-109,1973$.

44. Doolittle R.F., Watt K.W.K., Cottrell B.A. et al. Fibrinogen : A highly evolved regulatory agent for maintaining the integrity of the vertebrate circulatory system. In : Versatility of proteins, LI C.H. (Ed), New York Academic Press, p 393-411, 1978.

45. Doolittle R.F., Goldbaum D.M., Doolittle L.R. Designation of sequences involved in the "coiled-coil" interdomainal connections in fibrinogen : construction of an atomic scale model. J. Mol. Biol., 120 : $311-325,1978$.

46. Doolittle R.F., Laudano A.P. Synthetic peptide probes and the location of fibrin polymerization sites. Protides of Biological fluids. Peeters (Ed)., (Pergamm Press) 28, 311-316, 1980.

47. Eckhardt T., Nossel H.L., Hurlet-Jensen A. et al. Measurement of desarginine fibrinopeptide $\mathrm{B}$ in human blood. J. Clin. Invest. 67 : $809-816,1981$.

48. Edgington T.S., Plow E.F. Conformational and structural modulation of the NH2-terminal regions of fibrinogen and fibrin assoclated with plasmin cleavage. J. Biol. Chem., 250, 3393-3398, 1975.

49. Engwall E., Carlssan H.E. Enzyme linked immunosorbent assay elisa.Irst International Symposium on immunoenzymatic technique. INSERM Symposium n 2. Feldmann Ed. (North Holl and Publishing Company Amsterdam), 135-147, 1976.

50. Fair D.S., Edgington T.S., Plow E.F. Immunochemical mapping of the conformation of human fibrinogen. The $\gamma 95-264$ segment is sequestered in native fibrinogen but progressively exposed by plasmic cleavage. J. Biol. Chem, 256 : 8018-8023, 1981.

51. Fazekas de St Groth S., Scheidegger D. Production of monoclonal antibodies strategy and tactics. J. Immunol. Meth., 35: 1-21, 1980.

52. Ferry J.D. The mechanism of polymerization of fibrin. Proc. Nat'l Acad. Sci., 38 : 566, 1952.

53. Finlayson J.S. Mosesson M.W. Heterogenity of human fibrinogen. Biochem., 2, 42-46, 1963.

54. Fowler W.E., Erickson H.P., Hantgan R.R. et al. Cross-1inked fibrinogen dimers demonstrate a feature of the molecular packing in fibrin fibers. Science $211: 287-290,1981$.

55. Fowler W.R., Erickson H.P. Trinodular structure of fibrinogen. Confirmation by both shadowing and negative-stain electron microscopy. J. Mol. Biol. 134: 241-245, 1979.

56. Francis C.W., Marder V.J., Martin S.E. Detection of circulating crosslinked fibrin derivatives by a heat extraction-SDS gradient gel electrophoretic technique. Blood, 54 : 1282-1295, 1979.

57. Francis C.W., Marder V.J., Barlow G.H. Plasmic degradation of 
crosslinked fibrin. Characterization of new macromolecular soluble complexes and a model of their structure. J. Clin. Invest., 66 : $1033-1043,1980$.

58. Francis C.W., Marder V.J. A molecular model of plasmic degradation of cross-linked fibrin. Seminars in Thrombosis and Haemostasis, 8 : $25-35, \quad 1982$.

59. Francis C.W. Marder V.J.. Martin S.E. Plasmic degradation of cross-linked fibrin. 1. Structural analysis of the particulate clot and ldentification of new macromolecular soluble complexes. Blood, 54 : $456,1984$.

60. Francis C.W.* Nachman R.L., Marder V.J. Plasma and platelet fibrinogen differ in $\gamma$ chain content. Thromb. Haemost., 51, 1 : 84-88, 1984 .

61. Francis C.M., Marder V.J., Martin S.E. Demonstration of a large molecular welght variant of the 6 chain of normal human fibrinogen. J. Biol. Chem., 255 : 5595-5604, 1980.

62. Furlan M., Beck E.A. Plasmic degradation of human fibrinogen. I. Structural characterization of degradation products. Biochem. Biophys. Acta, $263: 631-644,1972$.

63. Furlan M." Beck E.A. Plasmic degradation of human fibrinogen. II. Further characterization of fragment D. Biochem. Biophys. Acta, 310: 205-216, 1973.

64. Gaffney P.U., Lane D.A., Kakkar V.V., Brasher M. Characterization of a soluble $\mathbb{D}$ dimer-E complex in crosslinked fibrin digests. Thromb. Res. 7 : 89-99 1975 .

65. Gaffney P.J. The biochemistry of fibrinogen and fibrin degradation products. In : Haemostasis: Biochemistry, Physiology and Pathology, Ogston D., Bennett B. (Eds). John Wiley and Sons, pp 105-168, 1977.

66. Gaffiney P.J., Mahmoud M. Influence of function on the recent evolution of fibrinogen. J. Mollecular Medicine, $2: 351-369,1977$.

67. Gaffney P.J., Whitaker A.N. Fibrin cross-links and lysis rates. Thromb. Fes. $14: 85-94,1979$.

68. Gaffney P.J. Joe F. The lysis of crosslinked human fibrin by plasmin initially a simple molecular complex Dudimer-E. Thromb. Res.. $15: 673-687,1979$.

69. Gaffney $P_{*} d_{\%}$, Joe $F$., Mahmoud $M$. Giant fibrin fragments derived from crosslinked fibrin: structure and clinical implication. Thromb. Res. $20: 647-662,1980$.

70. Gaffney P.U., Joe F., Mahnoud M., Spitz M. Crosslinked fibrin fragments : molecular characterization and zssay procedures in plasma. Progress in fibrinolysis. Ed Davidson J.F., Churchill Liningstone, 5 , 399-405, 1981. 
71. Gardlund B., Kowal ska-Loth B., Grondahl N.J., Blomback B. Plasmic degradation products of human fibrinogen. 1. Isolation and characterization of fragments $\mathrm{E}$ and $\mathrm{D}$, and their relationship to "disulfide knots". Thromb. Res. 1: 371-388, 1972.

72. Gardlund B., Hessel B., Marguerie 6., Murano G., Blomback B. Primary structure of human fibrimogen. Eur. J. Biochem., $77: 595-610$, 1977.

73. Gati W.P."Straub P.W. Separation of both the and polypeptide chaims of human fibrinogen into two main type which differ in sialic acid content. J. Biol. Chem., 253: 1315-1321, 1978.

74. Goldsmith G.M., Ziatzs N.P., Robertson A.L. Studies on plasminogen activation and other proteases in subcultured human vascular cells. Exp. Med. Path. 35: 257-264, 1984.

75. Gollwitzer R., Hahn E., Nowack H., Timpl R. Immunochemistry of bavine fibrinagen. I. Immunagenic activity and diversity of antigenic determinants of reduced and carboxymethylated and chains. Immunochemi stry, $12: 893-897,1975$.

76. Gollwitzer R., Timpl R. Isolation and immunological characterization of a disulfide loop region in human fibrinogen chain. FEBS Lett 58 : 269-272, 1975.

77. Gollwitzer F., Hafter R., Streifinger W., Graeff H. Comparative studies on FCB3 related antigen fibrinogen degradation products soluble fibrin monomer complexes and fibrinogen in patients with renal carcinoma. In fibrinogen-structure-functional aspects metabolism. W. de Gruyter Ed. (New York), 2 : 209-213, 1983.

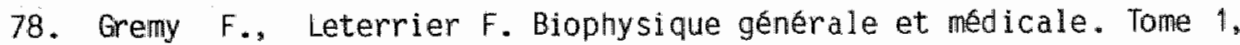
314-320, 1975. Flammarion, Paris.

79. Griffin J.H., Cochrane C.G. Recent advances in the understanding of contact activation reaction. Seminars in Thrombosis and Haemostasis. $4: 254-273,1979$.

80. Hafter R., Graeff $H$. Homologues of fibrin Xollgomers. In: Fibrinogen - Recent Biochemical and Medical Aspects. Henschen A., Graeff H., Lottspeich F. (Eds). Walter de Gruyter, (Berlin-Hawthorne, New York), 291-306, 1981.

81. Hall C.E. Slayter H.S. The fibrinogen molecule: Its slze shape and mode of polymerization. J. Biophys. Biochem. Cytol., 5 : $11-15$, 1959.

82. Hantgan R., Mc Donagh J.. Hermans J. Fibrin assenbly. Ann. N.Y. Acad. Sc., $408: 344-366,1983$.

83. Harfenist E.J., Canfield R.E. Degradation of fibrinogen by plasmin. Isolation of an early cleavage product. Biochemistry, 14 : $4110-4117,1975$. 
84. Haverkate $F$. Timan $G$. Protective effect in calcium in the plasmin degradation of fibrinogen and fibrin fragments 0 . Thromb. Res.s 10 : $803-812,1977$.

85. Hawiger J., Wiew arowski S., Grewich V., Thomas D.P. Measurement of fibrinogen and fibrin degradation products in serum ty staphylococcal clumping test. Clin. Med. 75:93-108, 1970.

26. Hawiger J., Kloczewiar M. Timmons 5. Interaction of fibrinogen with staphylococcal cluming factor and with platelets. Ann. N.Y., Acad. Sc1., 408: 521-535, 1983.

87. Henschen A. S-sulfo-derivatives of fibrinogen and fibrin preparations and general properties. Arkiv. Kemi., 22 : 1-12, 1964.

88. Henschen A. Number and reactivity of disulfide bonds in fibrinagen and fibrin. Arkiv. Kem., $22: 355-373,1964$.

89. Henschen A. Edman P. Large scale preparation of S-carboxymethylate chains of human fibrin and fibrinogen and the occurence of chain variant. Biochim. Biophys. Acta, $63: 351-367,1972$.

90. Henschen A. Disulfide bridges in the middle part of human fibrinogen. Hoppe-Seyler's Z. Physiol. Chem. 359: 1757-1770, 1978.

94. Henschen A., Lottspeich F., Hessel B. Amino acid sequence of ruman fibrin. Preliminary note on a disulfide-containing internal peptide of the chain, obtained by plasmic digestion of fibrinogen. Hoppe-Seyler's Z. Physiol. Chem. 359: 1607-1610, 1978.

92. Henschen A., Lottspeich F., Topfer-Petersen E., Warbinek F. Primary structure of fibrinogen. Thromb. Haemost., 41 : 662-670, 1979.

93. Henschen $A_{*}$, Lottspeich F., Southan C., Topfer-Fetersen E. Human fibrinogen : sequences, sulfur bridges, glycosylation and some structural varlants. In : "Protides of the biological fluids" Peeter H. (Ed) Pergamon press, 51-60, 1980.

94. Henschen A., Lottspeich F. Fibrinogen structure and fibrinolysis. Haematologica, $65: 535-541,1980$.

95. Henschen A., Southan C., Soria j., Soria C., Samama P\|. Structure abnormality of fibrinogen Metz and its relationshif to the clotting effect. Thromb. Haenost., $46: 103,1981$.

96. Fenschen A: Lottspeich F., Kehl M. Southan C. Covalent structlink cf tibrinogen. Anin. N.Y., Acad. Sc., 408: 28-43, 1983.

97. Herschen A. On the structure of functional sites in fibrinogen. Thromit. Res., suppt $V, 27-39$, 1983.

98. Hermans J. Models of fibrin. Frcc. Natl. Acad. Sci.s 76 : 1189, 1979 .

99. Hessel 10. On the structure of the COOH-terminal part of the Ad -chain of human fibrinoger!. Thromb. Res., $7: 75-87,1975$. 
100. Hoyllaerts M., Rijken D.C., Lijnen H.C., Collen D. Kinetics of plasminogen activation by tissue plasminogen activator. Role of fibrin. J. Biochem., 257 : 2912-2919, 1982.

101. Hudry-Clergeon G., Paturel L., Suscillon M. Identification d'un complexe $(D-D) \ldots E$ dans les produsts de degradation de la fibrine bovine stabilisêe par le facteur XIII. Pathologie et Biologie, 22 suppl : 47-53, 1974 .

102. Iwanaga S., Blomback B., Grondahl N.J., Hessel B., Wallen P. Amino acid sequence of the $N$-terminal part of -chain in human fibrinogen. Biochim. Biophys. Acta, 160:280-283, 1968.

103. Jakobsen E., Ly B., Kierulf P. Incorporation of fibrinogen into soluble fibrin complexes. Thromb. Res., 4: 499, 1974.

104. Kehl M., Lottspeich P., Henschen A. Genetically abnormal fibrinogen releasing abnormal fibrinopeptides as characterized by high performance liquid chromatography. In : fibrinogen structure, functional aspects and metabolism. Haverkate F., Nieuwerkuize W., Henschen A., Straub P.W. (Eds), W. de Gruyter, 183-193, 1983.

105. Kessler C.M., Bell W.R. Stimulation of fibrinogen synthesis : a possible

functional role of fibrinogen degradation products. Blood, $55: 40-47$, 1980 .

106. Kohler G., Howe S.0., Milstein C. Derivation of specific antibody producing tissue culture and tumor lines by cell fusion. Eur. I. Immunol., 5 : 292-295, 1976.

107. Kohler G., Milstein C. Continuous cultures of fused cells secreting antibody of predefined specificity. Nature, 256: 495-497, 1975.

108. Kudryk B., Robinson D., Ketre C., Hessel B., Blamback M., Blomback B. Measurement in human blood of fibrinogen, fibrin fragments containing the $B$ B 15-42 sequence. Thromb. Res., $25: 277-291,1982$.

109. Kudryk B., Rohoza A., Amadi M., Chin J., Wiebe M. A monoclanal antibody with ability to distinguish between $\mathrm{NH}_{2}$-terminal fragments derived from fibrinogen and fibrin. Molecular Imriunol., 20, 11 : $1191-1200,1983$.

110. Kwan Y.H., Haber E., Matsueda G.R. Monoclanal antibodies to a synthetic fibrin-like peptide bond to human fibrin but not fibrinogen. Science, 222 : 1129-1132, 1983.

111. LaGamma K.S., Nossel H.L. The stability of fibrinopeptide $B$ immunoreactivity in blood. Thromb. Res., $12: 447-454,1978$.

112. Lahiri B., Koehn J.A., Canfield R.E. et al. Development of an immunoassay far the COOH-terminal region of the gamma chains of human fibrin. Thromb. Res., 1-15;23(1-2): 103-112, 1981. 
113. Laudano A.P., Doolittle R.F. Synthetic peptide derivatives that bind to fibrinogen and prevent the polymerisation of fibrin monomers. Proc. Natl. Acad. Sci. U.S.A., $75: 3085-3089,1978$.

114. Laudano A.P., Doolittle R.F. Studies on synthetic peptides that bind to fibrinagen and prevent fibrin polymerization. Structural requirements, number of binding sites, and species differences. Biochemistry, 19 : 1013-1019, 1980.

115. Lehreer H.I., Van Vunakis $H$. Imunochemical studies on carboxypeptidase A. Immunochemistry, $2: 255-262,1965$.

116. Lipinski B., Hawiger J., Jel jaszewicz J. Staphylacoccal clumping with soluble fibrin monomer complex. J. Exp. Med."126:979-998, 1967.

117. Littlefield J. Selection of hybrids from mating of fibroblasts in vitro and their persumed recombinants. Sci., 145:700-710, 1964 .

118. Lorand 4 . Fibrinopeptides. New aspects of the fibrinogen-fibrin transformation. Nature, $167: 992-998,1951$.

119. Lorand L. Konishi K. Jacobsen M. Transpeptidation mechanism in blood clotting. Nature, $194: 1148-1149,1962$.

120. Marder V.J., Shulman N.R., Carroll W.R. The importance af intermediate degradation products of fibrinogen in fibrinolytic hemorrhage. Trans. Assoc. Am. Phys. 53 : 156-159, 1967.

121. Marder V.J. Immunologic structure of fibrinogen and its plasmin degradation products. Theoretical and clinical considerations. In : Fibrinogen. Laki K. (Ed). Arnold, London, 339-357, 1968.

122. Marder V.J.s Shulman N.R., Carroll W.R. High molecular weight derivatives of human fibrinogen produced by plasmin. I. Physicochemical and immunological characterization. $₫$. Biol. Chem.: $244: 2111-2119,1969$.

123. Marder V.J., Shulman N.R., Carroll W.R. High molecular weight derivatives of human fibrinogen produced by plasmin. III. Their NH2 terminal amico acids and comparison with the MHz terminal disulphide knot. J. Biol. Chem., 247: 4775-4781, 1969.

124. Marder V.J., Budzynski A.Z. The structure of the fibrinogen degradation products. Progress in Hemostasis and Thrombosis. In : Speat T. (Ed). Grune and Stratton, 141-147, 1974.

125. Marquerie G. The fibrinogen-dependent pathway of platelet aggregation. Ann. N.Y., Acad. Sc., 408:556-566, 1983.

126. Martinez S., Palascaz J., Kwasniak D. Abnormal sialic acid content of the dysfibrinogenemia associated with liver disease. $\mathrm{J}$. Am. Invest., $61: 535-538,1978$.

127. Marx J., Mudry-Clergeon G., Capet-Antonini F., Bernard L. Laser raman spectroscopy study of bovine fibrinogen and fibrin. Biochim. 
Biophys. Acta, 578 : 107-115, 1979.

128. Mckee P.A., Mattock P.s Hill R.L. Subunit structure of human fibrinagen soluble fibrin, and cross-linked insoluble fibrin. Proc. Natl. Acad. Sci. USA, $66: 472-479,1970$.

129. Merskey C., Lalezari P., Johnson A.J. A rapid, simple, sensitive method for measuring fibrinolytic split products in human serum. Proc. Soc. Exp. Biol. Med., 131 : 871-875, 1969.

130. Migeon B., Der Kalaustian V.M., Nyhan W.L. et al. X-1 linked H-G-PRT deficiency heterozygote has two clanal population. Science, $160: 425-427,1968$.

131. Mihalyi $\mathrm{E}$. Electrophoretic investigation of fibrin and fibrinogen dissolved in urea solutions. Acta Chemica Scand., $4: 351,1950$.

132. Mirshahi M., Soria J., Soria $C_{.}$, Boucheix $C_{\text {. }}$, Perrot J.Y., Nieuwenhuisen W., Haverhate F., Bernadou P., Samama M., Rosenfeld C. Characterization of differently expressed epitopes in fibrinogen, fibrinogen degradation products and fibrin degradation products using monoclonal antibodies. Thromb. Haemost., 50, 1 : 301 (abstract), 1983.

133. Mosesson M.W., Finlayson J.S. Umfleet R.A. Human fibrinogen heterogenetics III. Identification of chain variants. J. Biol. Chem., 247 : $5223-5227,1972$.

134. Mosesson M.W., Finlayson J.S. The search for the structure of fibrinogen. In : Progress in Hemostasis and Thrombosis, Spaet T.H., Ed., III : $61-107,1976$.

135. Mosesson M.W. Fibrinogen heterogeneities. Ann. N.Y., Acad. Sc., $408: 97-113,1983$.

136. Niewiarowski S., Prou-Wartelle 0. Rôlle du facteur contact (facteur Hageman) dans la fibrinalyse. Thromb. Diath. Haemost., 3 : $593-603,1959$.

137. Niewiarawski S., Kornecki E., Budzynski A., Morinelli T.A., Tuszywski G.P. Fibrinogen intreaction with platelet receptors. Ann N.Y., Acad. SC., 408 : 536-555, 1983.

138. Nieuwenhuizen $W$., Haverkate $F$. Calcium binding regions in fibrinogen. C.R. Acad. SC. (N.Y.), 408:92-96, 1983.

139. Nieuwenhuizen $W_{\text {. }}$ Vermond A., Hermans J. A calcium binding site in the central domain of human fibrinogen. Thromb. Haemost., 50,1 : 186 (abstract), 1983.

140. Nilhen J.E. Split products of fibrinagen after prolonged interaction with plasmin. Thromb. Diath. Haemost.. 18:89-100, 1967.

141. Nossel H.L., Younger L.R., Wilner G.D., Procupez J., Canfield R.E., Butler Jr" V.P. Radio-immunoassay of human fibrinopeptide $A$. Proc. Natl. Acad. SC. USA, 68: 2350-2353, 1971. 
442. Nossel H.L., Chatpar R., Butler V.P. Jr. Canfield R.E. Radio-immunoassay of fibrinopeptide B. Blood, $40: 955-959,1972$.

143. Nossel H.L., Vudelman 1., Canfleld R.E., Butler V.P. Jir, Spanodis K., Wilner G.0., Guresni G.0. Measurement of fibrinopeptide A in human blood. J. Clin. Invest. $54: 43-53,1974$.

144. Nossel H.L., TI M., Kaplan K., Spanodis K. Soland , Butler V.P. The generation of fibrinopeptide A in clinical blood samples. Evidence for thrombin activity. J. Clin. Invest., $58: 1136-1144,1976$.

145. Nossel H.L., Wasser J., Kaplan K.L., La Gamma K.S., Yudelman I." Canfleld R.E. Sequence of fibrinogen proteolysis and platelet release after intrauterine infusion of hypertonic saline. J. Clin. Invest., 64 : 1371-1378, 1979.

146. Nossel H.L. Relative prateolysis of the fibrinoger $\mathbb{B}$ chain by thrombin and plasmin as a determinant of thrombosis. Nature, 291 : $165-168,1981$.

147. O'Farrell P.H. High resolution two-dimensional electrophoresis of proteins. J. Biol. Chemis., 250, $10: 4007-4021,1975$.

148. 0lexa 5.A., Budzynski A.Z. Binding phenomena of isolated unique plasmic degradation products of human cross-linked fibrin. $J$. Biol. Chem., $254: 4925,1979$.

149. Olexa S.A., Budzynski A.Z. Evidence for four different polymerization sites involved in human fibrin formation. Proc. Natl. Acad. Sc., 77 : 1374-1388, 1980.

150. Olexa S.A., Budzynski A.Z., Doolittle R.F., Cottrel1 B.A., Greene T.C. Structure of fragment $E$ species from human cross-linked fibrin. Biochemistry, $21: 6139-6145,1981$.

151. Pasqua J.J., Pizzo S. The role of ligand-ligand interactions im competition by fibrinogen and fibrin degradation products for fibrinogen binding to human platelets. Biochem. Biophys. Acta, 757 : $282-287,1983$

152. Patscheke H., Worner P. Platelet activation detected by turbidimetric shape-change analysis. Thromb. Res., $12: 485-496,1978$.

153. Pizzo S.V., Schwartz M.L., Hill R.L., Mckee P.A. The effect of plasmin on the submit structure of human fibrinogen. J. Biol. Chem., 247 : $636-645,1972$.

154. Plow E.F. Edgington T.S. Molecular events responsible for modulation of neoantigenic expression: the cleavage-associated neoantigen of fibrinogen. Proc. Nat1. Acad. Sci. USA, 69: 208-212, $1972 b$.

155. Plow E.F., Edgington T.S. Emergence of neoantigenic expressions during physiologic cleavage in vitro and in vivo. J. Clin. Invest., 52 : 273-282, 1973a. 

156. Plow E.F." Edgington T.S. An alternative pathway for physiologic pH. J. Clin. Invest., $56: 30-38,1975$.

157. Plow E.F., Edgington T.S. Unique immunochemical features and intracellular stability of platelet fibrinogen. Thromb. Res. 7 : $729-742,1975$.

158. Plow E.F., Edgington T.S. A cleavage-associated neoantigenic marker for a chain site in the NH2-terminal aspect of the fibrinogen molecule. J. Biol. Chem. 250: 3386-3392, 1975.

159. Plow E.F., Edgington T.S. Localization and characterization of the cleavage-associated meoantigen locus in the $E$ domain of fibrinogen. J. Biol. Chem., 254: 672-678, 1979.

160. Plow E.F.. Edgington T.S. Surface markers of fibrinogen and its physiologic derivatives revealed by antibodies probes. Sem. Thromb. Haemost., $8: 36-56,1982$.

161. Rylatt D.B., Blake A.S., Cottis L.E., Massingham D.A., Fletcher W.D., Masci P.P., Whitaker A.N., Elms M., Bunce I., Webber A.J., Wyatt D., Bundesen P.G. An i mmunoassay for human 0 dimer using monoclonal antibodies. Thromb. Res. $31: 767-778,1983$.

162. Sasaki T., Page I.H., Shainoff J.F. Soluble complex of fibrinogen and fibrin. Science, $152: 1069,1966$.

163. Schwartz M.L., Pizzo S.V., Hill R.L., Mckee P.D. The effect of fibrin-stabilizing factor on the sub-unit structure of human fibrin. J. Clin. Invest., 50: 1506-1513, 1971.

164. Shainoff J.R., Page I.H. Cofibrins and fibrin-intermediates as modificators of thrombin activity, in vivo. Circulation Res., 8 : $1013,1960$.

165. Sharp J.J., Cassman K.G., Doolittle R.F. Aminoacid sequence of the carboxy terminal cyanogen bromide fragment from bovine and human fibrinogen chains. Feb. Letters, 25 : 334-336, 1972.

166. Singer J.M., Plotz C.M. The latex fixation test. I. Application to the serologic diagnos is of rhumatoid arthritis. Amer. J. Med., 21 : $888-892,1956$.

167. Sobel J.H., Briken S., Ehrlich P. et al. Characterization of a crosslink-containing fragment derived from the polymer of human fibrin and its application in immunologic studies using monoclonal antibodies. Thromb. Haemost., 46 : 240 (abstract), 1981.

168. Soria J., Soria C., Samama M., Coupier J., Girard M.L., Bousser J., Bilski-Pasquier G. Dysfibrinogenemies acquises dans les atteintes hépatiques. Coagulation, $3,1: 37-44,1970$.

169. Soria J., Soria C., Samama M., Poirot C., Kling C. Fibrinogen Troyes-fibrinogen Metz. Two new cases of congenital dysfibrinogenemia. Thromb. Diath. Haemost., $27: 619-633,1972$. 
170. Soria J., Soria C., Ryckewaert J.J. A solid phase immuno-enzymological assay for the measurement of human fibrinopeptide A. Thromb. Res., 20: 425-435, 1980.

171. Soria J., Soria C., Fabiani P.s Samama M. Determination of fibrinogen degradation products using anti fibrinogen serum and antipeptide E serum. Thromb. Res., 3 : 339-343, 1979.

172. Sorla J., Sorla C.. Boucheix C., Mirshahi M., Perrot J.Y., Bernadou A.s Samama M., Rosenfeld C. Manoclonal antibodies that react preferentially with fibrinogen degradation products or with cross-linked fibrin split products. Acad. Sci., N.Y, 409: 665-666, 1983.

173. Soria J., Soria C., Boucheix C., Mirshalii M., Perrot J.Y.. Bermadou A., Samama $M$. Immunochemical differentiation of $f$ ibrinogen fragment $D$ or $E$, and cross-1inked fibrin degradation products using monoclonal antibodies. In : Fïbrinogen, Structure, Functional aspects, Metabolism. Havertake, Henschen, Nieuwenhuizen, Straub (Eds), Walter de Bruyter, 2 : 227-233, 1983.

174. Stanilawski M., Harel A., Mitard M., Pene J. Attachment of lymphoid cells to glutaraldehyde activated plastic cups : a convenient means for quantitative estimation of cytoplasmic and membrane Ig. Provides of Blological Fluids, (Peeters. Ed). Pergamon Press, 479-482, 1980.

175. Straub P.W. A study of fibrinogen production by human liver slices in vitro by immunoprecipitin method. J. Clin. Invest., 42 : $130-135,1963$.

176. Straub P.W., Kuyas C., Herberli A. The plasma fibrinogen fraction with elevated sialic acid. Content and elongated chains. Ann. N.Y.s Acad. Sc., 408 : 114-117, 1983.

177. Strong D.D., Laudano A.P., Hawiger J., Doolittle R.F. Isolation characterization and synthesis of peptides from human fibrinogen that block the staphylococcal clumping reaction and construction of a synthetic clumping particule. Blochemistry, $21: 1414-1420,1982$.

178. Takagi T., Iwanaga S. Polypeptide chain involved in the crosslinking of stabilized bovine fibrin. Blochem. Blophys. Res. Commun ., $38: 129-136,1970$.

179. Takagl T., Doolittle R.F. Amino acid sequence studies on plasmin-derived fragments of human fibrinogen. Amino-terminal sequences of intermediate and terminal fragments. Biochemistry, 14 : $940-946,1975$.

180. Takagi T., Doolittle R.F. Amino acid sequence studies of the chain of human fibrinogen : location of four plasmin attack points and a covalent crosslinked site. Biochemistry, $14: 5149-5156,1975$. 
181. Tanswell P., Stan-Lotter H., Gollwitzer R., Timpl R. Immunochemistry of bovine fibrinogen-III. Localization of two antigenic determinants in fibrinopeptide $B$. Immunochemistry, 14 : $277-281,1977$.

182. Teger-Nilsson A.C. Degradation of human fibrinopeptide $A$ and $B$ in blood serum in vitro. Acta Chem. Scand., $22: 3171-3182$, 1968.

183. Topfer-Petersen E., Henschen A. Carbohydrate carrying peptide isolated from bovine fibrin and chain. Thromb. Res. "11:881-892, 1977 .

184. Watt K.W.K., Takagi T. Doolittle R.F. Amino acid sequence of the chain of human fibrinogen. Biochemistry, $18: 68-76,1979$.

185. Weber K., osborn M. The reliability of molecular weight determinations by dodecyl sulfate-polyacrylamide gel electrophoresis. J. Biol. Chem., $244: 4405-4412,1969$.

186. Wijngarras G., Kluft C., Groeneveld E. Demonstration of urokinase related fibrinolytic activity in human plasma. J. Haemost.; 51 : $165-169,1983$.

187. Wilner G.D., Nossel H.L., Canfield R.E. et al. Immunochemical studies of human fibrinopeptide A using synthetic peptide homologues. Biochemistry, $15: 1209-1213,1976$.

188. Wilner G.D., Thomas D.W., Nossel H.L. et al. Immunochenical analysis of rabbit antihuman fibrinopeptide $B$ antibodies. Biochemistry, $18: 5078-5082,1979$.

189. Wilner G.D., Mudd M.S., Hsien K.H., Thomas D.W. Manaclonal antibodies to fibrinogen : modulation of determinants expressed in fibrinogen by chain crosslinking. Biochemistry, $21: 2687-2692$, 1982.

190. Wolberg G. Liu C.T., Adler F.L. Passive hemagglutination. II. Titration of antibody against determinants unique for aggregated denatured bovine serum albumin and further studles on gelatin. J. Immunal., 105 : 797-801. 1970.

191. Wolfenstein-Todel C., Mosesson M.W. Human plasma fibrinogen heterogeneity : evidence for am extended carboxy-terminal sequence in a normal chain variant ( $)$. Proc. Nat1. Acad. Sci. USA, 77 : 5069-5073, 1980.

192. Wolfensstein-Todel C., Mosesson M.W. Carboxy-terminal aminoacid sequence of a human fibrinogen chain variant ( 1$)$. Biochemistry, 20 : 6146-6149, 1981.

193. Wolters G., Kuijpers L., Kacaki J., Schuurs A. Solid phase enzyme immunoassay for' detection of hepatitis B surface antigen. $J$. Clin. Path., $29: 873-879,1976$. 
Massoud MIRSHAHI est né le 19 Maj 1954 à Nishabour (Iran), 11 a fait ses études secondaires à Mashad (Iran) et a passé le baccalauréat Sciences Naturelles en 1973. Il a entrepris ensuite ses êtudes médicales qu'ît a poursuivi à Mashad de 1973 à décembre 1979 . A cette êpoque, i1 a été Interne des Hôpi taux de Mashad. En Janvier 1980 il est venu a Paris, tout d"abord dans le Service du Professeur Mathë, ou 11 a suivi l'enseignement du Certificat d'Etudes Supérieures de Cancêrólogie Générale et Expérimentale et a obtenu le diplôñe correspondant en 1982. Puis, il a suivi 1e Certufficat d'Etudes Supêrieures d"Imnunologie Génêrale du Professeur Homberg en 1983 et a obtenu le diplôme correspondant. Enfin, durant l'annêe universitaire 1983-1984 ill a suivi avec succès les êtudes de 3e cycle de Biochimie et Physiologie de l'Hémostase organisêes par le Professeur J. Caen et le Professeur G. Tobelem, ainsi que les études de $3 e$ cycle d'Immunagénétique et d'Immunopathologie organisées par le Professeur Dausset et le Professeur Brovet.

Au cours de ses études il a étê contactê par le Dacteur C. Boucheix qui l'a introduit dans le laboratoire du Professeur Bernadou à l'Hôtel-Dieu. Il a travaillé dans le domaine de l'immunalogie du cancer. Parallèlement sous la direction de $\mathrm{J}$. et $\mathrm{C}$. Soria, 11 s'est intëresse au problème de la coagulation et a entrepris la preparation d'anticorps monocionaux contre le fibrinogẽne et dont les applications pratiques sont nombreuses.

11 a également traval17e dans le domaine de l'immunopathologie de l'oeil oû 11 réalifse des travaux concernant 1 "antigène $S$ de la rêtine, sous la direction du Docteur J.P. Faure. 